\title{
MODERN STATE DEVELOPMENT, CAPACITY, AND INSTITUTIONS
}

Edited by

DERICA LAMBRECHTS

PIETER FOURIE 


\title{
Modern State DEVELOPMENT, CAPACITY, AND INSTITUTIONS
}

\author{
EDITED BY \\ DERICA LAMBRECHTS \\ PIETER FOURIE \\ DEPARTMENT OF POLITICAL SCIENCE \\ STELLENBOSCH UNIVERSITY
}


Modern State Development, Capacity, and Institutions

Published by SUN MeDIA Stellenbosch under the SUN PRESS imprint.

All rights reserved.

Copyright (c) 2017 SUN MeDIA Stellenbosch and the authors

This publication was subjected to an independent double-blind peer evaluation by the Publisher.

The author(s) and the publisher have made every effort to obtain permission for and acknowledge the use of copyrighted material. Please refer enquiries to the publisher.

No part of this book may be reproduced or transmitted in any form or by any electronic, photographic or mechanical means, including photocopying and recording on record, tape or laser disk, on microfilm, via the Internet, by e-mail, or by any other information storage and retrieval system, without prior written permission by the publisher.

The views expressed in this publication do not necessarily reflect those of the publisher.

First edition 2017

ISBN 978-1-928357-33-9

ISBN 978-1-928357-34-6 (e-book)

DOI: $10.18820 / 9781928357346$

Cover design and typesetting by SUN MeDIA Stellenbosch

SUN PRESS is an imprint of AFRICAN SUN MeDIA. Academic, professional and reference works are published under this imprint in print and electronic format. This publication may be ordered directly from www.sun-e-shop.co.za.

Produced by SUN MeDIA Stellenbosch

www.africansunmedia.co.za

africansunmedia.snapplify.com (e-books)

www.sun-e-shop.co.za 


\section{CONTENTS}

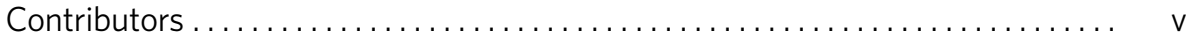

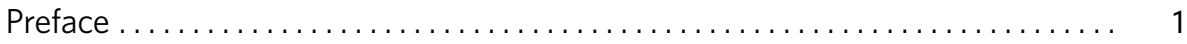

Hennie Kotzé

1 The state, state capabilities and non-state actors: A literature survey $\ldots \ldots \ldots \ldots$ Derica Lambrechts

2 The great democratic disillusionment? Perceptions of the South African

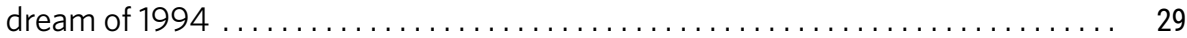
Joleen Steyn-Kotze

3 Transition to democracy in South Africa and Poland: The genetic approach ...... Ursula van Beek

4 Good faith or goodwill? The South African constitution as contested terrain

Salome Teuteberg

5 The rule of law and democracy in South Africa: Contending interpretations of core concepts

Charl Swart

6 Perceptions of evil and the erosion of social capital in South Africa Cindy Steenekamp and Reinet Loubser

7 South Africa's HIV and Aids response: Two scenarios towards 2019 Pieter Fourie and Charl Swart

8 Stellenbosch University's 'born-frees': Responsibly engaged Nicola de Jager and Ubanesia Adams-Jack

9 South African student protests as new imagined communities in the digital age

Barend Lutz

Postscript 


\section{CONTRIBUTORS}

Dr Ubanesia Adams-Jack is a lecturer in Political Science at Stellenbosch University. She holds a D.Phil in Development Studies from the University of Sussex, and specialises in public policy analysis.

Dr Nicola de Jager is a senior lecturer at the Department of Political Science and Head of the Transformation Research Unit (TRU) for Southern Africa. She was the co-editor with Pierre du Toit of Friend or Foe? Dominant party systems in southern Africa (2013) published by UCT Press and editor of South African Politics (2015) published by Oxford University Press.

Prof. Pieter Fourie teaches Political Science at Stellenbosch University and was trained at the Universities of Stellenbosch, Paris, London and Johannesburg. He has worked for the United Nations, the Australian Department of Foreign Affairs and Trade, in Civil Society, and has taught various aspects of international relations at universities in South Africa and Australia. His research focuses on HIV/AIDS, global health governance, political epidemiology and the political economy of global development.

Dr Derica Lambrechts is a senior lecturer at the Department of Political Science, Stellenbosch University. She obtained her PhD in 2013, under the supervision of Prof. Pierre du Toit and her research focused on state society relationships, specifically analysing the relationship between the gangs on the Cape Flats and the City of Cape Town. She is a trained political risk analyst, and has published extensively in the field of political risk and political security risk analysis. She continues to research the relationship between non-state and state actors on a local government level.

Ms Reinet Loubser studied Political Science and Global Studies at the University of Stellenbosch, the University of Leipzig and the University of Vienna. She previously worked as a researcher at the Centre for International and Comparative Politics at the University of Stellenbosch and is currently working as a Junior Political Risk Analyst. Her research interests are conflict studies, comparative politics, democratisation and quantitative analysis.

Mr Barend Lutz is a political scientist that is exploring the use of Big Data and machine learning to further the fields of political/security risk analysis, democratic 
theory and media studies. At least until the machines take over. He is in the process of completing his PhD at the Department of Political Science, Stellenbosch University.

Dr Cindy Lee Steenekamp is a senior lecturer in the Political Science Department at Stellenbosch University. Her research focuses primarily on the World Values Survey and several elite surveys conducted around the world and include research interests such as political behaviour; political culture; democratisation; attitudinal, public opinion, and values research; comparative studies: elite-mass studies and crossnational studies; and South African politics.

Dr Joleen Steyn Kotze is a senior research specialist in Democracy and Social Cohesion in the Democracy, Governance, and Service Delivery Research Programme at the Human Science Research Council. She is also a Research Fellow at the Centre for African Studies, University of the Free State. As an NRF Y2-Rated Researcher, Joleen Steyn Kotze's academic interests are democracy, citizenship, and political dynamics in democratizing post-authoritarian states.

Dr Charl Swart obtained his PhD in Political Science from Stellenbosch University in 2013. His PhD titled 'Contending interpretations of the rule of law in South Africa', focused on exploring whether there are discernible values attached to the rule of law by political stakeholders in South Africa. He currently holds a post-doctoral fellowship at the Centre for Research on Evaluation, Science and Technology (CREST) at Stellenbosch University.

Dr Salomé Teuteberg was awarded a PhD in Political Science in March 2015 at the University of Stellenbosch, under the supervision of Professor Pierre du Toit. Her studies have focused extensively on the negotiations leading up to the South African Constitution. Salomé currently works as a Managing Editor for Taylor \& Francis in Cape Town.

Prof. Ursula van Beek is a historian. Her main research area is a cross cultural comparative study of historical memory, identity and cultural values in the context of democracy. She heads the international research unit TRU: Democracy Globally. 


\section{PREFACE}

With this celebration publication, Modern State Development, Capacity, and Institutions, we honour Pierre du Toit, an esteemed colleague and mentor to so many Political Science students, on his retirement as a professor in Political Science at Stellenbosch University. This impressive collection of research articles, mainly with the state as focus, written by some of his former higher degree students and colleagues, is an indication of the high regard they have for him.

Pierre and I had been colleagues in the Department of Political Science since 1986 and from the beginning I was impressed by his scholarship, methodological rigour, original ideas, inspired teaching and general academic productivity. It is a near impossible task to survey his contribution to Political Science in any detail in this brief preface. However, this short summary of the influence that he has on Political Science, in South Africa and internationally, will clearly show how prolific he was as a researcher, supervisor of post-graduate students and lecturer to undergraduate students.

Trained at Stellenbosch University Pierre's first permanent appointment was at the University of the Western Cape in 1976 after three years in part-time lecturing posts at Stellenbosch. Three years later, in 1979 he was appointed as lecturer at Stellenbosch where he moved through the ranks to reach the level of professor in 2001. During this time he received several research grants from the Human Sciences Research Council (HSRC) and also served four years in the middle 1990s as editor of Politikon, flagship journal of Political Science in South Africa. Besides two co-authored books in 1987 and 1990, he also published his first sole author book, Power Plays - Bargaining Tactics for Transforming South Africa in 1991 that dealt with the difficult choices that had to be made during the negotiation process for a democratic South Africa. During this time he also participated with top researchers at the International Conflict Research Institute at Ulster University in a five nation comparative study on peace and conflict where he made excellent research contributions and broaden his network within the field of peace and conflict studies.

In the early nineties he received the prestigious Peace Fellow Award by the Jennings Randolph Program for International Peace which allowed him to spend a year at the United States Institute of Peace in Washington, DC. This was followed by another 
research sabbatical in 2002 in the USA when he was awarded a Fulbright New Scholars Award to work on ethnic and cultural conflict within and across national borders. Closer to home the quality and impact of his research output was also recognised by the high rating as an "internationally recognised" researcher awarded by the National Research Foundation in 2003.

In his research Pierre concentrated mainly on state-building, peace processes, ethnic conflict, and democratic consolidation and identity politics. Very few political scientists in South Africa managed to draw international attention to their research. However, Pierre managed to do just that with at least two of his three sole authored monographs. His research at the United States Institute of Peace in 1992/1993 resulted in the publication of State Building and Democracy in Southern African in 1995, where he built on solid theories and a deep understanding of the importance of empirical research. It focuses on the role of the state in political transitions. In the American Political Science Review $(90: 4,1996)$ the leading Political Science journal in the USA, James R. Scarritt opined that the "...combination of sophisticated macrotheory and solid micro-foundations means that this book will make a significant contribution to thinking about democratic sustainability in Africa, even for those who do not agree with every point made in it."

In his next book, South Africa's Brittle Peace - The Problem of Post Settlement Violence, published in 2001 by the highly regarded publishers, Palgrave-Macmillan, he shifted the emphasis to an important element of political transitions, namely the peace processes. This book showcased the ease with which he managed to apply and analyse the theoretical contributions of world famous social scientists like Charles Tilly, Michael Mann and Martin van Creveld in the South African context. Undoubtedly, a book that pointed to a new approach and unique direction in this field. It is an outstanding contribution with very original conceptualisations of new phenomena in the field of peace and conflict.

$\mathrm{He}$ also brought his knowledge and vast experience as a researcher in the field of democratic transitions to the Transformation Research Initiative which was establish in 2001 and renamed in 2015 to the Transformation Research Unit (TRU) attached to the Centre for International and Comparative Politics at Stellenbosch University. With the World Values Survey as basis the team of international experts' contribution on democratic transitions focused on a number of the "most different cases" (Poland, South Korea, South African, Chile and Turkey) with Sweden and Germany, being established democracies, as "control cases". He delivered close to ten chapters in three book publications of TRU. The first of which, Democracy under Construction - 
Patterns from Four Continents, was described by the renowned political scientist, Philip Schmitter, as "...a major, even seminal volume. No one interested in democratization, including a sceptic like myself, can afford not to come to terms with both its method and its findings".

Three co-authored books, all in the broad field of transitions and democracy, by Pierre since 2011 are an indication of his academic productivity. Moreover, it is also an indication of his accommodating nature without abandoning his high academic standard - a co-authored work needs a give-and-take approach. What impresses most, is also his originality and discipline when it comes to academic writing. One does not only see it in his books but also in the close to forty academic articles published in top journals as well as his numerous chapter contributions to edited books. As a lecturer his contribution and appreciation by undergraduate students were always reflected in the high ratings given to Pierre by the students. On a postgraduate level, especially on $\mathrm{M}$ - and PhD-level Pierre delivered many top students, a number of whom joined academia.

There are but a few South African political scientists that achieved the same level of local and international recognition for their contribution to the field of comparative political analysis as Pierre du Toit.

Despite his substantial contribution to Political Science in South Africa, Pierre managed to have a balanced family life with interesting outdoor hobbies, such as mountaineering in his younger days and more lately mountain biking and longboarding. All this mixed in with long, mostly camping trips exploring Southern Africa on holiday with his wife Laura and two sons Chris and Leon. 
1

\section{THE STATE, STATE CAPABILITIES AND NON-STATE ACTORS: A LITERATURE SURVEY}

DERICA LAMBRECHTS

\section{Introduction}

There exists a vast amount of literature on theories of the state, which mainly differs on what the nature of state power is and should be. In addition, there are also different perceptions on what the role of the state is and/or should be. The purpose of this chapter is not to provide a complete literature review of the abovementioned topics, but rather to focus on a number of conceptual clarifications of the state, based on state-society relations. ${ }^{1}$ The majority of the research on this topic utilises Migdal's (1988, 1994 and 2001) state-in-society approach in a comparative or case study design and there exists an opportunity for theoretical contributions, based on the more recent development of the position of the state locally, and globally.

That said there is a central proposition that grounds the majority of state-centred literature namely that: "...national states constitute the building blocks of legitimate world order..." (Rotberg, 2003:1). Accordingly, there is a focus on the search for the perfect formula and method in order to construct the state, which will indeed provide a system that will be the building blocks of a legitimate world order. These studies usually include an analysis of state failure and processes involving state reconstruction. However, there exists literature that is based on the proposition that the nation state is not the most important actor of authority in order to create a legitimate world order. Studies constructed on this proposition include an analysis of other actors of authority, both domestic and international. Accordingly, there is a broad theme that covers all literature: the question of the durability of the traditional Westphalian notion of the state. This literature survey is constructed on the proposition that the nation-state is the building block of a legitimate world order and the most essential institution in the political sphere, with specific reference to the local political sphere, and not the global.

1 The chapter will not focus on state-society relations in situations of conflict, or on relationship reconstruction in post-war states. 
The chapter will focus on state-society relations, concentrating on (amongst other works) the work of Joel S. Migdal (1988). Migdal (1988) looks at states from the perspective of states in society and more specifically, strong societies and weak states, thus state-society relations, with specific reference to state capabilities. In order to measure the social capabilities of the state, Migdal (1988) uses three concepts, namely compliance, participation and legitimacy. A brief overview will also be provided on state weakness, failure and collapse. Professor Pierre du Toit has through his academic career focussed on the different writings of Migdal, for example in his book State-building and democracy in Southern Africa: A comparative study of Botswana, South Africa and Zimbabwe (1995). His analysis and interpretation of J.S. Migdal's contribution to state theory, was the main inspiration for this text.

This chapter will continuously refer to the relationship between the state and nonstate actors (located within society). Within the state system, there can be the presence of non-state actors as social forces that may or may not work in favour of the state in sustaining the balance of power. Thus, there may or may not be a mutually beneficial relationship that works in favour of either the state or certain actors within the society. The contrasting view will also be discussed: rival social organisations (as an indicator of strong societies), with specific reference to local rival social organisations (as opposed to regional and international).

\section{Understanding the State: A Conceptual Framework}

There have been a number of seminal academic works based on the position, authority and continuance of the state in the global world order (for example Van Creveld, 1999; Strange, 1996 and Evans, Reuschemeyer and Skocpol, 1985 and Dryzek and Dunleavy, 2009). Van Creveld (1999) notes that although the state has been the most important of all modern institutions, a number of the functions of the state have been taken over by other actors, both local and domestic, and as a result, he observed a decline in the power, functions and capabilities of the state. Factors that led to the decline of the state include: the retreat of the welfare state, the waning of major wars, globalisation and the advancement of technology and also the withdrawal of faith that citizens have in the state. For example, Susan Strange (1996) refers to the decline of the state as the retreat of the state. Strange (1996) postulates that the state has lost political authority over the society and the economy, and discusses a series of non-state authorities in the international political economy, which have taken over some of the functions of the state. Thus, as there has been a decline in state authority, there exists: "... a diffusion of authority to other 
institutions and associations, and to local and regional bodies..." (Strange, 1996:4). One proposition that is provided as support for this argument is that a state's authority has been weakened by technological and financial change and the rise of a single global market economy. As a result of the retreat of the nation-state, what exists is a: "...yawning hole of non-authority..." (Strange, 1996:14). A power void or gap will accordingly exist, which will have the potential to be filled by an authority other than the state. This results in that the state as an organisation faces constant and increasing competition from other non-state organisations, who may challenge the authority of the state.

Nevertheless, as noted by Dryzek and Dunleavy (2009:6): "...the existence of contested, failing and failed states should not disguise the pervasiveness of the state form...". Accordingly, there is also the view that the retreat of the state is not as intense as described above. As with any organisation, external and internal elements will continuously have an impact on the structure and operations of the state. What is observed is that, the nation-state is no longer the only relevant actor (both domestically and in international relations) and that the monopoly that the state had over specific capabilities, tasks and roles has changed. However, the question remains: What is the effect of other actors on the role of the state and how will this change the authority and position of the state? For example, Friman and Andreas (1999:4) note that the: "...global division of labour and expanding power of global production and finance have increased the accountability of states to global markets and non-state entities...". Thus, according to Friman and Andreas (1999) the authority of the state is still confirmed in the global economy. Equally important is that the impact of globalisation on the state will differ in each case and it is important to take into consideration each state's position in the global economy, but also the historical context of each state (Friman and Andreas, 1999). Indeed, the Global Financial Crisis that started in 2007/2008, which was triggered by the housing bubble in the United States, and the European Sovereign Debt Crisis, has brought about a renewed interest in the position of the state in the global economy. As a result of the global recession, caused by these economic failures, national governments were forced to provide rescue packages to financial institutions, in an attempt to stabilise various sectors, most notably the banking sector. Thus, as states interceded, it brought about the reality of the interventionist state. Another, more recent example can be found in the migrant crisis in Europe. Mostly as a result of the war in Syria, Europe has been flooded with migrants. This has sparked a turn towards nationalist policies and government rhetoric in the region is increasingly 
becoming conservative (for example Croatia) and state policy affirmative towards protecting its borders. At the time of writing there were ongoing talks of the complete removal of the Schengen travel agreement and the ultimate collapse of the European Union; this signals that states are flexing their muscles and claiming back individual importance as opposed to regional. As will be highlighted below, defending the sovereign territory is a central function of the state.

With specific reference to international relations, it is important to note that the majority of literature on state authority in international relations has been focused on the challenges to the state coming from above; thus, the top down approach of challenges to the nation-state (for example the impact of globalisation or regionalism). There has however been an acknowledgement of the bottom-up challenges to the state, with specific reference to the criminal element or organised criminal groups: Strange (1996:110-120) writes on the symbiosis between the state and organised criminal groups, with the pre-1980s Italian state as the prime example. However, she claims that the symbiotic coexistence between the state and organised criminal groups, as a non-state actor, are not sustainable and will cease to exist in two cases: first, when there is a collapse in the hierarchy of power in the state and second: "... when the rival authority's power is perceived to threaten the state because it has acquired new foreign allies or new sources of wealth and influence..." (Strange, 1996:120).

Other studies of the relationship between organised criminal groups and the state in international relations (Mittelman and Johnston, 1999; Shelly, 1995 and 1999) focus on the transnational element of organised crime. Thus, the organised criminal group is viewed as a global actor in competition with the state for authority. Shelly (1999) hypothesises that the authority of the state is diminishing, but that this has not resulted in the disappearance of authoritarianism: "...transnational organised crime represents a new form of non-state-based authoritarianism..." (Shelly, 1999:25). In addition, Williams (1997) comments that the increase in the activities of transnational criminal groups, as facilitated by globalisation and the decline of the authority of the state, leads to these non-state actors to be one of the most important security challenges facing the $21^{\text {st }}$ century.

There are several theoretical propositions regarding the state, for example: Pluralism, Elite Theory, Marxism and Market Liberalism (only to mention the classical ones). In addition, there are just as many conceptual interpretations for the construct of the state. However, a number of these conceptual interpretations find their foundation 
in the seminal work of Max Weber. Weber (1978:56) provides a conceptualisation of the basic understanding of the modern state. He writes that:

"...The primary formal characteristics of the modern state are as follows: It possesses an administrative order subject to change by legislation, to which the organised activities of the administrative staff, which are also controlled by legislation, are oriented. This system of order claims binding authority not only over the members of the state, the citizens, most of whom have obtained membership by birth, but also to a very large extent over all action taking place in the area of its jurisdiction. It is thus a compulsory organisation with a territorial basis. Furthermore, today, the use of force is regarded as legitimate only so far as it is either permitted by the state or prescribed by it... The claim of the modern state to monopolise the use of force is as essential to it as its character of compulsory jurisdiction of continuous operation..."

A number of key elements can be extracted from this definition: binding authority, administrative order, citizenship, territorial basis, legitimate use of force and a monopoly on the use of force. On the concept of state authority, it can be defined as: "... a psychological relationship, between the governed and their governors, which engenders a belief that state personnel and institutions, should be obeyed..." (Thomson, 2004:201). From this definition two essential subjects arise: first, the importance of state-society relations and second, the legitimacy of the state. It is postulated in this chapter that state-society relations should be regarded as an essential component of maintaining the organisation of the state. Accordingly, an imbalance or a breakdown in state-society relations will have a negative impact on a sovereign state. For the purposes of this chapter, the importance of the society in the construct of the state is acknowledged.

On the topic of legitimacy, Thomson (2004:201) postulates that state authority is generated from two sources, namely legitimacy and coercion. He argues that governments use a combination of legitimacy and coercion to maintain their authority over a specific society. Furthermore: “...when the state's legitimacy declines, however, and rulers no longer command sufficient resources of coercion, authority is threatened..." (Thomson, 2004:201). If the citizens of a state regard the system as legitimate, the state will have the ability to mobilise society. As noted by Migdal (1988:21-22) several elements are central to the survival of the state, the most important of which, is the ability to mobilise society. The mobilisation of the society: "...involves channelling people into specialised organisational frameworks 
that enable state leaders to build stronger armies, collect more taxes...and complete any other number of complicated tasks..." (Migdal, 1988:22). Thus, the capacity of the state to mobilise society is a functional part of the conceptualisation of the state. Migdal $(1998,1994,2001)$ focusses strongly on the state-in-society perspective and hypothesise that "...States are part of societies. States may help mold, but they are also continually molded by, the societies within which they are embedded..." (Migdal, 1994:2). As will be noted later, this is a much more adaptable conceptualisation of the state.

In agreement with a more generic definition, Van Creveld (1999:1) postulates that the state is an abstract entity and furthermore, that it is an overarching invisible subject, which includes both the head of state and the common citizen of the state. In addition, Van Creveld (1999:1) suggests that there are three distinctive characteristics by which the state is defined: "...it authorises (other corporations) but is itself authorised...solely by others of its kind; secondly, that certain functions... are reserved for it alone; and thirdly, that it exercises those functions over a certain territory inside which its jurisdiction is both exclusive and all-embracing...". The third element that is mentioned by Van Creveld (1999) is control over a specific territory: failure to exercise control over the entire area of a state, may lead to state weakness and state failure. Indeed, this is recognised by Herbst (2000) when he addresses state development in Africa. ${ }^{2}$ Herbst (2000) explains how the process of statebuilding in Africa differs from state-building in Europe. He explains that a lack of permanent, well-defined boundaries in pre-colonial and colonial Africa is essential in terms of explaining a lack of state development. In addition, Herbst (2000) postulates that when explaining state weakness in Africa an important element is low population density as this complicates authority and control. In Africa, states were not centralised as in Europe as all leaders had to deal with the problem of low population densities, which in turn made it difficult for leaders to control the periphery from the capital. It was essential to control the main urban areas, and rural areas that were important in terms of the economy (for example region around the Nile river), but political control was limited to such regions and did not expand over the entire territory of states. Other elements, such as a lack of state institutions and the role of colonialism are also discussed by Herbst (2000). However, the inability of rulers to apply and maintain control over their territory is central to the clarification of why states in Africa fail. States can only survive if there is continuous control over their entire territory. In the introduction this central hypothesis is confirmed when

2 For reflections on state-society relations in Africa, see Rothchild and Chazan (1998). 
he states that "...states are only viable if they are able to control the territory defined by their borders..." (Herbst, 2000:3).

Another significant definition of the state is provided by Stepan (1978:xii), when he claims that: "...The state must be considered more than the "government". It is the continuous administrative, legal and coercive systems that attempt not only to structure relationships between civil society and public authority in a polity but also to structure many crucial relationships within civil society as well...". From this definition, as noted by Skocpol (1985:7), other organisations and agents are essential for the continuation of the state as they also take part in and facilitate social and political relationships.

These attributes of states are echoed by a number of authors. For example, Zartman (1995:5) stipulates three functions of a state. First, that the state is a sovereign authority (the arena of politics and the source of identity), second that the state is an institution (one single organisational entity, as also noted by Weber (1978), and an intangible symbol of identity and thirdly, that the state is the security guarantor for the populated territory, referring back to the legitimate use of violence noted by Weber (1978). In addition, what Zartman (1995) argues is that there is a significant blurring of these characteristics of the state and that it is difficult to perform the functional characteristics in isolation. Accordingly, each of these functions needs to be executed in order for the state to persist. Similarly, if one function is not executed it will result in a possible failing of the other.

Williams (2002:164) similarly outlines four main interpretations of the state: a) the state is a sovereign territorial entity, which controls the area under its jurisdiction, thus controlling who and what enters; b) the state is a system of rules, and thus the state has both authority over its citizens and obligations towards them; c) the state is a set of institutions and people who act on its behalf; and d) the state is a set of functions, which range from the state as guarantor of order and security, to the role as the manager of economic activity and provider of economic and social welfare. As previously mentioned, in order for the characteristics of a state to be functionally executable, at the core of the state exist administrative, legal, extractive and coercive organisations. More practically speaking, the state will facilitate revenue generation, safety, security and justice, basic service delivery and economic governance. If these core functions of the state can be performed, the legitimacy of the state will increase. It is important to note that these organisational structures will differ from state to state, mainly based on the legislations of that state and governmental 
structures (Skocpol, 1985:7). Also, as noted by Dunn (2001:55): “...the nation-state as an institution reflected the needs and demands of a specific time and place...". ${ }^{3}$

If a state is analysed based on the neo-pluralist theory, ${ }^{4}$ Rotberg (2003:2) provides a normative conceptualisation of the state. He explains that the main function of the modern state is to provide political goods to the citizens; thus: "...state answers the concerns and demands of citizenries...". What is important, however, is that there exists a specific hierarchy of political goods, of which the supply of security (specifically human security) is the most important one. As said, the provision of these political goods is regarded as the main function of the state. It includes the prevention of cross-border invasions and infiltrations; thus, the prevention of the loss of territory. Furthermore, domestic threats that may attack national order and social structure need to be eliminated. Also, crime and other related dangers to domestic security need to be prevented and last, citizens need to be enabled to resolve disputes with each other and the state, without fear of intimidation (Rotberg, 2003:3). A summary of the normative hierarchy of political goods, which the state needs to provide, as its main function, is listed in table 1 below.

TABLE 1 Hierarchy of Political Goods

\begin{tabular}{ll}
\hline Political Goods & Description \\
\hline Security & Prevent loss of territory \\
Political freedom & Citizens can participate freely, openly and fully in politics and political processes \\
Medical and Health care & Include medical and health care at varying levels and costs \\
The Knowledge Good & Schools and educational facilities of various kinds and levels \\
Physical Infrastructure & Including roads, railways and harbours \\
Communications Infrastructure & Including telephone networks and broadcasting stations \\
Money and Banking system & Including a national currency and system presided over by a central bank \\
Fiscal and Institutional Context & Citizens can pursue personal entrepreneurial goals/potentially prosper \\
Civil Society & The promotion of civil society \\
Environmental Commons & Methods of regulating the sharing of the environmental commons
\end{tabular}

(Source: Adapted from Rotberg, 2003:3,4)

3 Dunn (2001) discusses the African state in international relations theory and postulates that the generally accepted definitions of the state do not fit the reality in Africa.

4 According to the neo-pluralist view of the state there is an emphasis on individual rights and the freedom of political association in order to participate in political processes. This, as well as, emphasis on the importance of competitive elections and a constitutional framework are preserved. Public policy is formulated from interactions between several groups and actors. However, the inequality and imbalance of these groups are recognised, for example an imbalance between business and the rest of society (Dryzek and Dunleavy, 2009:132). 
To conclude this section, the state is regarded as: an abstract entity of administrative order with binding authority and a territorial basis and jurisdiction that is recognised by other similar organisations. There should be a separation between ruler and organisation and the organisational structure of each entity can differ, based on a number of elements including: History, legislative and governmental structure and location. In order to attain benefits for society, the state needs to fulfil a number of functions, which are intertwined and cannot be executed in isolation. As part of these functions, the state needs to provide political goods to citizens, of which the provision of security is the most important. Accordingly, the state claims the legitimate use of force and a monopoly on the use of force. The lack of provision of political goods can facilitate the breakdown of state-society relations. Thus, the ability of the state to mobilise society will weaken, and consequently, there may also be a decline in the legitimacy of the state.

Rotberg (2003) notion of political goods strongly reflects Weber's conceptualisation of the state. In addition, it has to be noted that Migdal (1988) concurs with Weber's conceptualisation of the state, but he attempts to reconceptualise this definition in later works. In his 2001 book State in Society: Studying how states and societies transform and constitute one another he explains his re-conceptualisation:

"...The assumption that only the state does, or should, create rules and that only it, or should, maintain the violent means to bend people to obey those rules minimizes and trivializes the rich negotiation, interaction, and resistance that occur in every human society among multiple systems of rules. It posits a human society where only incredibly coherent and complex organization exercises an extraordinary hegemony of thought and action over all other social formations intersecting that territory. It provides no way to theorize about arenas of competing sets of rules, other than to cast these in the negative, as failure or weak states or even as non-states (Migdal, 2001:15).

Migdal (2001:15-16) re-conceptualises the state as: "...The state is a field of power marked by the use and threat of violence and shaped by (1) the image of a coherent, controlling organization in a territory, and (2) the actual practices of its multiple parts...".

It is beyond the scope of this chapter to debate Migdal's (2001) re-conceptualisation of the state, but a few important notes can be provided. Although Migdal (2001) 
provides a re-conceptualisation the foundation is still located in the Weberian understanding of the state. The re-conceptualisation is rather more fluid and acknowledges the role and impact of multiple streams of interaction, either positive or negative for the functioning of the state. The state remains part of society, located in society, and each with the ability to shape each other. ${ }^{5}$ This understanding may allow for a better grasp of the process of state decay, as will be explained below.

\section{A Conceptual Clarification: State Decay}

A great deal of research has been devoted to analysing why states fail. This body of literature usually includes the reasons for state failure based on case study analysis. These cases typically include states such as Afghanistan, Sudan and Somalia. However, there has been a move towards incorporating the themes of breakdown, restoration and prevention into case study analysis. ${ }^{6}$

It is important to note that the concepts of state weakness, -failure, -fragmentation, -breakdown and -collapse are often used interchangeably to explain the deterioration and ultimate downfall of the state. This chapter distinguishes between state weakness (indicating initial fragmentation of the state, but also limitations on the capacity of the state), state failure (the visible non-functioning of state apparatus) and state collapse (a complete breakdown of most, if not all state systems). Thus, state weakness can result in state failure, which in turn can result in state collapse, and the process is referred to as state decay, as is presented in figure 1. It is important to note that states can progress or regress between the different categories of state decay, indicating that state reconstruction is also a possibility. For example Lebanon, Nigeria and Tajikistan have moved from collapsed to weak states, Afghanistan and Sierra Leone from collapsed to failed, and Zimbabwe from a once strong state to a failed one (Rotberg, 2003:10).

5 The latest text on the state-in-society approach developed by Migdal is the 2013 book The Everyday Life of the State: a State Society Approach.

6 A number of case studies related to state collapse and reconstruction can be found in Zartman (ed) (1995). This collection includes a historical analysis of state collapse and reconstruction in Chad (Foltz, 1995), Uganda (Khadiagala, 1995) and Ghana (Rothchild, 1995). The book further addresses the topics of states in danger and agents of state reconstruction. 


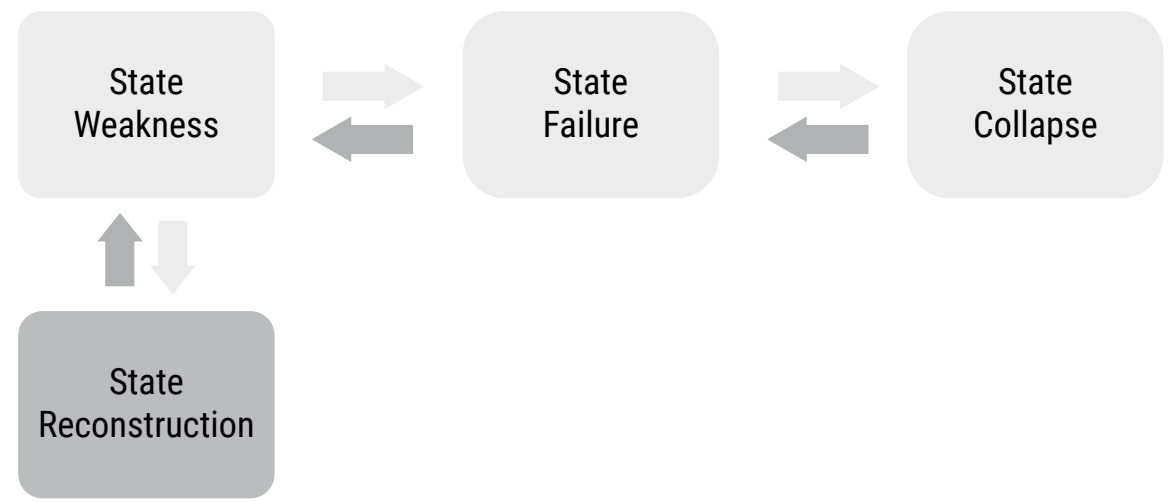

Figure 1 The Process of State Decay and State Reconstruction (Source: Produced by the author).

\section{State Weakness}

On the topic of state weakness, the most important element used to define a state as weak, is internal institutional weakness, as observed in a decline in the capacity of the state. Mentan (2004) argues that a state weakens when the state cannot provide citizens with a minimum level of security, when the state is vulnerable to external economic and political forces and when the state is not regarded as legitimate by groups of the population.

With regards to weak state capacity and the identifiable elements of a weak state, Williams (2002) furthermore lists weak border controls, lack of business regulations and an ineffective criminal justice system. Williams (2002) agrees with Mentan (2004), that weak states will have a low level of state legitimacy. Migdal (1988) also focuses on state capabilities when identifying weak states, in that such states will have low capabilities to extract resources, regulate relations between the state and citizens and amongst citizens themselves, and penetrate society and mobilize citizens. This relates to what Mann (1986:113) refers to as infrastructural power: "...the capacity of the state actually to penetrate civil society, and to implement logistically political decisions throughout the realm...". Accordingly, Williams (2002) refers to the weaknesses in the state as capacity gaps, which will lead to functional holes in the system of the state. These functional holes may then be utilised by non-state actors for their own benefit (Williams 2002:170). Similarly, Mentan (2004:20) claims that state weakness in Africa creates the ideal situation for violent non-state actors to capture the state. The author further describes several manifestations of weak states, including high rates of unemployment (specifically amongst historically disadvantaged groups), extremely high levels of corruption and 
a general absence of the rule of law. The result will be an abundance of unskilled and unemployed youths engaging in criminal activities, lack of law and order and a lack of legitimate government. Weak states can be summarised as states suffering from gaps in the capacity of the state, but also a lack of state legitimacy. Furthermore, a weak state will not be in control of its entire territory, with specific reference to areas where marginalised groups reside or peripheral areas. Indeed, Reno (1998:2) conceptualises a weak state as a state where: "...conventional bureaucratic state capabilities exists alongside (generally very strong) informal political networks...". Informal local non-state actors and informal political networks may subsequently challenge the authority of the state.

\section{State Failure}

The next step in state decay is state failure, but (as mentioned) it is important to acknowledge that state weakness does not automatically lead to state failure. Accordingly: "...crossing from weakness into failure takes will as well as neglect..." (Rotberg, 2003:14). State failure is thus mostly man made and does not happen by accident. As catalysts of state failure, two elements can be highlighted: Internal violence and (non)-delivery (of) political goods. Rotberg (2003:1) states that: “... Nation-states fail because they are convulsed by internal violence and can no longer deliver positive political goods to their inhabitants...". Indeed, failed states will only provide limited, if any, political goods. As explained previously, security is regarded as the most important political good and if there is a lack of security, the result would be internal violence and conditions conducive towards state failure. Indicators of internal violence and an inability to deliver political goods are the following: enduring political violence, victimisation of citizens by the state, loss of control over peripheral territory, growth of criminal violence, flawed state institutions, deteriorating infrastructure, failing provisions of basic services, economic opportunity for an elite, in the context of a generally declining gross domestic product, and widespread corruption (Rotberg, 2004).

First, Rotberg (2004:6) lists lack of control as an important indicator of a failing state. He says that: "...failed states cannot control their peripheral regions, especially those regions controlled by out-groups. They lose authority over large sections of territory...". Furthermore, this can be measured by the actual control of government officials over a geographical area. A second important indicator of state failure to be highlighted is the increase of criminal violence. In this case, lawlessness as a result of the lack of authority by the state will become more apparent. Criminal gangs will 
increase and extend their control over territories. Strongmen will become central to communities, as they will provide protection and security (Rotberg, 2004:6). As explained earlier, as part of the conceptualisation of the state, one of the main roles of the state is to provide political goods; as the state breaks down, it will not be able to provide basic political goods. In the case of failed states, this function can be taken over by non-state actors. If a non-state actor has a significant armed following, prevention of failure will probably not be possible (Rotberg, 2004). In addition, three other signs of imminent state failure can be highlighted: rapid reduction in incomes and a decline in the standard of living, an increase in the levels of violence and the subversion of democratic norms (Rotberg, 2004). If these characteristics are present, the ultimate result will be state collapse.

Reno (1998) takes a look at state weakness and state failure from the perspective of warlord politics. He argues that warlords stay in power as a result of their ability to manipulate resources and garner support from external sources. However, in order to maintain power and the accumulation of wealth, rulers ensure that the bureaucracy and the military stay weak. Thus, institutional state weakness needs to be kept in place therefore state failure is a deliberate strategy by the ruler. Such states will have no legitimacy as they will fail to provide political goods to citizens.

\section{State Collapse}

A simplistic definition of state collapse is that the state can no longer perform its basic functions, including that of maintaining the role of the decision-making centre of government, being a symbol of identity and territorial entity, being the authoritative political institution and a system of socio-economic organisation (Zartman, 1995:5; Thomson, 2004:211). Therefore, state collapse does not necessarily occur in the case of regime breakdown, such as a coup or rebellion, but when the: "...legitimate power of the state..." falls apart, together with the laws of the state and the political order (Zartman, 1995:1).?

Zartman (1995:1) and Rotberg (2003:9) further explain that when a state collapses, a vacuum is created, with specific reference to authority. The vacuum of authority may be filled by non-state or sub-state actors (also referred to by Zartman (1995) as local power grabbers): “...order and power (but not always legitimacy) fall down

7 An example of a collapsed state is Somalia. Thomson (2004:211) writes that “... Although Somali clans were united enough to bring down Siad Barré's corrupt regime in 1991, these disparate groups collectively failed to reconstitute a national government in its place. Somalia ... has not had an officially recognised central authority for the last 15 years...". 
to local groups or are up for grabs..." (Zartman, 1995:1). Thus, a local non-state authority could consume the power lost by the central government and fill the vacuum of authority. The non-state actor could control a territory within the original boundaries of the state. One example is Somaliland, a region located in the Horn of Africa. It is a self-declared sovereign state and not internationally recognised. ${ }^{8}$ It is important to note that in the case of Somaliland (located in the state of Somalia) the lack of a formal, internationally recognised state did not result in anarchy and chaos. The institutional system is based on local authority (coming from the society) which maintains order.

Thus, two important concluding remarks can be derived from the preceding conceptualisation of state weakness, state failure and state collapse: state collapse is the final stage in the process of state decay, preceded by state weakness and state failure. In the case of state collapse, a vacuum as a result of a lack of institutional capabilities of the state is created. This vacuum is often filled by a local non-state actor and although the authority exemplified by this actor would be in rivalry with the state (or what is left after state collapse), the authority of the non-state actor can have the ability to normalise and stabilise the situation, as in the case of Somaliland. This section has illustrated the interconnectedness of the state and the society and how the state is embedded in society.

\section{State-Society Relations}

The focus of the discussion of state-society relations will centre on the 1988 work of Joel S. Migdal: Strong societies and Weak States: State-Society Relations and State Capabilities in the Third World. Migdal's (1988) main research question was stated as: why specific states find it hard to foster strong state-society relations, by achieving high levels of social control, while other states find it easier to do? Thus, why does a specific state have the ability to successfully conduct policy implementation, as an indicator of high state capacity? Accordingly, Migdal (1988) creates a set of theories to examine state capabilities, which is based on state-society relations. What is central to the analysis is that states cannot be separated from society; and in order for a state to emerge and progress to a strong state, social control by the state, over society, is needed.

Migdal (1988:24) further focuses his analysis on: "...sources of resistance to the state's efforts at achieving predominance...". As part of this analysis, two themes are

8 For more information on statehood in Somaliland the following texts can be consulted: Buur and Kayed (2007), Menkhaus (2006 and 2007). 
focused on: How the: "...rules of the game..." have been established and maintained in society and second, that there should be a focus on all organisations in a society that have exercised social control; thus, both formal and informal organisations. According to the classical pluralist theory of the state, the analysis of state-society relations needs to include all significant political actors and on different levels. With regard to the levels of analysis, Migdal (1988) focuses on three levels of the state, namely the central executive leadership, central state agencies and officials at regional and local level. What he postulates, as will be explained later, is that in weak states local strongmen will work against the central state agencies, as created by executive leadership. The leadership will be challenged. Fragmented social control may result with state leaders prioritising their own survival and engage in the reshuffling of state agents and even "...dirty tricks...", such as corruption and buying of support (Migdal, 1988:257). This may however further weaken the state, through the deterioration of the capabilities of state agencies and a subsequent decline in legitimacy. As will be noted later, legitimacy is essential to foster strong statesociety relations.

\section{State Capabilities and State Social Control}

For the purposes of this chapter, state-society relations can be defined as:

"...interactions between state institutions and societal groups to negotiate how public authority is exercised and how it can be influenced by people... They are focused on issues such as defining the mutual rights and obligations of state and society, negotiating how public resources should be allocated and establishing different modes of representation and accountability..." (Department for International Development, 2010:15).

The focus of this definition is on ensuring accountability of the state and to make the state responsive to society. An essential element of state continuation is the strong connection between the state and the society. Here, two relationships need to be identified: first, the direct impact of states on society and second, that societies also affect states. With specific reference to the last mentioned relationship and as noted by Migdal (1988), structures of societies can affect the capabilities of the state.

State capabilities will be conceptualised in the following section. In order for a state to survive, a number of factors need to be present: "...including the organisational capabilities of its leaders, population size, potential material and human resources 
available, and larger international configurations..." (Migdal, 1988:21). In the case of states where all these elements are present, the state will technically survive. However, in addition to state survival, states aim to achieve a high level of specific capabilities, including the capability to penetrate society, regulate social relationships, extract resources, and use resources appropriately. ${ }^{9}$ Strong states are those with high capabilities to complete these tasks, which in turn will make it possible for them to achieve goals set out by leaders. On the other hand, weakened states will find it difficult to achieve changes sought by leaders (Migdal, 1988:4-5). State capabilities will increase if the state has social control or if the state can successfully mobilised society. Social control is defined as: "... the successful subordination of people's own inclinations of social behaviour or behaviour sought by other social organisations in favour of behaviour prescribed by state rules..." (Migdal, 1988:22). Accordingly, a state will have social control if people behave socially as the state prescribes, rather than in terms of what they desire for themselves or in terms of what other societal actors prescribe. In order for a state to achieve high levels of social control, the strategies of survival, as prescribed by the state, have to be part of citizens' daily life. All social organisations, formal or informal, can each present symbols, rewards and sanctions to citizens. Social control will be achieved by the organisation that can provide key elements of survival strategies: "...strategies of survival, sewn from the symbols, rewards, and sanctions, are roadmaps used to guide one through the maze of daily life, ensuring one's existence..." (Migdal, 1988:27). Thus, the state needs to ensure that its symbols, rewards and sanctions are the survival strategies of the society. These prescriptions of the state are expressed in the laws of the state.

As mentioned, in order to avoid state breakdown, a high level of state social control is needed. This level can be measured by three indicators: the compliance by the populace, the level of participation by the citizens in state sanctioned institutions and the legitimacy of the state (Migdal, 1988:32). The focus is accordingly on the criteria of compliance with state rules, participation in state structures and the legitimacy of the state.

For a state to achieve compliance, the citizens should yield to the rules of the state. Initially, compliance can be found by the use of force and thus, it is essential for a state to exercise successful control over its security forces. This is only possible if the strategies of the security forces and the other organisations of the state correspond. Furthermore, control over the extraction and allocation of resources will

9 As mentioned, see also Mann (1984) on what he referred to as infrastructural power and the ability of the state to regulate society. 
also determine the level of compliance. If the state is successful in the reallocation of resources, citizens will more willingly accept the prescriptions of the state (Migdal, 1988:32).

With regards to participation, the key factor is that the state should be able to mobilise citizens to repeated voluntary participation in the different institutional sectors of the state. Participation goes beyond only voting in elections; it should extend to engaging and contributing to state institutions. As participation increases, the state will gain strength. The practical example used by Migdal (1988:32) to illustrate participation is that a worker would rather make use of a state-licensed medical clinic, than of an illegal healer.

Legitimacy, most importantly, refers to the right to rule by a state. Successful legitimation of a state will see citizens voluntarily accept and approve the authority of the state. The legitimacy of a state is the most powerful indicator of the strength of a state - in the case of compliance and participation; citizens may conform to the prescriptions of the state in return for incentives or compensation (Migdal, 1988:33). Legitimacy can be conceptualised as: "...a psychological relationship between the governed and their governors, which engenders a belief that the state's leaders and institutions have a right to exercise political authority over a society..." (Thomson, 2004:108). Accordingly, legitimacy is only achieved if there is uncoerced acceptance of all the systems of the state by the citizens. In addition, Weber (1964:324-392) identifies three pure types of legitimate authority: Traditional authority (shaped by a society's culture, history and traditions), charismatic authority (a belief in the authority of an individual, as a result of exemplary character or sanctity) and legal authority (a belief in the legality of rules and a support of the authority to issue commands). In the case of legal authority, Thomson (2004:108) notes that a legal-rational government is based on a social contract, where citizens follow the rules of the state, as state institutions in turn will look after their interests; thus, in accordance with the pluralist view of the state, citizens will trust the state and view it as worthy. As has been explained, a lack of legitimacy is also regarded as one of the main reasons for state failure (Rotberg, 2003). If a state has high levels of legitimacy, there will be a significant amount of trust between the state and the society. The state's ability to manage citizens' demands is also dependent on the level of legitimacy of the state. 


\section{Strong/Weak States and Strong/Weak Societies}

Migdal (1988:35) distinguishes between different societies by measuring the distribution and the overall amount of social control exercised by the state. The following matrix is presented:

\begin{tabular}{c|l|l|}
\multicolumn{1}{c|}{} & \multicolumn{2}{c}{ STRONG } \\
\cline { 2 - 3 } \multicolumn{1}{c|}{ STRONG } & & \multicolumn{1}{c}{ WTATE } \\
\cline { 2 - 3 } SOCIETY & & $\begin{array}{l}\text { Diffused } \\
\text { (Sierra Leone) }\end{array}$ \\
\cline { 2 - 3 } WEAK & $\begin{array}{l}\text { Pyramidal } \\
\text { (France and Israel) }\end{array}$ & $\begin{array}{l}\text { Anarchical } \\
\text { (China, 1939-1945; Mexico, 1910-1920) }\end{array}$ \\
\hline
\end{tabular}

FIGURE 2 Social Control of States and Societies (Source: Adapted from Migdal, 1988).

In this matrix, the associations between strong/weak states and strong/weak societies are clarified. Four relationships are highlighted: strong states and strong societies, strong states and weak societies, strong societies and weak states and weak states and weak societies. In the first case, strong societies and strong states exist simultaneously. Migdal (1988) does not provide a description of such a situation. What is explained, however, is a situation where a pyramidal structure of social control is created. This results from social organisations with compatible and congruent rules and structures, with those of the state. In such a situation, the strong state will succeed in merging the survival strategies present within society, with those of the state. The resulting structure resembles a pyramid with the state at its apex. The key factor of a pyramidal structure of social control is that the survival strategies or rules of the state and that of the different societies will be reconcilable with each other (Migdal, 1988:34-35). Thus, the rules and structures different organisations such as the church and interest - and community groups, the family and cultural organisations will be compatible and mutually reinforcing, also with those of the state, fostering strong societies within the regulations of a strong state.

Du Toit (1995:24-25) further explains Migdal's (1988) theory on pyramidal structures of social control by stating that in a strong society with a pyramidal structure, a strong state will gain control by commanding the top section of the pyramid. The strong state will succeed in merging the strategies of the state and that of the society. This would be the ideal situation, which will lead to the continuation and further consolidation of the state and centralisation of state power. What is clear from figure 2 is that Migdal (1988:35) regards the presence of a pyramidal 
society the result of a strong state and a weak society. However, it is argued that a pyramidal society can be present where there is both a strong state and a strong society (See figure 3 below). As explained, if there is a society where there is a fused pattern of social control, the state will exercise control over the society by occupying the apex of the pyramid. Examples of pyramidal societies (as a result of the presence of a strong state and a strong society) include states with a strong and active civil society, but also high levels of legitimacy and state social control, such as the current situation in Norway and Germany. However, as mentioned, a situation can arise in which a society will have uneven levels of social control because of social organisations with diverse rules and structures, which are not compatible with those of the state. Thus, "...numerous systems of justices operate simultaneously..." (Migdal, 1988:39).

In the matrix presented by Migdal (1988:35) such a situation is referred to a diffused society, but it is later also described as a weblike society. Thus, there will be the presence of a weakened state and a strong society (See figure 3 below). In the case of fragmentation in the social control, weblike societies will emerge.

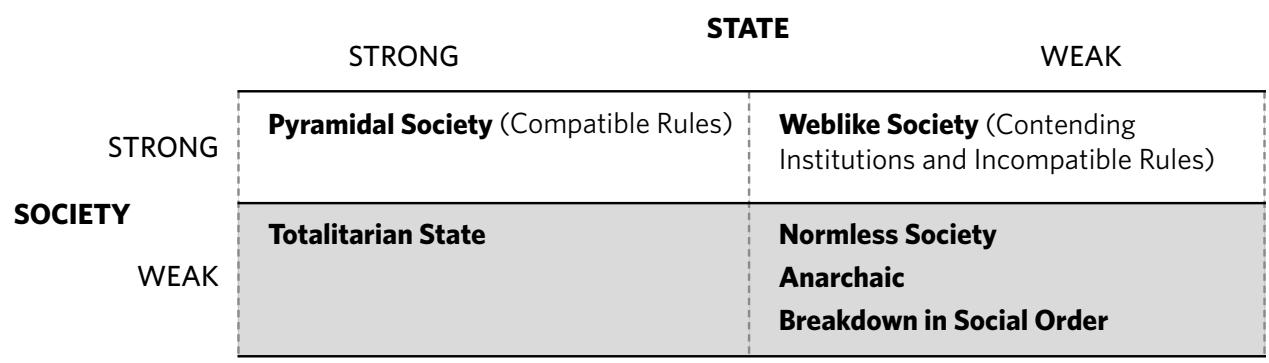

Figure 3 Typology of State-Society Relations (Source: Adapted from Migdal, 1988).

Weblike societies can be conceptualised as follows: "...In weblike societies, although social control is fragmented and heterogeneous, this does not mean that people are not being governed; they most certainly are. The allocation of the values, however, is not centralised..." (Migdal, 1988:39). In addition, as further explained by Du Toit (1995:25): “...in weblike societies no single strand of social control holds the social fabric together, but rather a network of such strands...". Thus, several systems of rule and law operate at the same time. In the case of weblike societies, where the social control is fragmented between numerous rival organisations, states will find it very difficult to achieve policy implementation.

Accordingly, weblike societies operate around strongmen who usually attempt to facilitate the disintegration of state social control by dominating aspects of the state. 
For strongmen to be able to dominate aspects of the state, the process of bargaining has to take place between state officials, implementers and the strongmen. This is described by Migdal (1988:249) as the "...triangle of accommodation..." (See figure 4). Inside the triangle of accommodation, the: "...state officials will formulate policy at national level; implementers who are officials entrusted to oversee policy execution at the local level and strongmen..." (Du Toit, 1995:26). Migdal (1988) makes specific reference to the regional and the local level and asserts that on these levels the state, through its implementers, may become involved in bargaining relationships with strongmen and with other implementers and other state and political officials. The result may be that mutually profitable agreements will be arranged between the actors and that each of the strongmen will succeed in creating its own set of rules for social control. ${ }^{10}$ To explain further, in the triangle of accommodation, various strongmen will function alongside each other, together with state implementers and state officials. Migdal (1988) further notes that where the triangle of accommodation is in place and where there is fragmented social control, the process is very difficult to turn around. The state will find it very challenging to claim back social control from the parts of the society where its control is fragmented.

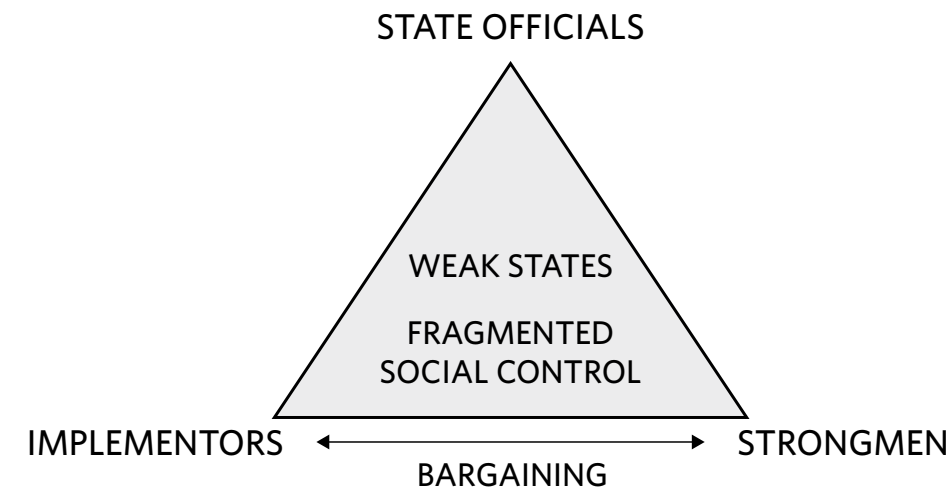

FIGURE 4 Triangle of Accommodation (Source: Adapted from Migdal, 1988).

Such a configuration of power, as the one in the triangle of accommodation, can be maintained for a limited period, as it may lead to increased weakening of the state and place strongmen in a more powerful position. Thus, the continuation of the triangle of accommodation can act as an accelerator for state weakening; as explained above, state leaders will implement political strategies in an attempt to

10 Williams (2002: 172-173) uses Russia as an example where a different construction, the 'iron triangle', is made up of an extremely complex relationship between politicians and government officials, businessmen, and criminals hamper democratic transition. 
keep power, but in effect decrease state legitimacy and from the local level triangles of accommodation enforce the rule of strongmen and fragmented social control.

The third relationship in the typology of state-society relations is a situation where there is a strong state, but a weak society. This may occur in a totalitarian regime, or regimes that exhibit features of totalitarianism, where aspects of civil society, or all aspects of individual life and civil society, are strictly controlled by the state, usually in the form of coercive measures.

The last relationship will occur in the case of both a weak state and a weak society. Such societies can be described as normless and anarchic, with a breakdown in social order. Migdal (1988:35) refers to China during World War II with the Japanese occupation and Mexico during the revolution between 1910 and 1920, as examples where both a weak state and a weak society existed. A more recent example is Haiti after the January 2010 earthquake. During the period immediately after the earthquake the United States were forced to take control of airports as looting was widespread and vigilante groups attempted to control neighbourhoods.

To summarise, with the increase of levels of compliance, participation and legitimation, a state will find it easier to achieve its goals (Migdal, 1988:32-33). A strong state will have high levels of social control, one set of survival strategies, high levels of capabilities and compliance, participation and legitimacy. In a weakened state societal organisations succeed in establishing their own survival strategies, alongside or in contention with those of the state; hence a multiplicity of survival strategies. This may lead to a weblike society. A good example of this is the Cape Flats, located outside of the city centre of Cape Town, South Africa. The Cape Flats are plagued with gangs and organised criminal activities. These groups provide their own set of survival and operational activities, most often as a result of a void of state co-ordinated strategies. The voids as a result of weakened state structures are filled by a series of non-state actors (Lambrechts, 2012).

\section{Conclusion}

This chapter used a pluralist theoretical view of the state and set out to establish a conceptual framework of the state. This conceptual framework was primarily based on the position of the nation state, in that it is the building block of the legitimate world order. Furthermore, the state was conceptualised as an abstract entity of administrative order with binding authority, a territorial basis and jurisdiction that is recognised by other similar organisations, and a separation between ruler 
and organisation. In order for the state to prosper, it should perform a number of functions, ranked in a hierarchical order, of which the provision of security is the most important. Accordingly, the state claims a monopoly on the use of legitimate force. The importance of state-society relations is emphasised as that the lack of provision of political goods may facilitate the breakdown of state-society relations. The state can lose the ability to mobilise society and ultimately lose legitimacy, which is the most important indicator of the social control by the state.

Next, the process of state decay was explained, fixed in a state-in-society perspective: first, the presence of elements of a weak state (gaps in the capacity of the state), second state failure (lack of territorial control, increase in criminal violence and the inability to provide political goods) and last state collapse (where the state can no longer perform any of its basic functions). This will leave a vacuum of authority, which may be filled by non-state actors.

The following section of the chapter focused on state-society relations, the central theme of this study. These relations were discussed by focusing on the work of Migdal (1988) and his indicators of social control: participation, compliance and legitimacy. If the state has low levels of social control there will be a decline in the capacity of the state, again opening the gap for rival social organisations to establish contending survival strategies that are in conflict with those of the state, for example local gangs or organised criminal groups.

As mentioned in the introduction, there is a need for more recent work on statesociety relations, which will take into consideration both local and domestic developments. The migrant crisis in Europe has been mentioned, and important events such as these will not only change the way the state is conceptualised, but also the connection between the state and the society. What is society's expectation of the state and what is the mandate that society gives the state that can be executed within which perimeters? Theoretical propositions that have been discussed in this literature survey, such as Zaartman (1995), Rotberg (2003; 2004) and Migdal (1988), need to be re-visited at the backdrop of a changing landscape." Migdal's state-in-society perspective also deserves robust application on the study of emerging strong societies, for example Brazil and China.

11 See for example Lambrechts 2012, where Migdal's 1988 Triangle of Accommodation was adapted to explain local state-society relationships on the Cape Flats, in Cape Town, South Africa. 


\section{Bibliography}

Buur, L and Kayed, H.M. 2007. State recognition and democratisation in Sub-Saharan Africa. A new dawn for traditional authorities? New York: Palgrave Macmillan.

Department for International Development. 2010. Building Peaceful States and Societies. Published by the Department for International Development: United Kingdom.

Dryzek, J.S. and Dunleavy, P. 2009. Theories of the Democratic State. New York: Palgrave Macmillan.

Dunn, K.C. 2001. 'MadLib \#32: The (Blank) African State: Rethinking the Sovereign State in International Relations Theory' in Dunn, K.C. and Shaw, T.M. Africa's Challenges to International Relations Theory. New York: Palgrave Macmillan. p. 46-63.

Du Toit, P. 1995. State-building and democracy in Southern Africa: A comparative study of Botswana, South Africa and Zimbabwe. Pretoria: Human Science Research Council Publishers.

Evans, P.B., Rueschemeyer, D. and Skocpol, T. (eds). 1985. Bringing the State Back In. Cambridge: Cambridge University Press.

Foltz, W.J. 1995. 'Reconstructing the State of Chad' in Zartman, I.W. (ed). Collapsed States: The Disintegration and Restoration of Legitimate Authority. Colarado: Lynne Rienner Publishers. p. 15-32.

Friman, A. and Andreas, P. 1999. The Illicit Global Economy and State Power. Boston: Rowman \& Littlefield Publishers, Inc.

Friman, A. Andreas, P. 1999. 'Introduction: International Relations and the Illicit Global Economy' in: Friman, A. and Andreas, P. 1999. The Illicit Global Economy and State Power. Boston: Rowman \& Littlefield Publishers, Inc. p. 1-23.

Khadiagala, G.M. 1995. 'State Collapse and Reconstruction in Uganda' in Zartman, I.W. (ed). Collapsed States: The Disintegration and Restoration of Legitimate Authority. Colarado: Lynne Rienner Publishers. p. 15-32.

Lambrechts, D. 2012. 'The Impact of Organised Crime on State Social Control: Organised Criminal Groups and Local Governance on the Cape Flats, Cape Town, South Africa' in Journal of Southern Africa Studies. 38/4.

Mann, M. 1984. 'The Autonomous Power of the State: Its Origins, Mechanism and Results' in European Journal of Sociology. 25 (2). p. 185-213.

Mann, M. 1986. 'The autonomous power of the state: its origins, mechanisms, and results, in Hall, J.A. (ed.). States in History. Oxford: Blackwell.

Menkhaus, K. 2006. 'Governance without Government in Somalia. Spoilers, Statebuildingand the Politics of Coping' in International Security. 31 (3). p. 74-106.

Menkhaus, K. 2007. 'Local security systems in Somali East Africa' in Andersen, L. Møller, B and Stepputat, F. (eds). Fragile States and Insecure People, Violence, Security and Statehood in the Twenty-First Century. New York: Palgrave Macmillan. p. 67-99.

Mentan, T. 2004. Dilemmas of Weak States: Africa and Transnational Terrorism in the Twenty-First Century. Aldershot: Ashgate.

Migdal, J.S. 1988. Strong Societies and Weak States: State-Society Relations and State Capabilities in the Third World. Princeton: Princeton University Press.

Migdal, J.S., Kohli, A. and Shue, V. (eds.) 1994. State Power and Social Forces: Domination and Transformation in the Third World. Cambridge: Cambridge University Press.

Migdal, J.S. 2001. State in Society: Studying how states and societies transform and constitute one another. Cambridge: Cambridge University Press. 
Mittelman, J. and Johnston, R. 1999. 'The Globalisation of Organised Crime, the Courtesan State, and the Corruption of Civil Society' in: Global Governance. 5(1). p. 103-127.

Reno, W. 1998. Warlord Politics and African States. London: Lynne Rienner Publishers.

Rotberg, R.I. 2003. 'Failed States, Collapsed States, Weak States: Causes and Indicators' in Rotberg, R.I. (ed). State Failure and State Weakness in a Time of Terror. Washington, D.C.: Brookings Institution Press. p. 1-25.

Rotberg, R.I. 2004. 'The failure and Collapse of Nation-States: Breakdown, Prevention and Repair' in Rotberg, R.I. (ed). When States Fail: Causes and Consequences. Princeton: Princeton University Press. p. 1-45.

Rothchild, D. 1995. 'Rawlings and the Engineering of Legitimacy in Ghana' in Zartman, I.W. (ed). Collapsed States: The Disintegration and Restoration of Legitimate Authority. Colarado: Lynne Rienner Publishers. p. 49-65.

Rothchild, D. and Chazan, N. (eds.). 1988. The Precarious Balance: State and Society in Africa. Boulder: Westview Press.

Shelley, L. 1995. 'Transnational Organised Crime: An Imminent Threat to the NationState?' in Journal of International Affairs; 48:2; 1995. p. 463-489.

Shelly, L. 1999. 'Transnational Organised Crime: The New Authoritarianism' in: Friman, A. Andreas, P. 1999. The Illicit Global Economy and State Power. Boston: Rowman \& Littlefield Publishers, Inc. p. 25-51.

Skocpol, T. 1985. 'Brining the State Back In: Strategies of Analysis in Current Research' in Evans, P.B., Rueschemeyer, D. and Skocpol, T. (eds). 1985. Bringing the State Back In. Cambridge: Cambridge University Press. p. 3-43.

Stepan, A. 1978. The State and Society: Peru in a Comparative Perspective. Princeton: Princeton University Press.

Strange, S. 1996. The retreat of the state: The diffusion of power in the world economy. Cambridge: Cambridge University Press.

Thomson, A. 2004. An introduction to African politics. Routledge.

Van Creveld, M. 1999. The Rise and Decline of the State. Cambridge: Cambridge University Press.

White, A. (ed.) 2013. The Everyday Life of the State: A State-in-Society Approach. Seattle: University of Washington Press.

Weber, M. 1964. The Theory of Social and Economic Organisation. New York: Free Press. Edited by Talcott Parsons.

Weber, M. 1978. Economy and Society. Berkley: University of California Press. Guenther Roth, $\mathrm{G}$ and Wittich, C. (eds).

Williams, P. 1997. 'Transnational Organised Crime and National and International Security: A Global Assessment' in Gamba, V. (ed). 'Society Under Siege: Crime, Violence and Illegal Weapons. Towards Collaborative Peace Series (I). Halfway House: Institute for Security Studies.

Williams, P. 2002. 'Transnational Organised Crime and the State', in Hall, B.R. and Biersteker, T.J. (eds) The emergence of private authority in global governance. Cambridge: Cambridge University Press. p. 161-183.

Zartman, I.W. 1995. 'Introduction: Posing the Problem of State Collapse' in Zartman, I.W. (ed). Collapsed States: The Disintegration and Restoration of Legitimate Authority. Colorado: Lynne Rienner Publishers.

Zartman, I.W. (ed). 1995. Collapsed States: The Disintegration and Restoration of Legitimate Authority. Colarado: Lynne Rienner Publishers. 
2

\section{THE GREAT DEMOCRATIC DISILLUSIONMENT? PERCEPTIONS OF THE SOUTH AFRICAN DREAM OF 1994}

JOLEEN STEYN-KOTZE

\section{Introduction}

South Africa is now in its third decade of democratic rule. Contemporary political analysis highlight that citizens are caught in a grand democratic disillusionment in the context of political decay. This is evident in political volatility through service delivery protest that escalate in both frequency and destructiveness, narrative of state capture, political corruption, and anorexic delivery of basic services. A dominant narrative is that the democratic dividend of a better life had not materialised for many who remain caught in the cycle of poverty and inequality.

The ruling African National Congress (ANC) is blamed for ineffective delivery, slack transformation, and self-benefit through corruption, which has not delivered the dream of 1994. This democratic disillusionment finds expression in often destructive and violent service delivery protests and an increase in voter disengagement from formal electoral processes (Schultz-Herzenberg, 2014). The Afrobarometer Survey 2015 found that South Africans are discontent with democracy and "...a majority of citizens would be willing to give up elections in favour of a non-elected government that would provide basic services" (Afrobarometer, 2016). This indicates that intrinsic support for democracy in South Africa is weak. It also shows that South Africans seem to generate instrumental support for democracy as opposed to intrinsic democratic support. Democratic legitimation based on instrumental support for democracy can be problematic as it is

...granted and may be withdrawn according the mood of the times. If citizens evaluate regimes mainly in terms of their capacity to deliver consumable benefits or to rectify material inequalities, they may also succumb the siren song of populist leaders who argue that economic development requires sacrifice of political leaders (Kotze and Steenekamp, 2009:72).

In this context, a narrative of renegotiating South Africa's political society also emerged in 2012 under the banner of Economic CODESA driven by perpetual high 
levels of poverty and inequality that mostly affect black South Africans. This narrative stresses growing discontent with a slow pace of transformation could potentially lead to a political and democratic crisis (Allix, 2012). The main thrust of this narrative stresses that "...we achieved political freedom without economic freedom...we never completed the job and we still have economic apartheid dividing the haves and the have-nots" (Sunter, 2015). It thus points to proverbial buyers remorse on the deal that inaugurated South Africa's democracy in 1994.

Du Toit (2003:104-105) observed, South Africa's early political decay should be read in relation to overall ideas and goals that parties came to the negotiation table with in the early 1990s. The inherent problem with negotiated settlements to secure democracy, for Du Toit, is incommensurables. Here he highlights those incommensurables

...accrue over time, as one party gains something tangible that yields quick benefits, while the other party gains an item that is harder to measure, takes longer time to produce observable benefits, and may not even be equally beneficial to all stakeholders on that side of the bargain (Du Toit, 2003:109).

In the South African case, it is evident that creating a political democracy was achieved as the "quick" outcome of the negotiations. A mere four years after the negotiations, a founding election inaugurated the post-apartheid state with a democratically elected ANC at its helm. This victory, however, came in the context of a contested narrative on reimaging the state for the political project of creating post-apartheid South African society. Twenty-two years after the miracle of 1994, as Robinson, Steinberg, and Simon (2016:1) highlight, "there is an increasing sense that the settlement reached in 1994 was not so much the foundation of a new order as a holding operation, keeping in abeyance a host of unresolved issues in regard to economic distribution and race relations".

This chapter presents an analysis of the emergent narrative of a buyers' remorse of the bargain of 1994 through Huntington's (1996) lens of transition and democratisation problems. First, I present an analysis of South Africa's transition problems, which may have culminated in signs of political decay evident after 22 years of democracy. South Africa may well be caught in the problems of transitions that may inhibit democratic consolidation and legitimation of an emerging democracy. Democratic consolidation and legitimation, Huntington argues (1996:209-210), may be impeded by three factors, which are transition problems, contextual problems, and systemic 
problems. This chapter focuses on two questions. First, what did the dream of 1994 mean for ordinary citizens? This is an important question considering the finding that South Africans have an instrumentalist construction of democracy. What did it mean that live would be better under the democratic rule? What were the expectations created during South Africa's transition period? This ties in with the second question this chapter focuses on: a democratic delegitimation rooted in a sense that life had not gotten better under democratic rule.

\section{The pitfalls of negotiations: Transition problems}

We know that South Africa's transition was an elite driven process. This enabled elites involved in the negotiations to set the tone of what was to come in future. As Southall (2012) highlights, "societal goals are established by elites and accomplished under their direction. This does not mean that societies do not change, only that most change comes about as a result of changes in the composition of elites". Here history is equated to elite struggle for societal control. In the South African, elite political control shifted from the Afrikaner Nationalist Party elite to ANC political elites. In this context, we find the perception that the former National Party had sacrificed political power for white South Africans in order to maintain economic power. This is evident in expressions that white South Africans must share the wealth and return what was stolen as the economy is still dominated and controlled by white South Africans (Essa, 2013). Thus, white South Africans may have lost political power, but they still maintain their white privilege.

Transitions involve intense political conflict among the political contenders competing to implement policies founded on different and mutually exclusive versions of government, state and economy. Here parties will negotiate and attempt to gain the most concessions on what the post-authoritarian state, society and economy will look like. It is not illogical to assume that both authoritarian and democratic actors in the negotiations will attempt to secure the most benefit for their respective constituents. Thus, we should not be surprised that the idea that Mandela's negotiated peace provided an empty shell of economic transformation as new political elites entered into a pact with big business and Afrikaner nationalists (Bond, 2016).

Transition problems are linked to the negotiations that bring about democratic rule and deal with agreeing on the institutions and processes that make democratic process work. In other words, is relates the institutions that make a new social contract between state and society work. It includes agreeing on the constitution and constitutional principles, as well as the basic institutional character of the 
new democratic state. This also, however, needs to extend to what the new postauthoritarian state will look like and what principles will guide the new social contract. Du Toit (2003:108-109), for example observe that the constitution was not founded on consensus. He asks:

was it a matter of win-win problem solving, or a war waged by other means? Was it to create procedural democracy guaranteed by a written contract, or was it to start a programme of sweeping redistribution subject to perpetual reinterpretation and revision?

By 2012 there had been 16 constitutional revisions (De Vos, 2012). What we see now, however, is an argument that the constitution was only a "...compromise document foisted on the people of South Africa by evil right-wingers, that the document has become a stumbling block to effective governing of the country and hence has become a hindrance to the economic transformation of the country" (De Vos, 2012). The constitution, a document that creates the political structure of South Africa's democracy, is now seen as a primary obstacle in achieving the great post-apartheid transformation. This is because, as Du Toit (2003:106) there were different views on the meaning of the negotiations. Consequently, "negotiators glossed over them [key issues] at the time in order to keep the negotiations moving forward, which was considered decisively important, and the long-term implications flowing from these unresolved differences have never been adequately weighed".

The ANC (1992) presented the negotiations as a "first option ... a victory for the democratic movement and a defeat for the forces of apartheid". In their Negotiations: A strategic perspective document, the ANC presents liberation as a phased process, with securing political power through negotiations as the first step. Here the ANC was of the view that "delays in the process of peaceful transformation are not in the interest of the masses, who seek liberation now, and do not enhance our possibilities to effect the transformation to genuine democracy as effectively and speedily as we should" (ANC, 1992). To facilitate a speedy resolution to create a postapartheid South African society on the principles of equal rights, non-racialism, nonsexism, democracy and mutual respect (ANC, 1993), the ANC adopted a phased liberation process. 


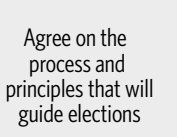
Consolidate peace through control of the armed forces, ensure free and fair elections, mobilise for a decisive victory

Establish interim government where the ANC is a major role player, adopt a new constitution, start process of socio-economic redress
Restructure state machinery and dismantle apartheid
Consolidate democratic transformation and reconstruction

Figure 1 The ANC's Phased Liberation Approach to creating post-apartheid South Africa

This view of phased liberation to recreate post-apartheid society demonstrates Du Toit's argument on good faith. He argues that in a non-Western and high-context cultural context negotiations do not necessarily constitute a binding agreement that must be upheld. Rather, as opposed to negotiations and agreement providing "...a fixed point of reference...", it rather signals "... a temporary benchmark, capturing the status of the relationship at that particular point in time..." (Du Toit, 2003: 106). Therefore, Du Toit, further observes, as new power structures and elite status emerge, negotiated settlements may become obsolete, requires a new deal. This much was evident in the views expressed by the ANC, as the only movement that can facilitate the creation of a truly democratic South Africa:
At all states, we should consider carefully the balance of forces, how to change the balance, and therefore place ourselves in a position in which we can determine the correct path to follow to futher the process of democratic change...The balance of forces, our specific objects and our long-term goard would at each stage dictate the need to: enter into specific, and perhaps changing, alliances; and, make certain compromises in order to protect and advance this process (ANC, 1992).

At its $53^{\text {rd }}$ policy conference held in 2012, the ANC thus presented its $A$ second transition? Building a national democratic society and the balance of forces in 2012 discussion document. Here we see a continuation of the phased liberation project evident in a sentiment that "...the first transition with its focus on democratisation over the last eighteen years..." has been concluded, the focal point is now "...a vision for a second transition that must focus on the social and economic transformation of South Africa..." (ANC, 2012). To this effect, the ANC thus sought to implement radical and transformative policies, which for them, finds expression in the National Development Plan. By 2015, however, the ANC noted a "...slow progress in...key 
transformative programmes" in the sphere of the state due to "...constitutional and resources constraints" (ANC, 2015a). These constraints, the ANC maintains, undermines their ability to deliver a better for all (Ndou, 2014).

Part of South Africa's transition problems, it would seem, is the belief of the ANC that it is South Africa's custodian of democracy. As the liberator, the ANC selfimage is one of a vanguard - a liberation movement that still continues to struggle for the liberation of South Africa. Thus, while the rules for the democratic game (institutionalisation of procedural democracy) was the outcome of the negotiations as well as an elite transfer of power, the ANC saw this as merely a first agreement or step towards achieving socio-economic transformation.

A little more than two decades after the Founding Elections of 1994, we now see a narrative constructing the constitution as an uncomfortable hindrance to achieving socio-economic liberation for South Africa's marginalised poor. It also sets the tone for the narrative that democracy failed, as opposed to the ANC as a ruling party not delivering on its electoral mandate. The basis of this disillusionment could be found in the nature of the social contract the ANC advanced through the National Democratic Revolution. The basis of this social contract was not necessarily rooted in an intrinsic commitment to a new constitutional order, but rather, a contract based on vanguardism where the ANC as a custodian of the state will deliver on the promise of liberation, and, if need be, revisit the terms of the settlement to enable a true liberation.

\section{Contextual problems of South Africa's transition}

The second set of transition problems for Huntington (1996:209-210) is contextual problems that focus on the type and nature of the society, the economy, the culture, and the history of the transitioning state. These problems include high levels of mass poverty, cultural and ethnic divisions, and overextended economies.

At the time of the negotiations, South Africa was a highly unequal and racist society. The apartheid state was built on a discriminatory and racist ideology that completely disempowered black South Africans politically, economically, and socially. The apartheid state acted as a vanguard for white interests that effectively created a society of white privilege and advancement at the cost of empowering black South Africans. The very basis of the liberation struggle was fought on securing political liberties, human dignity, and socio-economic advancement of ALL South Africans. Thus, towards the end of the negotiations, the ANC (1993) presented their vision for 
South Africa in their Ready to Govern document. The post-apartheid political project was to advance:

1. The achievement of the right of all South Africans, as a whole, to political and economic self-determination in a united South Africa;

2. To overcome the legacy of inequality and injustice created by colonialism and apartheid, in a swift, progressive and principled way;

3. To develop a sustainable economy and state infrastructure that will progressively improve the quality of life all South Africans; and,

4. To encourage the flourishing of the feeling that South Africa belongs to all who live in it, to promote a common loyalty to and pride in the country and to create a universal sense of freedom and security within its border (ANC, 1993).

The rationale for dealing with these contextual problems to achieve a democratic order in post-apartheid South Africa was premised on these four goals.

These are not mutually exclusive goals. On the contrary, the future of our country depends on the harmonious and simultaneous realisation of all four. The advancement of the majority of people will, in the mediumand-long-term, release hitherto untapped and suppressed talents and energies that will both boost and diversify the economy. Developing the economy will, in turn provide the basis for overcoming divisions of the past without creating new ones. Finally, the achievement of a genuine sense of national identity depends on all of us working together to overcome inequalities created by apartheid (ANC, 1993).

Economic empowerment and transformation was thus seen as the vehicle through which complete liberation and transformation of post-apartheid South Africa would be achieved. The underlying sense, it seems, was by virtue of generating economic equality through economic development with strong state capacity and political efficacy, South Africans would find a renewed sense of nationhood in the context of reducing racialised inequality and poverty as a new multi-racial class structured was engineered. It is also here where the intimate link between political (procedural) democracy and substantive democratisation (socio-economic transformation) lies:

...[the ANC] response must be aimed both at establishing a new and democratic political dispensation that replaces the racist and undemocratic apartheid constitution and addresses the legacies of apartheid in the broader socio-economic sphere...[thus] the ANC's 
broad policy response...to highlight the strong relationship between the creation of political democracy and social and economic transformation (ANC, 1993).

The National Democratic Revolution became the political expression of the postapartheid social contract. This revolution would work to advance a political project of creating a

...united, non-racial, non-sexist and democratic society. This in essence means the liberation of Africans in particular and black people in general from political and economic bondage. It means uplifting the quality of life of all South Africans, especially the poor, the majority of whom are African and female (ANC, 2000).

What is important, however, is that that an ANC-controlled state will advance this project. The ANC regards itself as the leader of transformation (ANC, 2000) that "... needs to exercise leadership in all pillars of transformation: building a democratic developmental state, transforming the economy, ideological work, international work as well as mass organisations and mobilisation" (ANC, 2015b). Substantive democratisation in this view is dependent on the ANC remaining in power. It creates a correlation between post-apartheid transformation and ANC governance, which in turn, may fuel the instrumentalist construction of South Africans view of democracy. In other words, because the ANC has not effectively delivered on the promise of National Democratic Revolution and societal expectations of a better life for all, South Africa's negotiated settlement needs revisiting to secure a better economic deal. Economic freedom remains elusive for those most oppressed during the brutal years of apartheid.

The debate on securing economic freedom emerged strongly in the South African post-apartheid political landscape in 2011 with the release of the African National Congress Youth League's (ANCYL) Declaration of the $24^{\text {th }}$ National Congress in 2011 signed under the banner of Economic Freedom Fighters (ANCYL, 2011). Using historical frames of racial oppression and economic exclusion of the black majority in general, but Africans in particular, ${ }^{1}$ through the continuation of colonialism of a

1 In terms of racial classification in South Africa the term black is used to refer to all non-whites. This includes the Indian/Asian and Coloured populations. The term African is used to refer to the indigenous black population. 
special type, ${ }^{2}$ this declaration issued a commitment to a new struggle "...in the war for economic freedom in our lifetime" (ANCYL. 2011). This struggle for economic freedom is premised on the Freedom Charter's clarion call to "...transfer the economy from the minority to the people as a whole" (ANCYL, 2011). There was a moral obligation, the ANCYL argued, for the African National Congress, South Africa's oldest liberation movement and current ruling party, to pursue a political and economic agenda to realise the Charterist vision of South Africa as a country that belonged to all and the people shared in its wealth (ANC, 1955). By 2014 the ANC Youth League was divided. Following a political clash with its mother body, the ANC, members of the ANCYL left to form the Economic Freedom Fighters of which Julius Malema is the public face.

The ANC Youth Leagues' Clarion call for Economic Freedom Fighters ${ }^{3}$ point to the failure of the ANC to deliver on the liberation promise of economic spoils envisaged in the Freedom Charter. Here the interpretation of South Africa's failed democratic experiment focused on the high levels of socio-economic inequality that continues to characterise South African society. This clarion call sought to mobilise society behind the seven pillars to achieve economic freedom in our lifetime. This included mass nationalisation of strategic sectors through a direct transfer of wealth, direct state intervention through a developmental state, expropriation without compensation to facilitate transformation and an amendment to the property clause to allow the state to expropriate property in the name of the public interest, inclusive and decentralised economic development based on the redistributive strategy of the Reconstruction and Development Programme, land restitution and agrarian reform, extension of South Africa's enterprises on the African continent, and the provision of education, skills and expertise to the people (ANCYL, 2011). Thus, the social contract requires an interventionist state that acts as a custodian and gatekeeper

2 The South African Communist Party advanced that South Africa suffers a colonial peculiarity known as colonialism of a special type. Here they highlight that 'within South Africa, bourgeois domination and capitalist relations of production, which emerged within the context of colonialism, have been developed and maintained since 1910 through a specific variant of bourgeois rule - colonialism of a special type. It is a variant of capitalist rule in which the essential features of colonial domination in the imperialist epoch are maintained and even intensified. But there is one specific peculiarity: in South Africa the colonial ruling class with its white support base on the one hand, and the oppressed colonial majority on the other, are located within a single country'. See SACP, The path to power, (1989), <http://www.sacp.org.za/main.php?ID=2638\#3.1> (26 November 2015).

3 Members of the ANC Youth League under the leadership of Julius Malema were expelled from the ANC in 2013 following an internal factional battle. They subsequently formed the Economic Freedom Fighters, a political party campaigning on the slogans of Economic Freedom in our Lifetime and drive a narrative of nationalization to establish a socialist state that will facilitate the full emancipation of the oppressed black majority. 
to economic resources and works to empower the poor. Implicit in this narrative is abandoning the procedural democratic structure negotiated in the early 1990s to allow an interventionist state in regulating societal and economic life.

Conventional wisdom in democratisation studies maintains that democratic regime performance is an essential element in constructing legitimation and democratic consensus (Ethier, 1990; Diamond, 1996; Diamond, 1999; Schneider and Schmitter, 2004; Chu, Bratton, Lagos, Shastri and Tessler, 2008). Underpinning the democratic consensus is a constitutional state where all the significant political actors are committed and adhere to the rules of the democratic game, and, no significant financial, human and social resources are spend on attempting to create authoritarian regimes (Schedler 2001:76-77). Diamond (1996:33-34) highlights that this consensus can only be built on the basis of effective state capacity to deliver on the hopes and aspirations of citizens. For him, the new democratic state must facilitate liberalising the economic structure secure social and political order, and maintain the democratic rights and liberty of citizens, while complying with the rule of law. This implies through delivering on a better life and improving the material conditions of citizens, the state will facilitate intrinsic democratic support as people evaluate the democratic regime in a positive light. Ethier (1990:15-16) presents a similar argument. Societies that suffer greatly economically and socially for extended periods of time are more susceptible to domestic instability and the overthrow of democratically elected regimes.

Vergopoulus (1990:139-140) pits political consolidation against social fragility. In poor social contexts were we find absolute poverty and high levels of inequality, citizens (especially the economically marginalised) create many expectations of a better life. Here a beliefs that under democratic rule material conditions will improve which will lead to a better life and social upliftment may dominate public perceptions. This great expectation, however, will eventually lead to great disappointment, as many new democracies cannot undo history that gave rise to particular social and economic problems. This, as Pereirra (1990:199) represents a major threat to securing a democratic consensus and consolidation. It also, however, speaks to elites managing perceptions and what is realistically possible during the transition phase.

For Fukuyama (2013:6), "the inability to 'make democracy deliver' in terms of shared growth and broadly available public goods has in turn weakened the legitimacy of democratic governments". There is a correlation relationship between political efficacy, economic development and growth, and political leadership. Strong political leadership to advance a post-conflict social contract is essential to facilitate 
substantive democratisation. And, for Fukuyama (2013:6) government performance and the quality of state bureaucracies are central to substantive democratisation and consolidation.

Fukuyama (2013:5-6) further notes that while many new democracies succeed in holding relatively free and fair elections, political efficacy remains a key obstacle to democratic consolidation due to continued patterns of patron-clientism, corruption and ineffective service delivery. These are exacerbated in one-party dominant systems as due to its electoral majority, dominant parties may govern without the opposition. Consider the passing of controversial legislation like the Protection of State Information Bill in in 2013 (News24.com, 2013) or the ANC's action in undermining constitutional structures, most notable in the battle of Nkandla and the Public Protector (Munusamy, 2016).

The problem of incommensurables becomes evident as South Africa progresses in its third post-apartheid decade. The ANC had won political rule through elections, but an improvement in the socio-economic conditions of the poor remains elusive. This is often attributed to the implementation of neo-liberal economic policies that exacerbated inequality as opposed to create conditions for transformation envisaged in the post-apartheid social contract. For example, the ANCYL argues that

...post-1994 democratic [South Africa] State has not achieved anything substantial due to the fact that the economic policy direction taken in the dawn years was not about fundamental transformation, but empowerment/enrichment meant to empower what could inherently be few black aspirant capitalists, without real transfer of wealth to the people as a whole (ANCYL, 2011).

The slow and unequal pace of transformation works to establish a grand disillusionment with ANC rule. Given that the ANC constructs itself as the custodian of democratic rule, it may play to the view that democracy has not delivered. In an attempt to maintain power, we find the ANC falling into a trap that had brought other dominant party liberation governments out of power, which relates to systemic problems of transitions Huntington (1996) identified.

\section{The systemic problems of transitions}

The third set of problems Huntington deals with is systemic problems (Huntington, 1996:209-210). These problems related to the democratic process, procedures, and institutions. Essentially Huntington argues that the nature of the authoritarian 
regime impacts on performance legitimacy of the new democratic order, as they may be elite driven. These systemic problems include stalemate, the inability to reach decisions, and domination of political responsibility to vested interest of political and economic elites.

In a post-apartheid context, systemic problems may be related to a continuation of one-party dominant tradition in South Africa's political system. Following dominant Nationalist party rule between 1948 and 1993, the ANC emerged a clear victor in the founding elections with more than $60 \%$ of the vote. The ANC has maintained an electorally dominant position, never achieving less than $60 \%$ of the vote at a national election since then. A different story emerges at the level of local government, where election results indicate that support for the ruling party is slowly slipping. Municipalities are characterised by defects in governance and a lack of accountability, underperformance in budgetary spending, maladministration, patronage and anorexic service delivery. In 2014 only $9 \%$ of South Africa's municipalities received a clean audit (Evans, 2014). A lack of accountability, wasteful expenditure and dubious procurement processes within local government that enrich government officials or those closely connected to political elites (Grant, 2014) are key factors that undermine political efficacy and clean governance. With the exception of eThekweni and Mangaung, electoral support for the ANC during local government elections has declined between 2000 and 2014.

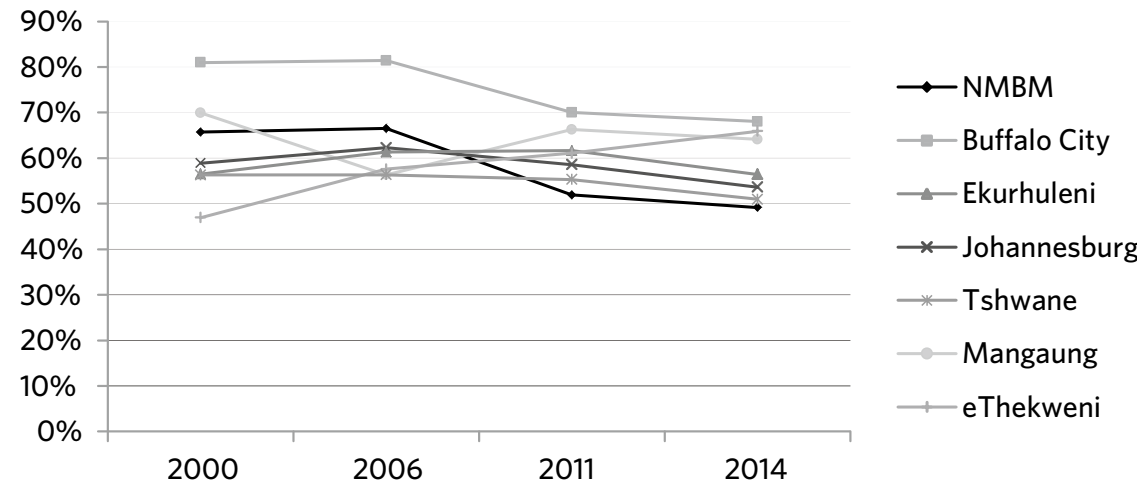

Figure 2 ANC's electoral Local Government Election Performance ${ }^{4}$ Data obtained from www.elections.org.za

Increasingly one sees the political party plagued by party-dominant "dilemmas". These include narrowing the scope of political competition, blurring the lines

4 I include the data for the 2014 General Election as a demonstration of the last election before the 2016 Local Government Elections scheduled for 3 August 2016. Cape Town is a DA governed municipality and was excluded from this analysis. 
between state and party, (perhaps unintentionally) encouraging corruption through a system of patronage, and policy stagnation as a consequence of a lack of policy innovation (Dunleavy, 2010). Narratives of state capture, the infamous Nkandla scandal, and cadre deployment policy that blurs the line between party and state are characteristic of South Africa's slow political decay early in its third decade of democracy. We have also seen a narrative of regime change and destabilisation of democracy where Western powers are seeking to remove the ANC from power emerged (Africa News Agency, 2016), which illustrates a very weak commitment to electoral processes that may eventually remove the ANC from power. The narrative of destabilisation of a democratic government by opposition forces is also evident in the emergent ANC policy narrative. For example,

The Fifth Parliament has been characterised by unity of the opposition with the intention of destabilising Parliament. This has been demonstrated through the attempted motions of no confidence targeting ANC leadership in parliament; the unruly and disobedient behaviour, walk outs; and flagrant disregard of electoral doctrines that underpin the role and character of the democratic Parliament (ANC, 2015a).

As dominant liberator parties generally emerge following major period of "...nationbuilding, revolution, independence, or reconstruction after war" (Greene, 2007:10), the ANC now reimagines the South African state with an "...activist parliament..." emphasising the developmental role of the state that requires "...vigilant and assertive..." action to "...guard against the erosion of dignity and the high levels of confidence..." society has in Parliament (ANC, 2015a). Thus, we find that the ANC may be seeking to recreate the liberation euphoria through this reimagining of the state as an additional site of struggle to advance the National Democratic Revolution. This social contract built on the National Democratic Revolution, after all, requires a strong state able to drive economic growth and uplift people out of poverty. Thus, the state and its associated institutions are seen as the epicenter for ensuring liberation. This view also dominates the EFF's construction of ensuring liberation for South Africa's economically disenfranchised.

Early democratisation periods are generally characterised by narratives and political agendas of reconciliation and post-conflict reconstruction. This works to create a sense of legitimacy built on ideas of societal transformation and a better life for all (Greene, 2007: 10). It may cement perceptions that a dominant party is the custodian of some future political project to recreate a democratic, just, and equal society. 
The danger, of course, is that by virtue of linking legitimacy to a party instead of a system, once the party cannot deliver on its promises, it may lead to disillusionment with democracy as a system. In addition to this, a dominant party, as the selfconstructed custodian of democracy, may seek to undermine the political and constitutional order in an attempt to maintain power.

We should pay attention to the emerging rhetoric of the ANC as they analyse the balance of forces and the institutional constraints on delivering on the dream of 1994 in preparation for their elective conference of 2017. Here the ANC constructs the nature of constitutional democracy as an obstacle to achieving the much promised democratic dividend for the masses. For the ANC, inherent weaknesses in the state works to maintain apartheid political economy, undermining the broader political mandate of societal transformation (ANC, 2015b). Here the "processes of societal transformation saw the rise of many Blacks into middle and upper strata...this had not translated into systemic changes in ownership and control of wealth, including land; with the locus of economic power largely unchanged" (ANC, 2015b).

Mbeki (2016) contests this notion, arguing, instead that the South African economy is not necessarily controlled by white South Africans, but rather by political and economic elites aligned to the ANC. This myth, Mbeki (2016) argues, is politically convenient for an ANC facing potential losses due to voter dissatisfaction with the party performance.

For Mbeki, it is a problem of accountability due to inherent weaknesses in the electoral system. Du Toit (2003) also advanced this argument. The nature of the electoral system is too elitists as elites in party leadership decide on representatives to be deployed to the various institutions. Rather, a reconfiguring of the electoral system to allow direct election should be pursued whereby leaders are directly accountable to the people. This is an old debate in our scholarship. As early as 2002 concerns that the closed list proportional representation system undermines democratic accountability emerged (Kakemba, 2002). Similar arguments emerged in 2012 after two ANC Members of Parliament were disciplined for their decision to abstain from voting in Parliament on the controversial Protection of State Information Bill (Sibalukhulu, 2012). This habitual debate, Solik (2014:40) argues, arises because South Africans want greater democratic accountability. Thus

In the wake of party political scandals and a lack of political alternatives, electoral reform has been cited as a much needed intervention; the PR system for national and provincial elections does not enable us to hold 
individuals to account. We are fed up with many politicians, especially in the ruling party, who simply toe the party line. Politicians at the end of the day are accountable to party bosses and we have no way to influence party lists. This impotence is often encapsulated most vividly through the protests by those least able to participate in public life and most burdened by the state of inequality (Solik, 2014:40).

The tension between accountability and governance is also exacerbated in a oneparty dominant context. Due to overwhelming electoral majorities, controversial motions, positions, and bills may pass with relative ease in Parliament, with the most recent example the failure of the motion to impeach President Jacob Zuma in April 2016 after the Constitutional Court found that he had violated his presidential oath through using public funds to renovate his personal residence. ${ }^{5} \mathrm{~A}$ lack of accountability also facilitates corruption, and in South Africa, a sense that corruption has gotten worse under the Zuma administration exits (Corruption Watch, 2014). This even though South Africa has thirteen public agencies mandated to deal with corruption (Corruption Watch, 2014). Increasingly one finds a sense that democratic accountability weakened under the Zuma administration, ${ }^{6}$ and a sense that "...ANC forgot about the people..." (Buntse, 2016). Of course, the correlations between perceived and actual corruption are complex (Africa Check, 2015), but democratic legitimacy is built on perceptions held by citizens. If citizens believe that their governments are corrupt and not acting in their interest, it may lay the foundation of a delegitimation of the government and societal unrest through civil disobedience and violent protest.

\section{A failed promise of a better life for all?}

Has the ANC delivered on the promise of 1994? The answer, it seems, depends on whom you talk to. For some a better life for all is seen as an expression of the ANC creating a better life for South Africa's poor and that life is generally better now under ANC rule than twenty years ago. This is evident in the number of people who now have access to basic services and the growth in a multi-racial middle class (Biko, 2013: 1). For others there is general acknowledgement that life is better under democracy, but that the socio-economic plight of the poor has still not been addressed. For producers

5 See http://www.bbc.com/news/world-africa-35966916.

6 See for example Buntse (2016), Matlala (2015), Maimane (2015), and http://www.news24.com/ SouthAfrica/Politics/DA-Zuma-govt-lacks-accountability-20110126. 
of this discourse, life under ANC rule has only benefited a few while leaving a large majority of the oppressed black majority behind (Biko, 2013:1).

The data presented here is drawn from 25 interviews ${ }^{7}$ conducted in Motherwell, Port Elizabeth. A poor township area established in 1982 in Port Elizabeth, Motherwell is home to approximately 450000 people (Affordable Land and Housing Data Centre, no date). Key challenges in the area are low skills level, high levels of HIV/AIDS, high crime, and high rates of unemployment. While there is evidence of progress in the area with RDP housing, unemployment remains a key issue for the community. The area is often plagued by violent and destructive protest action and evictions of foreigners. In essence, the area represents both the progress made in terms of housing delivery under the ANC government, but also stagnation due to high levels of crime, poverty, and unemployment.

South Africa's transition period was built on the dream of 1994: a democratic country where all will be equal and life will be better for all, not just those who benefitted from the apartheid regime. The dream of ' 94 was also seen as a first step towards restoring human dignity. Here participants noted that:

I was very happy. I felt extremely happy because this was the first time that black people gained freedom...And it made me feel free as a person as well. Even just strolling around I felt free; I didn't have to be so conscious around white people. There was no longer any fear...I felt good, really good.

What I was thinking. I was thinking that now we are free. That you can talk with everybody, you can walk with everybody. You know, that you can be friends with everyone that you want to be friends with. I thought that now that the party [ANC] would take over, they'd know what we had gone through then.

The dream of '94 was also built on the idea of a better life, a life where all races would be equal, and more importantly, have equal access to opportunities, most notably education.

Talking of expectations, because I grew up in that old era, in that old regime [apartheid]. So my intention was, should Nelson Mandela be free, we would be living in a free country...our expectations were that

7 The interviews were conducted in isiXhosa and English and translated by a Xhosa-speaking research assistant. 
we would gain free education and that there'd be lots of jobs, that everyone would be employed, things like that. And that everyone would have his or her own house, things like that... and those were the things that we expected; which I expected.

Yes, yes...I thought wow! I too would now live comfortably like white people did...you know that we would all now live in a big house, live comfortably and be happy, you know the same as white people did. That's really what I was now thinking, for real. And that everything was now going to be fine. But that is not how things turned out.

These views resonate with the expectations created during South Africa's transition. A equal South Africa where the state will treat all impartially, with equal opportunity and equal access to political and material goods. Indeed, one participant reflected:

I think this is a very tricky situation, it depends where you come from... not in terms of place but in terms of your birth...you know, age... In my case I say that during, what we call the revolutionary tribal days... how we defined freedom is not different to how freedom is supposed to...or is actually defined. And I understand that at that time we didn't want gold, we just wanted to get the regime out of the way and it was not only expectations which we are talking about, but it is what was promoted amongst the minds of the people. Because if you remember all our struggle songs we were just saying one thing; that there shall be houses, security and jobs for all, you know. So if you risked your life... we risked our lives, people went to jail, people got shot and got killed and they knew that this is what we are fighting for. Because this was what we were singing every day, this is what the media was telling us when we gathered in the stadiums, that this was the plan. So finally when 1990 came, when Madiba was unbanned, and Madiba was out from jail, we thought that yes, we are now heading the right direction... we didn't really look at the dynamics as to how are you actually going to get the land, it was just like an emotional thing that once you are free you are getting that.. I'm just going to go to Summerstrand ${ }^{8}$ and I'm going to pick that house. It was not put that way, but mentally ...If someone stands in a crowd and makes a big noise and says 'every street must have a car and we go yeah' and you know you wonder how are you

8 Affluent area in Port Elizabeth 
going to get that car, because you know we just wanted people to vote for the party, at that stage but come 1994 reality struck.

There are different interpretations of the meaning of freedom that 1994 was meant to bring. It depends on age, and for young participants, the notion of freedom is an illusion, something that remains elusive in South Africa's democracy. As one young participants noted:

I think, in my own opinion for those who lived before 1994, their aim of freedom was to free Mandela, then after it was to have their own black government. But for me, who was born in 1987, the word freedom for me is still an idea, which South Africa has not yet implemented. It is just an idea. The reason why I say that is because for me the word freedom is too big of a word for South Africa. Because yet you find that we have private schools, private hospitals, then in such instances, where is freedom there? They always say that freedom...they always say that education is the key to success. Therefore without education, there is no freedom. If education was free, then I would say that yes we do have freedom. The only place where you get free education is in prison. When you get in prison, you'll get education for free. After you've received that education you won't get anywhere because you'll have a criminal record, meaning that that education is useless, so where's freedom in that?

There is a sense that younger participants see freedom as having some form of tangible impact on their quality of life and future prospects. Class distinction also comes into effect as those with higher incomes are able to access private hospitals and schools, which often offer better services than government facilities. One senses that if government facilities were comparable to private facilitates, it would generate a sense of equality that could facilitate a view that South Africa is indeed a freesociety.

...for example those guys that are the MPs that are working for government, most of their kids are not attending those local government schools, they are sending their children to private schools, and they are more educated than those children in the township schools. So that clearly shows that we will never be the same up until we build the right foundation...

This is not surprising given that unemployment is high and the chance of finding a good job to lift oneself out of poverty is limited. The interviews revealed a sense that 
if you want to succeed in post-apartheid South Africa, then one needs resources to access private schools and health care. This, of course, places the poor in township communities at a continued disadvantage, as they do not have the financial means to afford fees at private schools, for example. If they do, it also comes at as a huge sacrifice for the family. It also reproduces apartheid patterns of exclusion due to the racialised nature of poverty and inequality, which in turn structures a narrative on starting afresh with a right foundation to recreate post-apartheid society.

The theme of building a right foundation emerged a number of times during the course of the interviews. Due to the continued sense of oppression, a view that one must destroy the "old" in order to rebuild the "new" South Africa emerged. However, there is debate on how to rebuild the "new" South Africa. For example, one participant stated that

Let me first start here, I'm not speaking against what you were saying but that can be dangerous, if we were to actually implement it and start fresh as you say. If we were to start afresh that might lead us heading to the Zimbabwean situation.

Those who lived during the transition and the elections remember the uncertainty that had characterised those times. For example, one participant stressed that the ANC should be recognised for managing the transition and taking power in a manner that did not lead to South Africa's political demise and civil war.

Personally I would give ANC a round of applause in terms of planning. Not that they have done well, but because they came in power with no experience, they took a country which is so much diverse. South Africa is a country filled with so much diversity that has a rich, painful history and they came into power. For me the fact that for the past 24 years we did not collapse as a country, that we can give them credit for. Because our government is still there. We have never woken up to a situation where one morning we are afraid that there might be bombs set off...

Thus, while there is recognition for the ANC's role in facilitating establishing a democratic South Africa, there is also a distinction between the ANC as a liberation movement and as a governing party. As a governing party, participants felt that the party lacked political efficiency in addressing their immediate concerns, which are quality education, health care, housing, and basic service provision. For example, one participant highlighted: 
But I think that the government in terms of the efficiency in running, its one thing of being able to do something [free South Africa] and it's another thing when one speaks of efficiency. If we look at the past and present, our main concern has to be now.

This links to a view of "starting afresh" and "building the right foundation", as the expectations of 1994 have not necessarily been delivered by the ANC as a governing party. The slow pace of socio-economic impact that translates drives this sentiment into a measureable impact on the quality of life of the participants, especially among younger participants. Here one participant highlighted that

I think the point is that people fear change, that's why they always stick with this ruling party [ANC] because of the fear of what happened before, I think if you may go through all the party's mandates, they make promises come election time, that were going to do a b c and d, so if you follow your $x$ or if you understand what that party promises you, then you put your $x$ there and you make sure that these are my expectations and this is what I'm hoping to get in return from my $x$. Because if you go through all the different parties mandates, you always get promise of free education, you always get talk of lots of jobs, houses, service delivery and all of that, but at the end of the day you don't get any of those in return.

One also notices a sense of disempowerment among young participants. This seems to be premised on the view that their voice is limited due to the lack of opportunities they have to recreate a better life for their families. After two decades of democracy, there may be a sense that oppression continues as the vote does not necessarily translate into a tangible opportunity to pursue their life choices. For example, one participant highlighted that she dreams of becoming a doctor, but due to the high cost and lack of medical schools in Port Elizabeth, she will have to give up on that dream (Motherwell Interviewee 5). Here she blames government, who should have provided free education as was promised in 1994. While their parents' value political freedom having lived with the dehumanising legislation of the apartheid regime, for younger participants the notion of freedom and the dream of 1994 is more instrumentalist. The optimism of 1994, it seems, had disappeared as the first post-apartheid generation came of age politically. The hand of apartheid reached in and touched the future, as one participant noted. Here the feeling is that 
I think we may have those that we call the Born Frees, but they too are affected by the....apartheid regime because I'm a father who is not that well educated. If I had been well educated I would be in a position now to provide for myself and my family. But now my children are suffering because of that...because of the suffering that I endured, and it's now a chain of suffering. So the past still affects the present generation to such an extent that even in terms of education, people are still yearning for quality education.

The lived reality of the youth is one of continued expression where freedom is still something that must be attained in the future.

I think when you compare my mother and I...my mother is more satisfied with the freedom we have now, whereas I don't see it as a freedom. She was forced to carry a dompass, there were whites only places, no black places. She didn't have a house at that time, whereas now she's living in a RDP house. She's willing to vote which is said that your vote is your voice, maybe she has a voice whereas I don't have it and that is why I'm saying that she's more satisfied than I am. I can say that now yes we can vote, and that our vote is our voice, and you vote for your own political party, and that political party will backstab you. That same political party will oppress you, and it's that same political party that we'll put our hopes on. So I don't see freedom yet, maybe freedom is still coming.

This sense of continued oppression was salient on issues surrounding education and service delivery. For example, one mother stated that

My little boy is 9 years old and they will keep on going with these strikes and burning schools and there's poor quality of education that our children get. At the end of the day our children complete grade 12 but they don't have the right qualifications. They just pass the students to the next grade, if there were inspectors like in the olden days then I think that the teachers would work harder and the person whose above the teacher would hire more teachers as the inspectors would see that the classrooms are overcrowded and that the teachers can't manage so many children...

There is a sense of disillusionment with electoral democracy, but not on the basis of the act of voting, but rather the expectations political parties create when 
campaigning for vote. This disillusionment is premised on the view that after 22 years of democracy, all the ruling ANC offers are empty promises.

...the ruling party $[A N C]$ has been promising South Africans the same thing for twenty years now. The first democratic leader of South Africa said free education for all and that has not yet happened. We as South Africans experienced load shedding for almost three years now, and the ruling party said that they would take care of that. All the other parties are promising to do what the ruling party is not doing, they are not bringing anything new of their own, and they are just saying that they will do that which the ruling party fails to do. So for me, voting is useless because of that reason.

I'm not voting. Because they don't give us what they promised, they don't deliver. We vote for them and they don't deliver look at the schools now!

How many times have we voted in order to make sure that our voices are heard? But still there's no change...even when they build us houses, they don't care who builds those houses or whether those houses fall on top of our children and on top of us because they don't even employ qualified builders for those houses. So that's why I say that they try but they don't try hard enough, or the people running the ward, they're not working together. So that's why I won't vote. Because I have voted several times before but my voice haven't been heard.

Other participants, however, noted the importance of voting, especially with regard to building opposition to an electorally dominant ANC. Here participants highlighted that

Going back to basics if you think of voting and you have the mindset that this government is going to give me this and that. I understand that for those that are saying that they will not vote, they are angry at the government that is ruling now... This government that is now is failing but your voice will only be heard if you vote against that government.... You know there is this saying that says that it is better to live as a lion for a day, then as a sheep for the rest of your life, which means that you have to wake up and do something. If this government is not treating your well then you must vote against this government, which is what Mr. Nelson Mandela once said. He said that if the ANC government 
does to you what the apartheid government did to you, then you must do to the ANC government what you did to the apartheid government! This is the correct stance to take. And I'm going to vote.

For me it's good to vote. Because what l've noticed as the ruling power loses its area or ward, then they start making improvements and that makes them realize that they must pull up their socks. That means that you must do what you must do as an individual. It's not good to vote for the same thing that happens to all the time. You must create some sort of balance, give others a chance so that the other can pull up their socks and do the right thing.

There is a political awareness of the importance of creating opposition for the dominant ANC, especially in order to ensure the democratic dividend of what was promised during the electoral campaign. This view, however, was more pronounced among younger interviewees as opposed to older participants. Older participants highlighted a fear of the opposition, noting that "...if a party had any inkling of apartheid..." they will not take a chance and vote for it. This also facilitates building legitimacy on the premise of fear of the opposition (Steyn Kotze and Prevost, 2015: 158). To this effect, phased liberation, a continued political agenda of transformation, race, and fear of the opposition interplay to create a historical obligation to continue voting for the ANC (Steyn Kotze and Prevost, 2015: 158).

The construction of political legitimacy of continued ANC rule is also based on the provision of social welfare goods, including food and stationary at schools, even if the services delivered are of weak quality. Seemingly the view is that some services are better than having no services at all. For example, some participants highlighted:

Yes I am going to vote...let's look at this in two ways because although we may grumble and say that they are not doing anything, we would find that if you were to visit the black schools you'd see that it's not that the government is not doing anything, in those schools you'll find that the stationery is free, that they get meals because the government understands that at times that those students did not get any meal at home even from the previous night, so at least at school they would get served breakfast and lunch. So we should consider those things, because even if I say that I will not vote, I should consider the difference that I would have made in the country. What I know is even if one votes or does not vote, in this country there is nothing that will be done that 
will reach us perfection. There will always be complaints and that is something we can't run away from. It's a fact. So I will vote, because the government does try even amongst all the complaints.

Whether the ANC has indeed created a better life for all remains a contested narrative, especially in the construction of political legitimacy of democracy and ideas of freedom. What is evident, however, is that there are generational differences in the perceptions of whether the Dream of ' 94 has indeed been achieved. Younger participants view the idea of democracy and freedom as empty given that a sense that democracy has not necessarily delivered on the promise of equal opportunities. There is also a sense among young participants that this failure needs to be corrected with a fresh start to recreate the economic structure of post-apartheid South Africa. This, of course, opens the space for more radical political parties advocating nationalisation as the path to economic prosperity of the poor to generate support. It could also drive perceptions that an authoritarian government will be acceptable if there is quality service delivery. Thus, as Du Toit (2003:112) highlight, this speaks to a sense that the rules must reflect changing power relationships, and not shape them.

Older participants, perhaps due to the lived experience of oppression during apartheid, however, guard against this view. While they concur that on a socioeconomic level the Dream of '94 remains elusive, they do value their political rights and freedom. For them, these rights are an expression of human dignity and equality denied to them by the apartheid regime. It would seem that older participants have more of an intrinsic support for democracy than younger participants.

Du Toit (2003:111-113) provides an insightful analysis on giving voice to deprivation. In deconstructing the notion of liberation, Du Toit identifies two relationships: (1) the link between liberation and poverty, and (2) the link between poverty and dignity. These themes, Du Toit argues, not only serves to explain a continued sense of deprivation, but also forms part of high-context cultural frameworks where "... human relationships (of domination, subordination, and emancipation) are at the core of issues, a historical sense of injustice is pervasive, and matters of status are central" (Du Toit, 2003:112). The themes of liberation and poverty play out in the views of younger participants, especially with their view that freedom remains an empty ideal in post-apartheid South Africa. Oppression is felt in the sense that life has not necessarily gotten better, and, as Du Toit (2003:112) highlights, as pressure for the ANC to make good on their promises increases, we may see an increase in rhetoric demanding a "...rewrite of constitutional rules as a way of escaping from the pressure of unkept promises". 
We find expressions of this in the perceptions that people hold on whether the ANC had indeed delivered a better life for all. The problem, of course, is that one entity or political party cannot solve the problems of incommensurables (Du Toit, 2003: 113). Rather it speaks to reimagining a new social contract the democratic dividend is not dependent on a political party (whether it is the ANC or EFF), but rather the ability of people to hold their leaders accountable for failing to deliver on their electoral promises.

\section{Conclusion}

We find two contending schematas for unpacking the problem of incommensurables flowing from South Africa's elusive dream of 1994: one of liberation and one of continued oppression. The construction of post-apartheid South Africa as either free or oppressive, seemingly, also depends on age as well as the instrumentalist view that quality of life has indeed improved. Here political freedom is valued on the basis that there are equal rights for all and that each person can vote, but it seems that this is more prevalent among those who had lived through the uncertain times of South Africa's transition and experienced the brutality and dehumanising oppression of the apartheid state.

One cannot ignore the view that apartheid oppression continues in the form of inequality, lack of socio-economic benefit, and job scarcity. There is a sense of disillusionment built on the failed promise of free education. There is broad consensus among the participants that the way out of poverty is education. But, this is a luxury that they cannot afford. It is here that the ANC has failed to transform life for those who had suffered most under the brutal apartheid regime.

The lack of delivery creates a foundation from which to construct the transition through the lens of a remorseful buyer who should start afresh in advancing the political project of freedom. This, of course, opens the political space for more radical parties to capitalise on this disillusionment with a superficial freedom that means little in transforming the lived experience of oppression.

\section{Bibliography}

Affordable Land and Housing Data Centre. n.d. Motherwell NU8. Available online at http://www.alhdc.org.za/static_content/?p=1959. Accessed on 19 May 2016.

Africa Check 2015. Is SA the most corrupt country in Africa, with Ghana and Nigeria on its heels? Available online at https://africacheck.org/reports/is-sa-the-most-corruptcountry-in-africa-with-ghana-nigeria-on-its-heels/. Accessed on 19 May 2016. 
Africa News Agency. (2016). ANC showing signs of paranoia by claiming regime changechange plot - EFF. Available online at https://www.enca.com/south-africa/ opposition-parties-slam-anc's-claims-of-west-influenced-regime-change-plots. Accessed on 14 May 2016.

Afrobarometer. (2016). Support for democracy in South Africa declines amid rising discontent with implementation. Available online at http://afrobarometer.org/ publications/ad71-south-africa-perceptions-of-democracy. Accessed on 11 May 2016.

Allix, M. (2012). South Africa at a crossroads, need an Economic CODESA. Available online at http://www.bdlive.co.za/economy/2012/12/06/south-africa-at-crossroadsneeds-an-economic-codesa. Accessed on 11 May 2016.

ANC. (1955). The Freedom Charter. Available online at http://www.anc.org.za/show. php?id=72. Accessed on 21 June 2015.

ANC, (1992). Negotiations: A strategic perspective. Available online at http://www.anc. org.za/show.php?id=4208. Accessed on 13 May 2016.

ANC (1993). Ready to govern. Available online at http://www.anc.org.za/show. php?id=227. Accessed on 13 May 2016.

ANC. (2000). Tasks of the NDR and the mobilization of forces. Available online at http://www.anc.org.za/show.php?id=2356. Accessed on 13 May 2016.

ANC (2012). A Second Transition? Building a national democratic society and a balance of forces. Available online at http://www.anc.org.za/docs/discus/2012/transition.pdf. Accessed on 13 May 2016.

ANC (2015a). 2015 NGC Discussion document on Governance and Legislature. Available online at http://www.anc.org.za/docs/discus/2015/governancep.pdf. Accessed on 13 May 2016.

ANC (2015b). Reflections on the balances of forces: Is the National Democratic Revolution in danger? Available online at http://www.anc.org.za/docs/discus/2015/balancer.pdf. Accessed on 13 May 2016.

ANCYL. (2011). Declaration of the 24th National Congress. Available online at http://www.ancyl.org.za/show.php?id=8037. Accessed on 21 June 2015.

BBC. (2016). South Africa's Jacob Zuma survives Nkandla impeachment vote. Available online at http://www.bbc.com/news/world-africa-35966916. Accessed on 19 May 2016.

Bond, P. (2016). Why South Africa should undo Mandela's economic deals. Available online at https://theconversation.com/why-south-africa-should-undo-mandelaseconomic-deals-52767. Accessed on 12 May 2016.

Buntse, M. (2015). I cannot defend Zuma's actions anymore. Available online at http://thoughtleader.co.za/readerblog/2016/02/24/i-cannot-defend-zumasdecisions-anymore/. Accessed on 19 May 2016.

Chu, Y., M. Bratton, M. Lagos, S. Shastri, and M. Tessler. 2008. "Public opinion and democratic legitimacy" in Journal of Democracy Vol. 19 (2): 74-87.

Corruption Watch, (2014). Why is corruption getting worse in South Africa? Available online at http://www.corruptionwatch.org.za/why-is-corruption-getting-worse-insouth-africa/. Accessed on 19 May 2016. 
De Vos, P. (2012). On changing the constitution. Available online at http://constitutionallyspeaking.co.za/on-changing-the-constitution/. Accessed on 12 May 2016.

Diamond, L. 1996. Is the third wave over?. In Journal of Democracy 7(3): 20-37.

Diamond, L. 1999. Developing democracy: Towards consolidation. Baltimore: John Hopkins University Press.

Dunleavy, P. (2010). Rethinking dominant party systems in Bogaards, M. and F. Boucek (eds). Dominant political parties and democracy: Concepts, measures, cases and comparisons. Routledge: London, pp. 23-44.

Du Toit, P. (2003). 'Why post-settlement settlements?' in Journal of Democracy Vol. 14 (3): 104-118.

Essa, A. (2013). South Africa's miracle transition has not put an end to white privilege. Available online at http://www.theguardian.com/commentisfree/2013/oct/21/ south-africa-white-privilege-afrikaner. Accessed on 12 May 2016.

Ethier, D. 1990. Democratic transition and consolidation in Southern Europe, Latin America and South East Asia. Basingstoke: Macmillan.

Evans, S. (2014). Clean audits for just $9 \%$ of South Africa's municipalities. Available online at http://mg.co.za/article/2014-07-30-clean-audits-for-just-9-of-sasmunicipalities. Accessed on 14 May 2016.

Fukuyama, F. 2013. "Democracy and quality of the state" in Journal of Democracy Vol. 24 (4), pp. 5-16.

Grant, L. (2014). Tender traps: How state employees are cashing in. Available online at http://mg.co.za/data/2014-08-05-local-government-tender-traps. Accessed on 14 May 2016.

Greene, K.F. (2007). Why dominant parties lose: Mexico's democratisation in comparative perspective. Cambridge University Press: Cambridge.

Gumede, V. (2014). 'Poverty, inequality and human development in South Africa', Conference paper presented at Overcoming inequality and structural poverty in South Africa: Towards inclusive growth and development, (University of Johannesburg, Johannesburg, 2010), Available online at http://www.plaas.org.za/sites/default/ files/publications-pdf/Gumede.pdf. Accessed 28 June 2014.

Huntington, S. (1996). Democracy's Third Wave. Oklahoma: Oklahoma University Press.

Kakemba, C. (2002). The South African Electoral System Roundtable Report. Available online at https://eisa.org.za/pdf/ettreport.pdf. Accessed on 16 May 2016.

Kotze, H. and Steenkamp, C.L. (2009). Values and democracy in South Africa: Comparing elites and public values Johannesburg: Konrad-Adenauer-Stiftung.

Maimane, M. (2015). Marikana reflects the accountability deficit of Zuma's administration. Available online at http://www.dailymaverick.co.za/opinionista/2015-0706-marikana-reflects-the-accountability-deficit-of-zumas-administration/\#. Vz2Es1eQHdk. Accessed on 19 May 2016.

Munusamy, R. (2016). Nkandla judgment: The mastery of Concourt vs the invicibility of Jacob Zuma. Available online at http://www.dailymaverick.co.za/article/2016-0401-nkandla-judgment-the-mastery-of-the-concourt-vs-the-invincibility-of-jacobzuma/\#.VzcvKTarclY. Accessed on 14 May 2016. 
Ndou, C. (2014). Give us enough votes to change the constitution - Zuma. Available online at http://citizen.co.za/158002/give-us-enough-votes-to-change-constitution-jz/. Accessed on 13 May 2016.

News24. (2013). Controversial secrecy bill passed. Available online at http://www. news24.com/SouthAfrica/Politics/Parliament-passes-controversial-secrecybill-20130425. Accessed on 14 May 2016.

News24. (2015). DA: Zuma lacks accountability. Available online at http://www. news24.com/SouthAfrica/Politics/DA-Zuma-govt-lacks-accountability-20110126. Accessed on 19 May 2016.

Pereira, L. (1990). "Economic ideologies and the consolidation of democracy" in Ethier, D. (ed.) Democratic transition and consolidation in Southern Europe, Latin America, and South East Asia. Basingstoke: Macmillan. Pp. 197-213.

Pzerworski, A., M. Alvarez, J.A. Cheirub, and F. Limongi. 1996. "What makes democracies endure?" in Journal of Democracy Vol. 7 (1): 39-55.

SACP. (1989) The path to power, (1989), Available online at http://www.sacp.org.za/ main.php?ID=2638\#3.1. Accessed on 26 November 2015.

Schedler, A. (2001). Measuring democratic consolidation in Comparative and International Development Vol. 36 (1): 61-87.

Schneider, C.Q. and P.C. Schmitter. 2004. "Liberalisation, transition and consolidation: Measuring the components of democratisation" in Democratization Vol. 11 (5): 59-90.

Schultz-Herzenberg, C. (2014). Voter participation in the South African elections of 2014. Available online at https://www.issafrica.org/uploads/PolBrief61_Aug14.pdf. Accessed 16 May 2015.

Sibalukhulu, N. (2012). SA's electoral system fails the people. Available online at http://mg.co.za/article/2012-04-20-sas-electoral-system-fails-the-people. Accessed on 16 May 2016.

Southall, R. (2012). South Africa's fractured power elite. Available online at http://wiser. wits.ac.za/system/files/seminar/Southall2012_0.pdf. Accessed on 12 May 2016.

StatsSA (2011). Census 2011: Provinces at a glance, Available online at http://www.statssa.gov.za/Census2011/Products/Provinces\%20at\%20a\%20 glance\%2016\%20 Nov\%202012\%20corrected.pdf. Accessed on 28 June 2014.

Steyn Kotze, J. and G. Prevost. 2015. 'Born Free: An assessment of political identity formation and party support for South Africa's first post-apartheid generation' in Africa Insight Vol. 44 (4): pp. 142-168.

Steyn Kotze, J. and . Ralo. (2014). "Bitter battles for survival: Assessing the impact of political factionalism in Nelson Mandela Bay Municipality". Administratio Publica 22 (2): 93-114.

Sunter, C. (2015). Time for Economic CODESA. Available online at http://www.news24. com/Columnists/ClemSunter/time-for-an-economic-codesa-20151217. Accessed on 11 May 2016.

Vergopoulus, K. (1990). "The political economy of democratic consolidation in Southern Europe" in Ethier, D. (ed.). Democratic transition and consolidation in Southern Europe, Latin America and South East Asia. Basingstoke: Macmillan. Pp. 121-139. 


\title{
TRANSITION TO DEMOCRACY IN SOUTH AFRICA AND POLAND: THE GENETIC APPROACH
}

\author{
URSULA VAN BEEK
}

\section{Introduction}

In 2002 Thomas Carothers published his since much talked about article about the end of the transition paradigm. The paradigm, which he contested, evolved in the early 1990s when close to a hundred countries across all cultural regions of the world began to move away from authoritarian rule towards a more liberal form of governance. The phenomenon followed in the wake of the collapse of the Soviet Bloc, and later the Soviet Union itself. It was generally assumed at that time that democracy won the war of attrition between the two competing political systems, which had bisected the globe since the end of the Second World War in 1945. Most observers also assumed transitions in the individual countries to be a global trend that constituted a part of - and gave greater impetus to - the Third Wave of Democracy (Huntington, 1991).

Five assumptions underpinned the paradigm. First, all the countries in transition were moving away from authoritarian rule towards democracy; second, democratisation unfolded in a sequence of well defined phases; third, elections were of key importance; fourth, structural factors did not play a major role; fifth, transitions making up the Third Wave were built on functioning states.

Many important analyses of transitions emerged. Among them the pioneering work by O'Donnell, Schmitter, and Whitehead (1991) who explained the process of democratisation of South American and Southern European regimes; Linz and Stepan (1996) who focused on the problems of democratic transition and consolidation in Southern Europe, South America and post-Communist Europe; Dogan and Higley (1998) who compared the role of elites in the transition process; Gilliomee and Simkins (1999) and van Beek (1995) who analysed various transitions, with the latter making an initial attempt to compare the transition in South Africa and Poland; Meyer and Ryszka (1991) who conducted a comparative study of political participation and democracy in Poland and East Germany; and Szelenyi, Wnuk-Lipinski, and Treiman 
(1995) who studied the emergence of economic, cultural and political elites in Poland, Russia and Hungary.

Carothers challenged the continuing validity of the transition paradigm by pointing out that of the hundred, or so, countries considered as transitional in the 1990s, probably fewer than twenty retained the positive dynamic of the early days and were on their way to become well-functioning democracies in the following decade. The vast majority of the cases did not seem to be deepening whatever initial democratic progress they may have made. Carothers categorised the latter countries as those that have moved, or were about to move, into the "grey zone", pointing out that two common defects dominate this dynamic. The one is "feckless pluralism", a syndrome in which significant amounts of democratic trimmings remain, but where alternation of power seems to do no more than to shift the country's problems back and forth; where democracy remains shallow and troubled; and where the ruling groups are considered to be corrupt, self-interested and inept. The other defect is the "dominant power politics" syndrome. ' Countries falling into the latter category also retain some important vestiges of democracy, including space for political contestation by the opposition, but in those cases one political grouping dominates the system to such an extent that the possibility of an alternation of power in the foreseeable future is unlikely.

South Africa and Poland, the two countries to be analysed here, have been both considered as transitional in the literature. They both moved away from authoritarian regime at the height of the Third Wave, and each has made impressive strides towards democratisation in the initial period of their respective transitions. Yet Carothers classified Poland as belonging to the successful minority of countries that are well on their way to a consolidated democracy; while placing South Africa as a country edging ever closer to the "grey zone". ${ }^{2}$ The question is why the divergence?

\section{The framework}

Searching for answers the empirical part of the inquiry that follows will test a model proposed in a much earlier yet just as influential article entitled "Transitions to democracy: Toward a dynamic model" (1970). Its author, Dakart Rustow, is considered to have introduced the term "transition" in reference to a change in political regime. In contrast to most political scientists at that time, Rustow was less curious about how

1 For insightful analyses of South Africa in this context see: De Jager and du Toit (2012).

2 Pierre Du Toit elaborated on the dynamics behind democratic degeneration in a long-term historical perspective (2010). 
an existing democracy might best be preserved or strengthened, than in the problem of how it comes into being in the first place. Focusing on the "genetic question", as he called it, Rustow turned to the study of the conditions existing at the birth of a democracy. In his opinion such an approach offered valuable insights into why some democracies improve and persist while others weaken over time, or even perish. Writing before the onset of the Third Wave, Rustow also considered an inquiry of this kind to be of more interest, and possibly of more usefulness, to students of democracy in the parts of the world that were yet to democratise. Now that this has happened, his hypotheses are worth revisiting for their potential explanatory value.

Rustow emphasised agency, process and bargaining over functional approaches. Without denying the significance of the latter, he argued that even the most prominent attempts to offer a worldwide comparative perspective on democracy such as those by Martin Seymour Lipset $(1959,1960)$, bore only on function. Taking the form of correlations measured at a given point in time these data did not reveal, for example, if affluent and literate citizens make for better democrats; whether democracies provide superior schools; or create conditions more propitious to economic growth; or whether an "industrial" economy causes democracy, as well as affluence and literacy. In a similar vein Rustow questioned the contemporary opinion-based findings of Almond and Verba (1963), pointing out that it was not clear whether willingness to participate in public life or a consensus on fundamentals that form "civic culture" were the effect of democracy, its cause, or neither.

Taking pains to distinguish clearly between cause and correlate, Rustow did not commit his model to the simple view of causality where every effect has only one cause, and every cause but one effect. Instead, he allowed for a two-directional flow of causality between politics, on the one hand, and the economic and social conditions, on the other, cautioning the social scientist to be specific about the mechanisms by which social or economic conditions penetrate the political democratic foreground. Nor does the model impose uniformity. Instead it stresses there are many roads to democracy, and it assumes that transition is not a steady process progressing over time because both continuity and discontinuity are possible. The model imposes three restrictions. It calls for a specific time-frame; it requires an internal logic of transition, with no major impetus from abroad; and, it recommends a close examination of two or three cases that could by application be tested later on a broader sample of cases.

The transition model consists of a single background condition and three followup phases. 
Background condition: The initial condition is national unity, understood not as pledges of allegiance to soil and blood, but defined by the absence of any mental reservations or doubt by the vast majority of the democrats-to-be that they belong to the same political community. The background condition is best fulfilled when national unity is unquestionably taken for granted.

Preparatory phase: This phase builds up against the background condition in a prolonged and inconclusive political struggle between well entrenched social forces rallying around issues of great meaning to each side. The struggle leads typically to polarization rather than pluralism. The dynamic process of democratization is usually set off by the emergence of new elite that is able to mobilise a previously leaderless social group into concerted action.

Decision phase: The decision phase is activated when leaders of the contending social forces accept the existence of diversity and recognize that a fundamental power shift is underway. This may lead them to make a conscious decision to institute a political change. A decision in favor of democracy will typically entail a lengthy process of negotiations, which is fraught with risks for the future and is conducted by a small circle of leaders who play a disproportionately large role at that stage. Among them are the protagonists of the preparatory struggle. The phase terminates when a compromise has been reached, even if there is no general agreement on fundamentals and differences in preference on procedures have not been resolved.

Habituation phase: The final phase entails reconciling professional politicians and the citizenry at large with the imperfect agreement worked out by the leaders. The very establishment of a democracy by means of the principle of conciliation and accommodation can be helpful to the process as it provides proof that negotiations can work as a conflict resolution mechanism. This in turn might encourage the contending political forces and their leaders to continue seeking resolution to conflicts through this democratic procedure. But, according to Rustow, success or failure is related to the nature of the conflicting issues at hand. Historical examples show how effective democracy has been in resolving political questions where the major divisions are social and economic. The same cannot be said of countries divided by religion, ethnicity or race. In those cases tenacious and recurring bitterness causes divisions, which democracies struggle to settle. Rustow sees this difficulty in resolving community issues as an indication of the importance of national unity as the background condition of the democratization process, concluding that "the hardest struggles in a democracy are those against the birth defects of the political community" (1970: 360). 


\section{South Africa and Poland in transition}

\section{The background condition}

Since national unity as the background condition plays such a singularly important role in the model, the term has to be clearly defined. This is especially so that "national unity" might easily be confused with the term "state", where the latter is understood - and is routinely listed - as one of the preconditions of achieving a democratic transition. Larry Diamond (Discussion, 2014), for example, censured Rustow for going too far by labeling as national unity something that should have rather been called a "reasonably coherent state". But the two terms are not always interchangeable. There can be national unity without there being a state, and there are examples of existing states, which lack national unity. The deliberate distinction Rustow made in this regard is exceptionally well illustrated by the history of the two cases examined here: South Africa and Poland.

In South Africa the Dutch and the British settlers have been vaguely united over the centuries by the notion of their shared European roots and by the alleged achievements of their common mission of 'civilising' the indigenous inhabitants. At the same time they viewed each other with suspicion, and many would argue that some of these negative sentiments linger to this day. While the English speakers considered South Africa a colonial outpost and traced their own roots back to Europe, the identity narrative of the Afrikaners developed a fierce allegiance to Africa, but one that excluded the indigenous people of the land (Mda, 2002). This divergence in historical allegiance, coupled with a different sense of belonging and, above all, competition for resources, led to a collision course that culminated in the Anglo-Boer war. Besides combat casualties, some 26000 Boer women and children perished in British concentration camps and in their homesteads during the war, leaving the Afrikaners with a determination never to be victimised again. The subsequent fervent brand of their exclusive nationalism may have paved the way to the crafting of the policy of apartheid (Krog, 1998).

Colonialism initiated the degrading social differentiation, apartheid made it legal. The apartheid narratives portraying the non-white ethnic and racial groups in the country as inferior or threatening prevented the forging of any sense of common national unity. The narratives and the associated discriminatory policies were, in fact, designed for precisely the opposite purposes: they were to keep the various groups apart. The institutionalization of segregation excluded by law the majority of the population from citizenship in the state. 
The history of Poland could not have been more contrasting as the country ceased to exist as an independent state and yet the sense of national unity survived the absence of statehood. In three successive territorial seizures (1772, 1773 and 1795) Russia, Prussia and Austria carved up and divided the land among them, until they erased Poland entirely from the map of Europe for 123 years (Cegielski and Kadziela, 1990). Alarmed by the loss of territory following the first partition, Polish intellectuals strove to assure that the thought of Poland and its language, along with the ideas of Polish Enlightenment, were carried forth. The most notable achievement of these patriotic thinkers was to reform the educational system in the wake of the papal dissolution of the Society of Jesus, which removed Jesuits from the Polish school system. In 1773 they set up the National Education Commission, which is considered to have been the first ministry of education in Europe (Davies, 2005). The Commission restructured education from primary to college level, established Polish as the language of instruction, and introduced university courses on citizenship, public responsibilities and the arts of state (Wroczynski, 1983).

The final partition of Poland was a response to the first and most extensive in the series of three national uprisings against the occupying powers. The 1794 rebellion led by Tadeusz Kosciuszko, one of the heroes of the American revolutionary war, gave the initial impetus to the following November Insurrection of 1830 and the January Uprising ${ }^{3}$ of 1864 . Although all three uprising ended in failure, they helped to keep the spirit of national unity alive until the Treaty of Versailles recreated the Polish state in 1918.

\section{Preparatory phase}

In contrast to the differences in the "background condition", South Africa and Poland shared many similarities during the "preparatory" phase, which both countries entered in 1948. In that year the apartheid regime took the reins of power in South Africa, while in Poland the last vestiges of freedom were eliminated following the fraudulent election, which gave the Soviet-supported communist regime total control over the country and its people. The lines of conflict became clearly demarcated in both countries.

The African National Congress (ANC) played a leading role in the struggle against white racial domination in South Africa. The forms of the struggle ranged from non-violent mass actions, to armed resistance and acts of terrorism against the

3 Karl Marx in his speech marking the fourth anniversary of the January Uprising referred to the spirit of the Polish nation as that of the "immortal knight of Europe (Marx, 1867). 
apartheid state. The struggle was informed by Christianity, Liberalism, Marxism, Pan-Africanism and Black Nationalism. The initial input into this curious fusion of concepts came from the Christian tenets disseminated by missionaries who were the earliest opponents of segregation and segregationist legislation. Their social gospel fostered through the educational system promoted social reform that was meant to lead to an equitable and just society. In political terms the Christian ideal found expression in the Freedom Charter, adopted in 1955. The document, which the apartheid regime banned, envisaged South Africa as belonging to all who live in it and who should enjoy equal rights and opportunities, including the right to a democratic vote without distinction of colour, race, sex or creed. The Freedom Charter was formulated primarily by people whose biblical knowledge acquired in the mission educational system helped them articulate the blueprint for a free and democratic South Africa (Xundu, 1988).

But Christianity arrived in tandem with European colonization and in time an antiChristian bias emerged among the younger generation. This development gave rise to African Nationalism and prepared a fertile ground for Marxism. In the ensuing course of the struggle, liberationist political thinking about future citizenship coalesced into two broad trends: "Charterist" non-racial integration, and Black Nationalism. The liberal multiracialism of the former captured in the Freedom Charter was set against the Marxist vision for a non-racial post-liberation South African society based on class distinctions. The polarity in African political thinking led in 1959 to a break-away Black Nationalist movement, the Pan Africanist Congress (PAC), which splintered from the ANC.

For South Africa the defining moment in the "preparatory phase" was the 1976 Soweto Uprising. The brutal suppression of the uprising jolted into action the formerly low key United Democratic Front (UDF). In the aftermath of the uprising the UDF managed to give shape to mass political culture by directing it towards engagement in popular activism. The movement provided a powerful rallying platform at the national level for the hundreds of anti-apartheid civil society organisations that had sprang up at local levels throughout the country in response to Soweto. These were church and civic bodies, as well as various workers, youth, student and women structures. The UDF was a strictly non-racial and non-violent movement. It brought together people from across racial, ethnic and class boundaries. The movement was modelled on the strategy of civil disobedience promoted in the 1950s by the ANC, with which the UDF shared the Christian heritage (Van Beek, 2010). 
Poland entered the communist era significantly weakened. World War Two claimed almost one fifth of the population, with more than 90 percent of Polish Jews and three million ethnic Poles having been exterminated. Landed gentry, the intellectuals and the middle classes were the main social groups targeted by the Nazis. The Soviets aimed to eliminate the same strata of population during their occupation of eastern Poland (September 1939 to June 1941), with the 1940 Katyn massacre of several thousands of Polish reserve officers as the most telling example (Wawrzonek, 2008). The combined impact of the Nazi, Soviet and Polish communists' policies decimated Polish elites, making the communist takeover of the country that much easier.

German wartime occupation policy also decimated the Catholic clergy. Significantly weakened, the Church nevertheless entered the communist period as an enduring symbol of what it meant to be Polish. The traditional model of the Catholic-Pole was to become the defense mechanism in the face of Stalinist repression in Poland (1948-1956). The embodiment of the anti-communist defiance was Cardinal Stefan Wyszynski who repeatedly dared the regime. He called for freedom of assembly by invoking the 1948 Universal Declaration of Human Rights and he encouraged inner freedom, which allowed "the citizen not to be afraid to defend his rights when they are violated" (Michnik 1993: 116). After some years of evident secularisation, ${ }^{4}$ the model of the Catholic-Pole returned with a vengeance in the post-Vatican II period, initiating the division between 'us', the Poles, and 'them', the communists (Grabowska, 2001). By then the 'us' meant a coalition of workers and intellectuals that, most significantly, included not only Catholic intellectuals but also dissident left intellectuals. Despite their longstanding anticlerical tradition the latter engaged in a dialogue with the Church. This unlikely alliance created the embryo of the future trade union Solidarity (Michnik, 1998; Garton Ash, 1983).

While Soweto was the defining moment of the "preparatory phase" in South Africa, for Poland the catalyst was the election of a Polish pope in 1978. More precisely, it was the pilgrimage of the newly elected Pope John Paul II to his homeland a year later that rekindled in the Polish society the dormant sense of national and ethical unity, shattering thereby the societal atomisation engineered and imposed on the society by the communist regime. In August 1980, this re-discovered oneness gave rise to Solidarity, a ten million-strong social movement. As in the case of the ANC, Solidarity was also outlawed when the regime declared martial law in December 1981. And as the ANC, Solidarity survived underground, while its spirit was kept alive

4 Polish sociologists noted increased levels of secularisation between 1956 and 1968, especially among intellectuals, high school pupils and university students (Szawiel 1989). 
by the Church. With the ascent of the Gorbachev era in the Soviet Union and the resultant emergence of a reformist faction within the Polish Communist Party, the robust counter-elite created by Solidarity seized the moment.

The ultimate collapse of the authoritarian regimes in South Africa and Poland was the outcome of very different and internally highly complicated social processes that did, however, share one general characteristic: a yearning for freedom. The eventual success of achieving transition in both cases can be attributed to another common factor: a universal discrediting of the respective types of autocracy. Whereas apartheid was from the start rejected by the majority of South Africans and was condemned throughout the world for its racist foundations, communism held the power to move the hearts and minds of millions and for a time communist ideology was successfully substituting for regime legitimacy. This changed in 1956 after the ruthless suppression by the Soviet Army of the Hungarian uprising the purpose of which was to depart from the imposed rigid totalitarian communist dogma. In Poland and elsewhere in the Soviet Bloc, the revisionist reaction to the suppression of the uprising was an attempt to reform communism from within. The experiment of trying to build 'socialism with a human face' ended with the 1968 invasion of Czechoslovakia by the forces of the Warsaw Pact. The experiment failed, but the romantic veneer came off leaving communism exposed for the repressive system that it was.

\section{Decision phase ${ }^{5}$}

Formal government negotiations with the opposition movements began in the two countries just over two years apart. The February 1989 Round Table talks brought together delegates from the ruling Polish United Communist Party and the Solidarity trade union. In South Africa the Convention for Democratic South Africa (CODESA 1) met in December 1991 with the two major participants representing respectively the ruling National Party and the ANC. At the outset, both the Polish and the South African governments seemed to have been in a stronger position than was the opposition. The Polish government, fully aware of the abysmal state of the Polish economy, realized that to undertake meaningful economic reforms it needed societal support and that such support would only be forthcoming if a compromise were reached with the opposition. The expectations of the opposition at that point were rather modest,

5 Pierre du Toit offers an insightful analytical framework within which to assess the bargaining relationships that precede negotiations and extend beyond the decision phase. Although focused more specifically on South Africa, the framework helps both making a distinction between potential power, tactical action and bargained outcomes, and studying the effects of specific tactics on outcomes and subsequent power relations (du Toit, 1989 and 1991). 
merely to be returned to public life by enjoying the status of a legal organisation. The South African government already unbanned the ANC and committed itself to political liberalisation, but it hoped to prolong the process while retaining maximum influence over its implementation. The expectations of the ANC were much more radical than those of Solidarity. The ANC wanted a swift introduction of majority rule by means of an interim government and called for the election of a body to draft a constitution (Nel, 1995; Paczkowski, 1995).

The balance of power between the negotiating parties shifted along the way, with control over the process slipping away from the respective governments. In South Africa this happened more gradually, between the second half of 1992 and the end of 1993, when it became clear that the agenda of the government was increasingly losing traction vis-à-vis the wishes of the opposition. Nevertheless, the National Party emerged from the first democratic election in April 1994 in a much better shape than the Polish Communist Party whose fortunes changed virtually from one day to the next. The election of 4 June 1989 took on the unexpected form of a plebiscite that stripped the regime of the last vestiges of legitimacy. In an overwhelming victory for the opposition the government candidates lost the vote even in the so-called "closed circuits" that is, among the military and the police, which sent a strong signal to the authorities that the "force option" was no longer an option (Wnuk-Lipinski, 2014:9). Although the illusion of control lasted a little longer the end of communism in Poland was inevitable.

\section{The habituation phase}

According to the discussed model the "background condition" of national unity is the key predictive determinant on whether or not a new democracy will fail to consolidate or will persist. The acid test comes during the phase of habituation. In the two cases reviewed here, as in most other cases, institutional engineering has been completed by then and democracy is seemingly regarded by the majority of citizens as 'the only game in town'. One could be forgiven for assuming that the most difficult stages of the process of democratic transition have been left behind. But this is, in fact not so. Instead, the well-defined division between the aspiring democrats and the oppressive regime fractures, bringing to an end the strong unity of purpose that had kept the opposing sides together during the preparatory and decision phases. The new fault lines are many and differ from case to case. The question is whether national unity is indeed the indispensable condition that makes habituation possible, as Rustow presumed. 
In Poland, the new divisions appeared only after the country was admitted into the European Union in 2004. Once the Copenhagen criteria of democratic governance, the rule of law, protection of minorities and a functioning market economy were declared to have been met and accession was assured, the political landscape in the country changed quite rapidly with the appearance of Eurosceptics and populists in party politics. The populist theme of redistribution of the benefits of the economic transition resonated with many voters in the 2005 parliamentary and presidential elections (Kucharczyk and Fomina, 2007). Nationalism, often intertwined with political Catholicism, has also arrived on the scene, making the role of the Catholic Church far less clear-cut than is used to be. Previously, and enjoying strong support from the late Pope John Paul II, this once most trusted of institutions in Poland had managed to take the wind out of the Eurosceptic campaign that opposed Poland's entry into the EU on the grounds that Europe was morally decadent, atheist and represented a threat to national sovereignty. This resolute pro-Europe stance by the Church helped assure a resounding 'yes' vote in the accession referendum. But the Church no longer stands united as some currents within it carry much more sympathetic views of nationalism and Catholic fundamentalism (Kucharczyk and Zbieranek, 2010).

The strong background condition notwithstanding, Poland has been experiencing deep cleavages along party lines. In a democratic polity differences in party preferences are, of course, normal, but in Poland these differences appear to be so deeply entrenched and so highly charged emotionally that they restrict room for compromise across party lines and impede thinking in terms of the common good for the society as a whole (Wnuk-Lipinski, 2014). The divide shapes and defines the Polish political scene, which continues to be dominated by two main parties, the liberal-conservative Civic Platform and conservative-populist Law and Justice. Nevertheless, the Poles and the Czechs were the most convinced among their Central Europeans counterparts that democracy building in their country has been a success. This opinion was expressed by two thirds of Polish respondents surveyed by the Institute of Public Affairs and its partners (Butorova, 2009). Such individual perceptions continue to be borne out by a variety of data, which point towards a healthy state of democracy in Poland.

In South Africa the first indication of the impending political and social reconfiguration was signaled at an ANC conference in 1997, dimming the vision for a country that belonged to all who lived in it as the "Rainbow nation" promoted by the leading lights of the struggle. To the fore came the concept of "African hegemony in the context of 
a multi-cultural and non-racial society". The "national objective" to build a non-racial democratic society of equals was supplanted by the idea of a 'National Democratic Revolution' (NDR), which would improve the quality of life of the poor, who were 'by definition mostly black' (African National Congress Strategy, 1997).

The largely rhetorical notion found much fuller expression and is slowly being implemented following the 2007 ANC conference where the left faction within the party - allied closely with the trade unions and the Communist Party - gained the upper hand. The conference resolutions reaffirmed the ANC as the "key strategic centre of power" called to exercise leadership over the state and society in pursuit of the objectives of the NDR. Uncannily reminiscent of the Marxist-Leninist language once used in the Soviet Union and throughout the Soviet Bloc, the resolutions of the conference expressed anxiety over a "counter-revolution" and stressed the need to remain vigilant in the face of forces seeking "to subvert and disrupt the agenda of revolutionary change" (Polokwane conference, 2007).

The most significant resolution taken at the 2007 conference was the reconfirmation of the "national groups" concept for societal transformation. This model is envisaged as "concentric circles" with black workers at the centre and the wider black communities as the "motive forces". The dynamic of the concentric circles tapers towards the outer edges where the "balance of the majority" - made up of all races - steadily forges a social compact of common interest, and where all the circles are eventually expected to intertwine as the NDR reaches maturity (Polokowne conference, 2007). Supporters of this transitional model identify with the ANC's outlook and norms, which among others promote a developmental state, collective rights, values of community caring, and communal solidarity. The other side, regarded as counter-revolutionary, is said to follow the ideological outlook of the media and support values that include neo-liberalism, weak and passive state, overemphasis on individual rights, and market fundamentalism. The rhetoric represents a clear departure from the principles of reconciliation and cultural tolerance enshrined in the post-apartheid constitution, creating instead a new and most troubling cleavage. The rhetoric also indicates a departure from democratic values.

\section{Closing reflections}

At a first glance the main premise of the tested model has been confirmed. Poland, whose citizens had no mental reservations or doubts about belonging to the same political community, is consolidating the gains of its democratic transition; South 
Africa, where the majority was excluded from citizenship and was denied the feeling of belonging together as a nation, is experiencing serious transitional hurdles.

Of course, one cannot generalize from just two cases and expect to reach universally applicable conclusions. However, drawing on historical examples and looking at the now much larger and much more varied set of democratization cases than Rustow was able to assess, it appears that the presence of "national unity" continues to be a valid explanatory variable as to why some democracies strengthen over time and others weaken or perish. What ought to be reexamined, though, is the definition of the term "national unity" itself.

Rustow considered such unity to be the single most important background condition for the entrenchment of a democracy and he assumed that its absence at the threshold of transition was a serious "birth defect". But does such birth defect represent an incurable genetic impediment, which will condemn a new democracy to an early demise? Not if we remember that both the modern concept of national unity and modern democracy emerged during the same historical process. The French and American revolutions are the two paradigmatic examples of events during which the idea of togetherness as a nation was forged and was equated with citizenship in a democratic state. In these two cases national identity, or national unity, became rooted in the deep conviction of people that they belonged to a community of citizens who constituted the democratically organised state and whose memory of the revolutionary events that brought them together defines who they are, and is being celebrated.

The model proposed by Rustow will remain valid if a distinction is made between the concept of national unity formed by objective historical pre-configurations, and the type of national unity that arises from a subjective decision and is the outcome of a normative discourse. Transition to democracy, in other words, should be a process allowing citizens to retain their sense of belonging to a social group that might be distinctly different from other groups, but where all the groups are bound together within the larger national community. When this happens, norms such as equality, liberty and human and civil rights, start playing a constitutive role in developing a new sense of national unity that was not imposed by history, or by 'nature', but has been decided by the people themselves (Ruesen, 2005).

Once so habituated democratic values become the goalposts on the road to resolving problems. As Rustow noted, democracy is not about maximum consensus, but about finding the tenuous middle ground where social and economic conflicts 
can be expressed and resolved. But conflict resolution will succeed only if a general acceptance of democratic rules becomes the common language of transition.

\section{References}

African National Congress. 1997. Strategy and Tactics. As amended the 50th National Conference [Online]. Available: http://www.anc.org.za/ancdocs/history/conf/ conference50/strategyamend.html [Full text no longer available on-line. Last accessed, October, 2010)

Almond, G. \& Verba, S. 1963. The Civic Culture. Princeton: Sage Publications.

Bútorova, Z. \& Gyarfásova, O. 2009. Return to Europe: New freedoms embraced, but weak public support for assisting democracy further afield, PASOS Brief No.3, 2009, www.pasos.org

Carothers, T. 2002.The End of the Transition Paradigm. Journal of Democracy, 13(1):5-21. https://doi.org/10.1353/jod.2002.0003

Cegielski,T. \& Kądziela, L. 1990. Rozbiory Polski 1772-1793-1795 (The partitions of Poland 1772-1773-1795). Warsaw: Wydawnictwo Szkolne I Pedagogiczne.

Cutright, P. 1963. National Political Development: Measurement and Analysis. American Sociological Review, 28(2), April: 253-264. https://doi.org/10.2307/2090612

Davies, N. 2005. God's Playground: 1795 to the present. New York: Columbia University Press.

Discussion: "Reconsidering the Transition Paradigm". Larry Diamond, Francis Fukuyama, Donald L. Horowitz, and Marc F. Plattner 2014. Journal of Democracy. 25 (1): 86-100.

Dogan, M \& J Higley (eds.). 1998. Elites, Crises, and the Origins of Regimes Oxford: Rowman \& Littlefield Publishers.

De Jager, N. \& du Toit (eds). 2012. Friend or Foe? Dominant Party Systems in Southern Africa: Insights from the Developing World. Tokyo, New York, Paris: United Nations University Press.

Du Toit, P. 1989. Bargaining about bargaining: Inducing the self-negating prediction in deeply divided societies - the case of South Africa. Journal of conflict resolution, 33 (2): 210-230. https://doi.org/10.1177/0022002789033002002

Du Toit, P. 1991. Bargaining power: dependence capabilities and tactical options in South African politics. Politikon, 18 (2): 74-90. https://doi.org/10.1080/02589349108704952

Du Toit, P. 2010. Conclusions, in U. Van Beek (ed.). Democracy under scrutiny: Elites, citizens, cultures. Leverkusen and Ridgebrook: Barbara Budrich Publishers.

Garton Ash, T. 1983. The Polish revolution: Solidarity, 1980-1982. London: Jonathan Cape.

Gilliomee, H. \& Simkins, C. (eds.). 1999. The Awkward Embrace: One-Party Domination and Democracy. Cape Town: Tafelberg.

Grabowska, M. 2001. Religijnosc i Kosciol w procesie transformacji w Polsce, in E. Wnuk-Lipinski, E. \&M. Ziolkowski (eds.) Pierwsza dekada niepodelglosci. Proba socjologiczej Syntezy. Warsaw: ISP-PAN.

Horowitz, D. 1975. Ethnic identity, in N. Glazer \& D. P. Moynihan (eds.). Ethnicity, theory and experience. Cambridge Mass: Harvard University Press. 
Huntington, S. P. 1991. The Third Wave. Democratization in the late twentieth century. Norman: Oklahoma University Press.

Krog, A. 1998. Country of my skull. Johannesburg: Random House.

Kucharczyk, J. \& Joanna, F. 2007. Poland After the 2005 Elections:

Domestic Discontent or EU Backlash? in M. Bútora, O. Gyárfášová, G. Mesežnikov,

\& T. W. Skladony (eds.). Democracy and Populism in Central Europe: The

Visegrad Elections and Their Aftermath. Bratislava: IVO.

Kucharczyk, J. \& Zbieranek, J. (eds.). 2010. Democracy in Poland 1989- 2009. Challenges for the future. Warsaw: Institute of Public affairs.

Linz, J.J. \& Stepan, A. 1996. Problems of democratic transition and consolidation: Problems of democratic transition and consolidation: Southern Europe, South America, and postcommunist Europe. Baltimore, London: Johns Hopkins University Press.

Lipset, M.S. 1959. Some Social Requisites of Democracy: Economic Development and Political Legitimacy. American Political Science Review, LIII 53(1), March: 69-105. https://doi.org/10.2307/1951731

Lipset, M.S. 1960. Political Man. New York: Johns Hopkins University Press.

Marx. K. January, 1867. Speech commemorating the fourth anniversary of the Polish January Uprising. In: Janowska, H. and Jedruszcak, T. 1984. Powstanie drugiej II Rzeczypospolitej. Wybor dokumentow: 1866-1925. (The establishment of the Second Republic. Selection of documents: 1866-1925). Warsaw: Ludowa Spoldzielnia Wydawcznicza.

Mda, Z. 2002. Fumbling for the meaning of African identity. Cape Times, 6 February: 15

Meyer, G. \& Ryszka, F. (eds.). 1991. Political participation and democracy in Poland and West Germany. Warsaw: Osrodek Badan Spolecznych.

Michnik, A. 1998. Kosciol, lewica, dialog. Warsaw: Swiat Ksiazki.

Michnik, A. 1993. The Church and the Left. Chicago: University of Chicago Press.

Nel, P. 1995. Transition through erosion: The Round Table in Poland and South Africa, in U. Van Beek (ed.). South Africa and Poland in transition: A comparative perspective. Pretoria: Human Sciences Research Council.

O'Donnel, G., Schmitter, P.C. \& Witehead, L. (eds.). 1986. Transition from authoritarian rule. Baltimore, London: Johns Hopkins University Press.

Paczkowski,A. 1995. The "Great historical experiment" or the demise of real socialism in Poland, in E. Wnuk-Lipinski E. (ed.). After communism. A multidisciplinary approach to radival social change. Warsaw: Institute of Political Studies.

Polokwane Conference resolutions, 2007. [Online]. Available: http://www.anc.org.za/ ancdocs/history/conf/conference52/ [Full text no longer available on-line. Last accessed October, 2010)

Ruesen, J. 2005. Historical memory and democracy: Setting the scene, in U. Van Beek (ed.). Democracy under construction: Pattern from four continents. Pretoria: Barbara Budrich Publishers, Bloomfield Hills \& Opladen \& Van Schaik Publishers.

Rustow, D. A. 1970. Transitions to democracy: Toward a dynamic model. Comparative Politics. April 2(3): 337-363.

Szawiel, T. 1989. Religijnosc i jej korelaty, in S. Nowak (ed.). Ciaglosc i zmiana w tradycji kulturowej. Warsaw: Panstwowe Wydawnictwo Naukowe. 
Szelenyi, I., Wnuk-Lipinski, E. \& Treiman, D., (eds.). 1995. Circulation of elites? Old and New Elites in Post-Communist Societies, in Theory and Society - Special Issue, October: 615-800.

Van Beek, U (ed.) 1995. South Africa and Poland in transition: A comparative perspective. Pretoria: HSRC Publishers.

Van Beek, U. 2010. Südafrika: Liberal oder demokratisch? (South Africa: Liberal or democratic?). Zeitschrift für Parlamentsfragen, 2:438-452. https://doi. org/10.5771/0340-1758-2010-2-438

Wawrzonek, W.R. 2008. Zbrodnia Katynska i jej biale plamy. (The Katyn Massacre and its white spots). Lodz: Interdruk.

Wnuk-Lipinski, E. 2014. 25 lat po przelomie (25 years after the change). Wolnosc $i$ Solidarnosc. 7: 6-11.

Wroczynski, R. 1983. Dzieje oswiaty polskiej do roku 1975. (History of Polish education until 1795). Warsaw: Panstwowe Wydawnictwo Naukowe.

Xundu, C. 1988. The Congress of the People campaign and the overall view of the Freedom Charter, in J. A. Polley (ed.). The Freedom Charter and the Future. Cape Town: IDASA. 


\section{GOOD FAITH OR GOODWILL? THE SOUTH AFRICAN CONSTITUTION AS CONTESTED TERRAIN}

\section{SALOME TEUTEBERG}

This contribution formed part of a doctoral study under the supervision of Prof. Pierre du Toit, Department of Political Science, Stellenbosch University

\section{Introduction}

Since South Africa's dramatic but unexpectedly peaceful transition to democracy in the early 1990s, it has been used as an example of peace-making and constitutionmaking. Authors such as Harris and Reilly (1998) and Darby \& MacGinty (2003 \& 2008) have hailed the nature of the process. However, Teuteberg (2015:1) found that by 2014 'evidence was accumulating of an emerging dissensus, or lack of convergence of interpretation of agreement, on the South African Constitution'. Teuteberg cites an example in the Sunday Times of 3 May 1998. Kgalema Motlanthe, then secretary general of the ANC, claimed that the ANC would 'review the power held by independent watchdogs if it won a two-thirds majority' in the 1999 election (Paton \& Schmidt, 1998). In this article, Motlanthe is quoted as saying that by winning the majority, the ANC could govern 'unfettered by constraints.' According to Teuteberg, this statement 'casts doubt on the actual, authentic intentions of the ANC as to the status of the new negotiated constitutional regime'.

Not many authors have explored the idea that varying perceptions of the South African outcome may exist among its original negotiators. Horowitz (1991) and Sisk (1995) investigate this idea, but both studies were undertaken before the final constitution of 1996. Pierre du Toit (2001:104) noted this disparity in his book South Africa's Brittle Peace: The Problem of Post-Settlement Violence, and specifically mentions the lack of data available regarding participants' views on the outcome of the South African negotiations. Using the limited data, Du Toit finds a number of divergent views present among those involved in the process, noting that the ANC and PAC focused on the outcome as part of a liberation process, as a mere 'landmark' in a larger process. The NP, on the other hand, focused on the establishment of a 'rechtsstaat'. 
In this chapter, the concept of a Benchmark Agreement, first noted by Cohen (1997), elaborated by Du Toit (2001) and later Teuteberg (2015) will be explored and applied to selected negotiators. I hope to establish a clear path from Du Toit's earlier work to a more fundamental exploration of this concept. By investigating this concept in the context of the South African negotiations, I will seek evidence that the thinking associated with the Benchmark Agreement was present during the negotiations leading to the South African Constitution (1993 and 1996).

\section{What happens when parties hold opposing contextual perspectives?}

Du Toit (2001:103) clearly states the importance of establishing a 'clear and explicit understanding' between negotiators regarding the approach to be taken on negotiations. He goes on to mention four problems (2001:103-104) associated with the absence of an explicit understanding among negotiators regarding their approach to negotiations:

First, it may lead to a disagreement on the importance of procedures, the establishment of procedures and the following of procedures. Second, in low-context cultures, tactics beyond the negotiating table are 'discreet' from official negotiations, while in high-context cultures, these types of tactics form part of and complement official negotiations.

Third, in low context cultures, the outcome is considered contractually binding. However, in high-context cultures, the outcome is 'just another platform for further contestation and for remoulding' the power relations between the parties. Fourth, low-context cultures consider negotiators as equal when coming to the negotiating table. Negotiators from high-context cultures 'insist on recognition of their own high moral superiority' (Du Toit, 2001:104).

Confronted with high-context negotiators, low-context negotiators can accuse their opponents of bad faith, while when high-context negotiators are confronted with opponents from a low-context culture, they may claim those negotiators to be morally insensitive. Differing definitions of how agreements are made and interpreted in the long run may cause disruptions in conflict settlements.

\section{The Benchmark Agreement}

Cohen (1997) sets out to establish a theory to varying perceptions of contracts in the form of low- and high-context negotiators. When negotiation takes place across cultures, these shared 'semantic assumptions' are often absent and present 
persistent problems in understanding. Parties' perceptions and interpretations are formed by cultural experiences and cannot be defined with a simple dictionary definition of concepts (Cohen, 1997:27). High-context cultures tend toward allusive communication as opposed to direct communication. High-context cultures are concerned with the implicit content of a message, the nonverbal clues and 'hintedat nuances of meaning' (Cohen, 1997:31). High-context cultures are very concerned with maintaining face, and therefore, the loss of face is seen as a penalty to be avoided. Cohen (1997:32) identifies this type of cultures as being 'shame oriented rather the guilt oriented'.

In high-context cultures, the negotiation process is not seen as a 'specific event with a discrete character and finite, clearly demarcated boundaries' (Du Toit, 2001:102). According to Cohen, a process of negotiation is more likely viewed as 'one event in a longer process including other events and interactions' (Cohen, 1997:34, in Teuteberg, 2015). According to Du Toit (2001: 102), '[a]t worst, such an event is merely an episode in the ongoing relationship, at best a benchmark.' Teuteberg (2011:9) writes that in this type of negotiation culture, 'negotiated agreements do not represent rigid contracts but are rather seen as flexible arrangements that are entirely subject to renegotiation. In such agreements, the relationship is upheld by goodwill rather than good faith'. Goodwill derives from 'joint recognition of the justness of the cause of one party over the other, and from their joint, but not identical, contributions to right some large historical wrongs' (Du Toit, 2001:102).

Agreements can become outdated as relationships change. The negotiated outcome becomes merely an episode, a benchmark, in a larger process, which reflects the nature of the relationship at the time of negotiation. In this context, negotiation becomes a continuous process. A Benchmark Agreement 'allows for revisiting and changing agreements as relationships change, making negotiation a continuous, ongoing process' (Teuteberg, 2015:59). A single agreement, which may come in the form of a contract, is 'certainly not a conclusion', but merely a document of transitory status in which 'nothing is ever definitively closed' (Cohen, 1997:200). Relationships are openended, and as such, so are agreements within those relationships. The agreement is subject to the relationship and the predominant aspect of the relationship is the power relationship. This does not mean that high-context parties enter into contracts in the low-context idea of 'bad faith', or with 'malicious intent'.

Cohen (1997:201) contends that in high-context cultures, unforeseeable difficulties arising in future are renegotiated in a 'spirit of goodwill.' Teuteberg (2015:59) provides a summary of thinking in this context: 
High-context negotiators insist that the context reveals historical wrongs committed by one party over the other. 'Goodwill' then, as derived from the above, requires the perpetrator to appease the victim in the negotiating process, and places pressure on the perpetrator to accept terms of settlement that go some way to amending these historical wrongs. Therefore, a culture of ongoing negotiation is cultivated and required.

According to Du Toit (2001:102): 'From this perspective, the goodwill necessary for sustaining the process of negotiating for peace has to derive from joint recognition of the justness of the cause of one party over the other, and from their joint, but not identical, contributions to right some large historical wrongs.' Du Toit proceeds to ask the question whether South Africa represents a process based on good faith or on goodwill. He concludes that this is a 'crucial, but under researched aspect of the process.' (2001:104). He goes on to say that the ANC seemed to openly view negotiations as a 'fifth pillar of the struggle' - from which could be inferred that their view of the negotiation process would fail to deliver the irreversible outcome the NP wished to achieve. Joe Slovo, a seminal figure of the ANC struggle, argued that good faith was immaterial to the process and that negotiations were but a strategy toward the ANC achieving complete victory. On the other hand, Nelson Mandela appears to have wanted to negotiate in good faith.

Teuteberg (2015:213) finds that the 'Benchmark Agreement is not as easily operationalised as in its nature it is fluid and changeable. This type of agreement tends to be found in cultures that regard contextual factors, located within the particular history of conflict as salient. This kind of agreement tends to focus on past injustices, and tend to identify victims and perpetrators, with the concomitant implication that all negotiators are not equal in moral standing.' Historical context plays a formative role in how high-context negotiators react toward each other, and as such has the ability to shape, or at least act as a factor in, negotiations and their outcome. Within high context cultures, a lot of focus is placed on who holds the moral high ground in negotiations. Historical context may favour one party over the other in terms of morality, or one party may view itself as having the moral high ground because of past injustices. Third parties may also assign participating parties moral high ground when entering into negotiations.

Parties who enter into negotiations believing they hold the moral high ground may see themselves as being entitled to the bargain falling in their favour. Those who believe themselves to hold the moral high ground tend to expect more concessions 
from their opponents. This perceived 'unequal standing' usually stems from past injustices where one party is considered by the other party to have acted immorally, unfairly or wrongly toward the other.

Present within the benchmark perception of the outcome is the idea that the outcome, or bargain, is subject to a larger, and definitely superior, objective. The settlement, or outcome, reflects only the commitment and relationship at the time of the negotiations, and is not intended to be governing 'law' with any sense of permanence. The settlement is a means to a larger end.

Instead of signifying the end of a relationship between the opposing parties, the negotiations and the outcome thereof signifies the beginning of an ongoing and changing relationship. The settlement is instrumental in reflecting the power relationship at the time of the negotiations, and may further shape the relationship, but will become obsolete as the relationship changes.

The view of the settlement as temporary as opposed to permanent is the basis of the benchmark view. Du Toit (2001:102) terms it as such: 'The agreement does certainly not hold the status of an irrevocable contract, but is always subject to renegotiation, to reinterpretation, and is as fluid as the ongoing relationship is indeterminate.

\section{Elements/Components typical of a Benchmark Agreement from the South African Constitution (1996)}

Teuteberg (2015:140) writes that 'while in itself a Benchmark Agreement does not necessarily take the form of written agreement, certain elements contained within a written agreement may allude to the existence of such an agreement'. Phrasing used within the written constitution may point to the intention to 'address past injustices, the superiority of a larger goal in the minds of some authors, as well as the overall status of the document being of a permanent or transitory nature.'

There is clear evidence in the 1996 constitution that righting past injustices was on the agenda, as well as ensuring that these types of injustices do not happen again. Wording from the 1996 Constitution (emphasis added) indicates an allusion to this type of thinking:

- Preamble 'Recognise the injustices of our past... Heal the divisions of the past and establish a society based on democratic values, social justice and fundamental human rights...'

- In Section 25: Property: (7) A person or community dispossessed of property after 19 June 1913 as a result of past racially discriminatory laws or practices is 
entitled, to the extent provided by an Act of Parliament, either to restitution of that property or to equitable redress.

- Section 195: Basic values and principles governing public administration (1) (i) Public administration must be broadly representative of the South African people, with employment and personnel management practices based on ability, objectivity, fairness, and the need to redress the imbalances of the past to achieve broad representation.

\section{Two Negotiators: Mac Maharaj \& Thabo Mbeki}

\section{Mac Maharaj}

Mac Maharaj, who formed part of ANC lead negotiator Cyril Ramaphosa's team during the negotiations, and later negotiated directly with Fanie van der Merwe of the NP can be associated with the benchmark view. A series of interviews by Patti Waldmeir and Padraig O'Malley provide the basis for the assessment of Maharaj's beliefs and opinions, with a follow up, in-depth interview by the author, originally cited in Teuteberg (2015).

Maharaj explains the act of negotiating: 'Compromises and concessions are very interesting for selling a package... Good line, good persuasion, useful negotiating tactic.' (1993). To Maharaj, negotiations between conflicting parties by nature 'mean a give and take and a compromise' (Maharaj, 2000A). In 2014, Maharaj stated that 'we started as opponents, and in the process we became partners in a process that took SA to democracy based on one-person-one-vote enshrined in the final Constitution adopted [by] the two houses of parliament sitting together as a Constitutional Assembly' (Maharaj, 2014). He was very clear that the relationship between the parties involved was 'not static' (Maharaj, 2014).

Maharaj refers to the Record of Understanding as 'a reflection of the changed balance of forces internally and externally' (Maharaj, 1997). He goes on to say that this reflected the reality that the NP was no longer a legitimate government and represented a minority. In 1994, Maharaj admitted that while he had realised that negotiations were inevitable, the ANC approach would have to be to 'pursue a strategy that doesn't say we are heading for negotiations. Build your strength so you can wage the struggle for any eventuality' (Maharaj, 1994B). Teuteberg (2015:174) finds that Maharaj was not entirely committed to the negotiations, showing that 'he would like the ANC to maintain another source of power, perhaps in order to create leverage.' 
In 1993, Maharaj claimed that the ANC used the argument of certain deals being hard to sell to their grassroots supporters as enhancing 'the moral high ground' (Maharaj, 1993). On the unilateral suspension of the armed struggle before the August 1990 negotiations which lead to the signing of the Pretoria Minute, Maharaj says that the ANC asked itself what it could do to gain the moral high ground in order to force the NP to 'respond in kind' (Maharaj, 2000B). This continued referral to the moral high ground as a bargaining chip is congruent with a Benchmark Agreement.

In an interview with Patti Waldmeir in 1995, Maharaj admits that he was 'very disgusted with FW [de Klerk] as a person' (Maharaj, 1995A:1). Maharaj continued to note his negative feelings on De Klerk, likening his experience to that of Nelson Mandela's losing confidence in De Klerk. According to Maharaj, De Klerk 'likes to behave like he knows, he is going to tell us how to run government' (Maharaj, 1995A:2). Maharaj found he couldn't relate to De Klerk, and referred to De Klerk as 'pretty racist' (1995A:2). Maharaj found Meyer to be a 'difficult guy', referring to him, as well as 'their culture', as 'very officious' (Maharaj, 1995A:14).

Regarding the issue of trust, Maharaj is ambivalent. He notes that he 'never approached FW [de Klerk] from the point of view do I trust him or don't I. I accepted that he will try and slip something past us' (Maharaj, 1999). He continues by saying that (Maharaj, 1999):

...trust is not the issue for me. What is important is that you recognise that you are rivals sitting at a table, that you are seeking an outcome which will give you as a particular political force greater space to gain advantage from it but that you conduct yourself in such a way that no matter how much heat is generated at the moment you are constantly keeping your eye on the ball, that you are not engaged in negotiations simply to bring it to an end so that you can revert to the earlier status quo.

On the Interim Constitution, Maharaj found that the 'other side' (the NP) held 'third power in hoping to co-opt us... we must understand the sunset clauses and the negotiating process' (1995A:4). Maharaj was hoping to manipulate the power relationship so that the ANC 'will be in the position to say now we have created the condition where we can co-opt them for our needs' (Maharaj, 1995A:4). He said that 'we [the ANC] only carry out that negotiation with that perspective with the view that once April takes place there'll be a changed relationship where our objective would be to co-opt them because we now sit in that framework' (Maharaj, 1995B). This shows an inclination toward thinking about the negotiations process as a more 
fluid and changeable agreement in the form of a Benchmark Agreement. Maharaj was hoping to change the power relationship in such a way that the ANC held the stronger position and could impose its will unilaterally.

On the issue of the Sunset Clauses and creating a vice presidential post for FW de Klerk, Maharaj said that the ANC waited to deliver this idea until they knew that both the ANC and De Klerk's personal interests could be accommodated (Maharaj, 1995A:13). By April 1995, Maharaj found that the 'transition was moving smoothly' and that they had 'it on track' (1995B). Maharaj considered the right wing to be under control, and on the issue of the economy, he noted that the ANC was ready to commit to an agreement 'that all of us can agree with' (Maharaj, 1995B).

While recognising that the NP would continue to push for permanent power-sharing, Maharaj was certain that an elected Constituent Assembly would not permanently entrench power-sharing (1993). In the period of five years in which the Government of National Unity would rule, 'the arrangements must be such that there cannot be a denial of majority rule. They must be such that they lead the country towards majority rule, an acceptance of majority rule' (Maharaj, 1993). However, in 2014, Maharaj said that he 'would assert that both in the period of the GNU and up to the present, it is seldom that cabinet decisions are arrived at through a formal vote' (Maharaj, 2014). Maharaj is adamant that while the ANC was elected 'by overwhelming majority', they continued to seek a 'spirit of consensus' (Maharaj, 2014).

On the settlement itself, Maharaj believes that it 'favoured all parties in the sense that it created the conditions where all parties could take advantage of it and benefit from it' (1997). He stated that the NP failed to make use of this opportunity by continually trying to weaken the ANC, while Mandela negotiated to become 'better and stronger' (1997).

Maharaj felt that throughout the negotiations, the NP had tried to 'co-opt' the ANC, but that the ANC had anticipated this strategy and had avoided it. Maharaj was very clear that by 1999, the constitution would not include 'enforced coalition' (1995B). Maharaj also says that 'views are not immutable, the Constitution is not mechanical. It will change. That's the nature of the convention of ideas' (2014). Maharaj continues to mention the changing power relationship and the ability of co-opting one's opponent once that relationship 


\section{Thabo Mbeki}

Thabo Mbeki, who would later become president of South Africa, played a vital role in the secret meetings leading up to the substantial negotiations in the early 1990s. Mbeki was present at the Groote Schuur Minute, and started out as leader of the ANC's negotiating team. He was later replaced by Cyril Ramaphosa. At Codesa I and Codesa II, Mbeki lead the ANC's team in Working Group 3, and he was part of Ramaphosa's team at the MPNP. The assessment of Mbeki's views relies primarily on two interviews conducted by Patti Waldmeir (1995A; 1995B) as well as a book of his speeches (Corrigan, 1999).

Mbeki specifically mentions what the NP has 'lost' and what they have 'gained'. According to him, the NP has not lost 'whatever prosperity they had, they haven't lost language and a whole manner of things', nor has the transition had a 'negative material impact on them' (Mbeki, 1995A:3). What the NP has gained, according to Mbeki, is 'a rediscovery of South Africaness - they are proud to be South African' (Mbeki, 1995A:3). He also finds the new political arrangements to be beneficial to the NP, adding that having a deputy president and several cabinet ministers meant that the NP was 'very much part of the process of governing the country... So I think in reality in terms of the trappings of power they think they have got a fair share and they probably have' (Mbeki, 1995A:3). Mbeki does not believe that anyone on the side of the NP could have 'produced a result that was any different' (Mbeki, 1995A:8).

In a book of speeches and quotes by Thabo Mbeki, Mbeki: His Time Has Come, compiled by Corrigan (1999), some insight into Mbeki's opinion on the 1993 and 1996 constitutions can be identified. More specifically, at a business conference in London in September 1990, Mbeki defined what the ANC meant by majority: 'When we speak of a majority, we refer to a political majority and not one that is defined in racial or ethnic terms. At no stage have we ever spoken of black majority rule' (Mbeki, 1990, in Corrigan, 1999:23).

In 1995, Mbeki assured the media that the ANC was not drafting an 'ANC constitution', but rather a constitution that could be supported by all South Africans (Mbeki, 1995, in Corrigan, 1999:23). That same year in a speech made in Vienna, Mbeki stated that 'nobody would lose and everybody would gain from sharing a common nationhood' (Mbeki, 1995, in Corrigan, 1999:33). At the same conference, Mbeki spoke of the development of a national consensus on 'the basic constitutional and political requirements which would assure everybody that they are assured of equal 
and inalienable rights in a free and prosperous society' (Mbeki, 1990, in Corrigan, 1999:23).

Mbeki is of the opinion that over the years that it took from negotiations to the elections, 'some kind of consensus about some things' was forming among the participants (Mbeki, 1995B). Mbeki believed that all the parties involved had one purpose: 'to get rid of apartheid and the consequences of apartheid' (Mbeki, 1995B). Because of this, Mbeki held that a 'more classical opposition' party would only emerge in time.

Mbeki is convinced that all parties had to make compromises to achieve the outcome, and the no party will be 'happy with all its provisions' (Hansard, 1996:91). He mentions specifically the Property Clause as a provision that the ANC was unhappy with, but had complied with in the spirit of 'give-and-take' (Hansard, 1996:91). In the same speech in the Constitutional Assembly in 1996, Mbeki identified the final Constitution as 'another peg in the negotiated transition process begun in 1990, but we have not yet completed that process' (Hansard, 1996:90). This type of argument is usually found in negotiators congruent with a Benchmark Agreement.

In 1998, Mbeki stated that the ANC-run government believed that 'any changes to the constitution must reflect a broad consensus. It must also involve not only the other parties in Parliament, but also the citizens of the country, who have already played such an important role in drawing up the constitution' (Mbeki, 1998, in Corrigan, 1998:24). However, Mbeki is later quoted as saying that 'the negotiations for an interim constitution were "contrived elements of a transition" necessary to end white domination. At no time did the ANC consider them "as elements of permanence"' (Giliomee, 2012:361). Mbeki felt that the constitution 'is meant to overhaul and redress socio-economic distortions and imbalances which are so deeply embedded in the fabric of society... the task of maintaining and defending the unity and the integrity of the state should be done with appreciation and sensitivity to the rich diversity of our demography, ethnicity, language, culture and environment' (Mbeki, 1995, in Corrigan, 1999:23). This type of thinking is usually exhibited when seeking an agreement akin to a Benchmark Agreement.

\section{Conclusion}

Mac Maharaj represents the Benchmark Agreement, with a clear preference towards a constantly changing agreement, a contract that evolves as society and the power 
relationships change. Thabo Mbeki shows signs of differing types of thinking, and his views are reconcilable with more than one type of negotiator.

Du Toit's question whether South Africa represents a process based on good faith or on goodwill may be answered in that negotiators have divergent opinions on this, as evidenced in Teuteberg (2015), and that certain negotiators may be associated with the concept of goodwill. Identifying those views congruent with the Benchmark Agreement proved difficult. It was found that the nature of a Benchmark Agreement as such may not be solely identifiable within the opinions or views expressed by the negotiators, specifically at the time leading up to the agreement. A Benchmark Agreement may be more easily identifiable after the outcome has been implemented (thus after 1996). The nature of the Benchmark Agreement in itself makes it difficult to identify during the initial negotiating period as often negotiators seek to conceal this view. Negotiators that have a Benchmark Agreement in mind tend toward Constitutional Contract-like agreements which are then altered by the dominant party once the power relationship has shifted decisively in their favour.

While both Thabo Mbeki and Mac Maharaj's opinions can effectively be placed within this category, it 'proved difficult to definitely place either negotiator as deliberately agreeing to the outcome in order to change it in the long run, once the power has shifted in their favour.' Both Du Toit (2001) and Teuteberg (2015) note that a study of political culture later, after 1996, may produce a more conclusive result, as well as a study of ANC policy documents, 'Strategy and Tactics' (1997; 2002; 2007; 2012). Negotiators seeking a Benchmark Agreement may make use of promises of more permanent agreements in order to advance the agreement.

\section{Bibliography}

Cohen, R. 1997. Negotiating Across Cultures: International Communication in an Interdependent World. Washington: United States Institute of Peace Press

Corrigan, T. 1999. Mbeki: His Time has Come. Johannesburg: South African Institute of Race Relations.

Du Toit, P. 2001. South Africa's Brittle Peace: The Problem of Post-Settlement Violence. New York: Palgrave.

Giliomee, Hermann. 2012. The Last Afrikaner Leaders: A Supreme Test of Power. Cape Town:Tafelberg.

Hansard. 1996. Republic of South Africa. Debates of the Constitutional Assembly. Third Session - First Parliament. 29 March to 8 May 1996. No 1.

Maharaj, M. 1993. Interviewed by O'Malley, P. 18.08.1993.

Maharaj, M. 1997. Interviewed by O'Malley, P. 13.03.1997.

Maharaj, M. 1998. Interviewed by O'Malley, P. 24.08.1998. 
Maharaj, M. 1999. Interviewed by O'Malley, P. 06.12.1999.

Maharaj, M. 2000A. Interviewed by O'Malley, P. 21.08.2000.

Maharaj, M. 2000B. Interviewed by O'Malley, P. 18.09.2000.

Maharaj, M. 2014. Interview by Teuteberg, S.M., 21 July 2014.

Mbeki, T. 1995A Interviewed by Waldmeir, P. 19.01.1995

Mbeki, T. 1995B. Interviewed by Holman, M.; Suzman, H. and Waldmeir, P. 18.06.1995.

Teuteberg, S.M. 2015 A Framework for Constitutional Settlements: An Analysis of Diverging Interpretations of the South African Constitution, PhD, Stellenbosch University. 


\title{
THE RULE OF LAW AND DEMOCRACY IN SOUTH AFRICA: CONTENDING INTERPRETATIONS OF CORE CONCEPTS
}

CHARL SWART

This contribution formed part of a doctoral study under the supervision of Pierre du Toit, Department of Political Science, Stellenbosch University

\begin{abstract}
This chapter investigates the contribution Professor du Toit made to exploring what the rule of law and democracy means in post-apartheid South Africa. The chapter presents a conceptual typology of democracy co-developed by Professor du Toit which describes two contending views of democracy: liberal and liberationist. This conceptual distinction has subsequently been verified both empirically and conceptually. Drawing on his work, I present a conceptual typology of the rule of law that describes two conceptions of thereof: liberal rule of law and social rule of law. The liberal rule of law shares many of the fundamental precepts of Professor du Toit's liberal democracy, whilst the social rule of law is closely aligned to the liberationist strand of democracy. Discord amongst South Africans on the key concepts of democracy and the rule of law may hold important implications for creating a unified citizenry and ensuring a durable and stable constitutional order. The chapter concludes by presenting possible pathways for consensus between these fundamentally divergent views of democracy and the rule of law. Nearly 20 years after the adoption of the Constitution of 1996, it may be time for South Africans to seek consensus on what type of society the constitution envisions.
\end{abstract}

\section{Introduction}

This volume illustrates the wide scope of Professor Pierre du Toit's research interests and scholarly contributions in the field of Political Science. My personal relationship with Professor du Toit started when I enrolled for a masters' study in the Political Science Department at Stellenbosch University. My interests at the time was merely to complete my degree, and I had no suspicion that survey data on land reform and the rule law Professor du Toit had available would eventually lead to the completion of a PhD. The ability to mentor and guide students, which is often times neglected in the publishing-focused modern academia is one of Professor du Toit's greatest attributes. It was his passion for Political Science and broad scope of knowledge that cultivated a deep interest in South African politics within me. 
One of his interests lies in transitional and post-conflict societies and specifically the case of South Africa's post-apartheid democratic society. In that sense, this volume comes at an opportune time, nearly 20 years after the adoption of the Constitution of 1996. It is opportune considering that according to Elkins, Ginsberg and Melton (2009) the median period of duration (or life-span) of constitutions is 19 years. After 19 years, half of the constitutions they studied ceased to be in operation. Considering such a finding, it can be argued that the South African constitution, and therefore the democratic society established after apartheid, is at a critical juncture.

Professor du Toit has argued that, since its inception, the very nature of our democracy has been contested and is therefore in danger of faltering if the fundamental differences are not addressed. Writing with Gagiano in 1996, they argued that there is no consensus on what democracy means in the South African context and, if there is no consensus about what democracy is, then there can be no consensus on how to consolidate our fledgling democratic regime. At the epicentre of such a thesis lies a simple question: what does democracy mean? On the face of it, the question appears painfully simple. However, as is the case with many challenging research questions that appear simple, the possible solutions and explanations they present are anything but straight forward. This is in part due to the fact that if democracy is a contested term, then the accompanying ideals subsumed under modern democracy are also contested. This includes, but is not limited to, notions of justice, equity, the common good and the rule of law.

Fortunately, the scope of my contribution is dedicated to highlighting the how Professor du Toit has added to understanding democracy and the rule of law in South Africa, and not in exploring all the conceptual challenges posed by the abovementioned question. Following in the footsteps of Professor du Toit, or as he would put it "standing on the shoulders of others", my humble contribution lies in attempting to gain a deeper understanding of an equally straight forward question: what does the rule of law mean? This is a question I inadvertently stumbled upon during my masters' study, and it was with the assistance of Professor's du Toit's surgical analytical ability that I was able to further explore the question in my PhD study.

The chapter will commence by highlighting that as early as 1996 Prof du Toit helped put forward a thesis that is now nearly common knowledge in the field of Political Science in South Africa, namely that there are distinct and identifiable views of what constitutes democracy in South Africa. The argument put forward by Gagiano and du Toit in 1996 was subsequently verified by public opinion surveys conducted by some of the most renowned scholars in the quantitative field as well as authors who 
employed similar dichotomous conceptions in analysing politics in South Africa, thusly validating such a theoretical argument. Thereafter the focus shifts to the rule of law, relying on the work of distinguished scholars as well as my MA work wherein it was shown that public opinion on the rule of law differs substantially between racial groups in South Africa. Before concluding, I briefly put forward my typology of the rule of law in South Africa emphasising that my work is wholly situated in that of Professor du Toit's contribution to theories of democracy within the South African context.

\section{Democracy in South Africa: Liberal and liberationist perspectives}

As early as 1996, the year of the adoption of South Africa's constitution and the question of what democracy means in the South African context was tackled by Prof du Toit. Gagiano and u Toit (1996) explored the meaning of democracy within the South African context and argued that there are two distinctly identifiable views of democracy and labelled them as the liberal and liberationist perspectives. The work by Gagiano and du Toit (1996) was a one of the earliest pieces dealing with a central question confronting the new South Africa and other transitional societies namely, what does democracy mean?

The difference between the liberal and liberationist perspectives of democracy can be illustrated by highlighting how they differ on the concepts of inequality and transformation. The liberal view, which is primarily focused on maximizing individual freedom, holds that inequality in the distribution of economic, political and social power hampers the freedom and autonomy of individuals (Gagiano and du Toit, 1996:50-59). The liberal view postulates that inequality can be mitigated by ensuring a clear separation of the political, social and economic spheres. This would ensure that a single power bloc does not have simultaneous influence in all three spheres. Such an arrangement will, according to the liberal view, ensure that individuals can enjoy the greatest sphere of autonomy. Furthermore, the individual is the primary focus in relation to transformation within the liberal framework. For the subscribers of this view, transformation "...entails the transformation of members of society into individuals" (Gagiano and du Toit, 1996:54). Successfully addressing the challenges of transformation and inequality in this strand of democracy requires a strong, independent state and the principle of rule of law - all individuals must be treated equally before and under the law. This notion of liberal democracy therefore subscribes to many of the normative precepts associated with the standard liberal democratic theory. In essence, for those subscribing to this view, "[d]emocracy ... is 
about the rules that secure the boundaries of state, civil society and economy" (du Toit, 2006:3).

In contrast, the liberationists have a diametrically opposed views to addressing the challenges posed by inequality and transformation (Gagiano and du Toit, 1996:59-64). The liberationist strand draws support from the previously disadvantaged majority in South Africa and holds that democracy is more than a means of safeguarding rights and upholding the legal order. For them, democracy has a distinct emancipatory goal and is viewed as the next site of the liberation struggle. The liberationist strand is grounded firmly in the Marxist thesis that capitalist societies are fundamentally unequal. In order to rectify such inequalities, the state must actively distribute and allocate resources. The state can therefore not act as custodian or neutral referee that maintains the separation of the political, social and economic spheres of society. "What the liberals see as the remedy, the liberationists interpret as the problem" (Gagiano and du Toit, 1996:61).

Accordingly, the liberationists view of transformation is also fundamentally different than that of the liberal strand. According to the liberationists, transformation refers to the emancipation of the previously oppressed community. Specifically, all those that were disadvantaged under the apartheid regime require the necessary social, political and economic resources in order to gain freedom. For the liberationists, transformation is not about individuals, but about groups, and specifically the groups that suffered under the apartheid regime. The liberals and liberationists therefore have completely contrasting views of the role of the state, individual autonomy, transformation and (in)equality. Published in 1996, the work by Gagiano and du Toit was one of the earliest attempts to describe the different views of democracy present within the South African context. Subsequent authors have developed similar dichotomous descriptions of democracy employed as analytic frameworks, although not all of them reach the same conclusions (Johnson, 2003; Zuern, 2009).

In a similar vein, other authors, such Pretorius (2006), have investigated how the ruling party conceptualises notions of democracy, the role of the state and the role of the individual in society. By analysing various policy and party documents of the ANC, Pretorius (1996) found that the party holds to very specific views of what constitutes of democracy and associated concepts. Importantly, this includes very particular conceptions of the demos, what the public good is, what the goal of democracy is and how these goals need to be achieved. Importantly, the view subscribed to by the ANC is somewhat exclusionary, with a focus on a particular group of people, i.e. those who were previously disadvantaged under apartheid. The role envisioned 
for the state is also far more active than a mere referee-state. Rather, within ANC vernacular, the state is the vehicle that must be used to actively ensure that certain societal goals are met, including transformation, the redistribution of public goods and addressing inequality.

The findings of Pretorius (2006) place the ANC's view of democracy in line with the liberationist perspective of democracy put forward by Gagiano and du Toit (1996). Other studies' findings focusing on how the ANC views transformation (Hudson, 2000) and equality (Stacey, 2003) also show high levels of congruence with the liberationist perspective on democracy. Suffice to say, since the publication of Gagiano and du Toit's 1996 work, numerous authors investigating wat democracy and associated concepts mean to powerful elites and the ruling party in South Africa, have produced findings that show a high level of congruence between these stakeholders and the liberationist perspective on democracy. The idea that certain groups of people in South Africa hold to identifiable and varying notions of what democracy means has also subsequently verified through studies relying on public opinion data.

Bratton and Mattes (2001), relying on extensive public opinion survey data, found that support for democracy in South Africa can be described as either intrinsic or instrumental. Intrinsic support is a commitment to democracy that does not depend on economic, social or political conditions. It is the support of democracy as an end in itself, therefore intrinsic. Contrastingly, instrumental support for democracy relies on the government's ability to provide substantive goods, such as jobs, basic services and housing. The authors found that there is a disparity amongst the racial groups in South Africa in their type of support for democracy. Bratton and Mattes (2001:455) found that "...while many South Africans of all races say they accept the necessity of redistributing jobs, houses and incomes, blacks seem to focus more on 'equality of results' while whites stress 'equality of opportunity'". This is an understandable, and socially justifiable view, if one takes into account the degree to which non-whites experienced discrimination and 'second-class' citizenship in South Africa prior to the democratic order.

However, this also illustrates that there is no consensus amongst South Africans about the type of society we are building. Different groups have contrasting, and any many cases mutually exclusive, views of what constitutes a democratic society. This contention over what our society should be, is not limited to only democracy, but stretches to one of the building blocks of democracy: the rule of law. 


\section{Public opinion on the rule of law in South Africa}

There are also studies that specifically investigate public opinion on the rule of law in South Africa. Once such study by Gibson and Gouws (1997) employed four survey items to gauge public opinion on the rule of law. The items employed to gauge respondents' opinions on the rule of law were: Sometimes it might be better to ignore the law and solve problems immediately rather than wait for a legal solution; It's all right to get around the law as long as you don't actually break it; In times of emergency, the government ought to be able to suspend law in order to solve pressing social problems; and It is not necessary to obey the laws of government that I did not vote for (Gibson and Gouws, 1997:179). The authors found that, based on responses to the survey items, many citizens feel that if the law does not produce specific outcomes, it can be manipulated, ignored or bypassed (Gibson and Gouws, 1997:188). The attitudes expressed also showed a marked difference between the racial groups in South Africa. Suport for universalism and the rule of law showed higher levels of support amongst white respondents than black respondents (Gibson and Gouws, 1997:188).

Twelve years later, investigating support for redistributive land policies in South Africa, Gibson (2009a), employed some of the same items as the Gibson and Gouws (1997) study, and also concluded that support for rule of law and legal universalism in South Africa is limited. Gibson (2009:158) also found large differences between racial groups with black South Africans supporting fewer of the rule of law statements, followed by coloured and Asian South Africans, with white South Africans showing the highest level of support (Gibson, 2009a:158). Again, the different opinions of held by varying racial groups is understandable considering the history of apartheid South Africa. The point here is not investigate causal mechanisms or to seek explanatory variables, but merely to show that there are different views of the rule of law present amongst different groups of South Africans. The race-based classification is the unfortunate legacy of our discriminatory history.

It is within this sub-field of Political Science that my path crossed with that of Prof du Toit as he had survey data available on public opinion on land reform that could be used for a MA study. The dataset in question was from surveys carried out by IpsosMarkinor in 2004 and 2007 amongst the general population. The samples and items, although not large in scale, offered the opportunity to further explore what South African thought about land reform and its relationship to the rule of law. The surveys included four items, of which three are of relevance here. The items were framed as statements to which respondents were required to list their level of agreement on a five point Likert scale. The relevant items were: landowners who dispute land claims 
by going to court are racist; landowners who dispute land claims by going to court are blocking transformation; and landowners who dispute land claims by going to court are fairly using the rights awarded them by the constitution. Support for the rule of law was indicated by disagreement with the first two statements, and agreement to the last.

The responses were similar to those of the studies cited above showing a difference in responses between racial groups, with white respondents showing a higher level of support for the rule of law than the other racial groups, and black respondents showing lowest level of support (Swart, 2010). Interestingly, all respondents, regardless of race, showed support for the last statement. This level of support for the rule of law was found by both Gibson (2009a) and Swart (2010), who noted that all racial groups in the country do have a level of support for the rule of law. In my masters' study all racial groups supported the notion that disputing land claims in court is a constitutional right, and Gibson (2009:149) found that "...South Africans of every race believe it quite important that land policy should be based strictly on the law." Taken together with the work by Gibson (2009a) showing that South Africans wish land reform to follow the law, as well as the works by Carter (2011), Du Toit and Kotzé (2011) and Gibson (2009b) which demonstrate that South Africans have faith in the intuitions associated with the rule of law, an argument can be made that even though South Africans believe in the rule of law, they may attach fundamentally divergent values and beliefs to the ideal. This is based on the notion that all South Africans show a level of support for the rule of law, even when it is juxtaposed to a substantive and emotive issue, that of land reform. The challenge then becomes to make sense of such a finding. How is that racial groups can have polarising views on the rule of law, yet still believe in it? What then, does the rule of law mean in South Africa?

\section{Contending interpretations of the rule of law in South Africa}

Before one can explore possible typologies for categorising and analysing different views of the rule of law it is necessary to explore what the concept means in a normative sense. One of the more concise definitions of the concept was put forward by Hayek (1944:75-76) who argued that: "Stripped of all technicalities this means that government in all its actions is bound by rules fixed and announced beforehand - rules which make it possible to foresee with fair certainty how the authority will use its coercive powers in given circumstances, and to plan one's individual affairs on the basis of this knowledge." However succinct as this definition may be, it does not 
address the relationship between democracy and the rule of law, nor does it address the values that may or may not be attached to the ideal.

The relationship between democracy and the rule of law is an interesting one. In a sense, the two concepts have become indistinct in modern notions of liberal democracy. This can, in part, be attributed to the notion that for a democracy to thrive and become consolidated, it requires the rule of law. Diamond and Morlino (2004:23) note that the "...rule of law is the base upon which every other dimension of democratic quality rests". Other authors writing in the field of democratic consolidation also note the necessity of rule of law in order for a regime to be considered democratic and for democratic consolidation to take place (Linz and Stephan, 1996; Bratton and Chang, 2006). The prominence of the rule of law within democratic regimes is also observable in the spread of the concept throughout the post-communist Eastern European states (Esquith, 1999) and a host of countries and regimes ranging from Russia, Indonesia, Mexico, China, Zimbabwe, and even the Taliban (Tamanaha, 2004:2). Carothers (1998:95) remarked that the "...concept is suddenly everywhere..." with a range of regimes claiming to be, in some way or another, involved in rule of law reform initiatives.

What makes the rule of law so peculiar is that it has gained a level of global endorsement that no "...other single political ideal has ever achieved" (Tamanaha, 2004:3). Furthermore, despite such global endorsement by a range of regimes, there is no "...agreement upon precisely what it means" (Tamanaha, 2004:4). The rule law is therefore peculiar in the sense that most people, regardless of their political orientations and views of democracy and associated ideas, believe in the ideal without there being any form of consensus of what it is they believe in. The variance found within definitions and conceptions of the rule of law has thankfully been explored by other scholars. One such a typology of conceptions is put forward by Tamanaha (2004) and is presented below in figure 1. The literature on the rule of law suggests that one of the main distinctions that can be drawn between different definitions of the term is that of formal and substantive versions.

The difference between formal and substantive versions of the rule of law is explained by Craig (1997:467) as follows: "Formal conceptions of the rule of law do not however seek to pass judgement upon the actual content of the law itself. They are not concerned with whether the law was in that sense good law or bad law, provided that the formal precepts of the rule of law were themselves met. Those who espouse substantive conceptions of the rule of law seek to go beyond this. They 
accept that the rule of law has the formal attributes mentioned above, but they wish to take the doctrine further."

Thinner

\begin{tabular}{ll}
\hline $\begin{array}{l}\text { Formal } \\
\text { Versions }\end{array}$ & $\begin{array}{l}\text { 1. RULE-BY-LAW } \\
\text { law as instrument of } \\
\text { government action }\end{array}$ \\
$\begin{array}{l}\text { Substantive } \\
\text { Versions }\end{array}$ & $\begin{array}{l}\text { 4. INDIVIDUAL RIGHTS } \\
\text { property, contract, privacy, } \\
\text { autonomy }\end{array}$
\end{tabular}

to Thicker

\section{DEMOCRACY +} LEGALITY

general, prospective, clear certain

consent determines content of law

\section{Social Welfare}

substantive equality, welfare, preservation of the community

FiguRE 1 Varying rule of law formulations (Source: Tamanaha, 2004:91)

Formal conceptions of the rule of law are therefore not concerned with the content or outcomes of the law, but rather with the process whilst their substantive notions place greater emphasis on the nature of the laws and what is to be achieved therewith. Within the South African context, this has a particular relevance due to the discriminatory nature of the legal system under apartheid. Dyzenhaus (2007:735) has noted that the "...apartheid legal order implemented a racist ideology through law but was formally no less committed than the new order to both the supremacy of the constitution and the rule of law. If one ignored the ideology and focused on the formal features of the apartheid legal order, it replicated the constitutional structure of the British legal order". Due to the historic role of the rule of law, the nature of our constitution and the spirit of democratic society, the conception of the rule of law present in democratic South Africa will not be a strictly formal and legally orientated version of the ideal. However, this does not mean that there is clarity or consensus on what the rule of law means in democratic South Africa. In a way, the question about what democracy means in South Africa is mirrored in the rule of law. The conceptual typology of democracy as put forward by Gagiano and du Toit (1996) and the public opinion surveys of democracy and the rule of law illustrate South Africans hold to varying opinions of both these concepts. The challenge lies in creating a conceptual typology with which to classify and describe such varying views.

In order to achieve this, I drew heavily on the work of Gagiano and du Toit (1996) highlighting the congruence between liberal and liberationist democracy, and liberal and social rule of law respectively. The interpretive framework is presented in table 1. The development of the conceptual typology of the rule of law was verified 
empirically by applying it to a specific case, the AfriForum v Malema hate speech case. Social and liberal rule law can be differentiated on the grounds of three main elements (Swart, 2013:89-90):

- whether the rule of law serves the interests of all individuals in society or that of specific communities or collectivities. All individuals are either treated equally, or some individuals, collectivities, groups or communities are given preferential treatment based on their group affiliation, i.e. whether the individual or the group is afforded more status in society;

- whether the rule of law promotes a specific conception of the public good and if such a conception is one that affords primacy to a group or collectively, or whether the conception of the good is one that promotes creating a rule based society that affords every individual the opportunity to pursue their own conception of the good; i.e. whether the public good allows moral pluralism or whether it is collectively determined (by the state or government);

- whether the rule of law is implemented in order to entrench legal, social, political and economic norms for ensuring a stable society for tomorrow, or as a tool for righting past legal, social, political and economic injustices; i.e. is the rule of law orientated towards rewriting historic injustices (backward-looking) or creating a predictable rule based society of the future (forward-looking).

TABLE 1 Interpretive framework of democracy and the rule of law

\begin{tabular}{|c|c|c|}
\hline & Liberal Rule of Law & Social Rule of Law \\
\hline Democracy & $\begin{array}{l}\text { - Liberal: focus on individual freedom and } \\
\text { autonomy } \\
\text { - Autonomous state with separation of spheres of } \\
\text { government } \\
\text { - Goals of democracy are: } \\
\text { 1. Create a rule-based society } \\
\text { 2. Transform society to ensure individual } \\
\text { autonomy } \\
\text { 3. Create framework for future society based on } \\
\text { individual rights }\end{array}$ & $\begin{array}{l}\text { - Liberationist: focus on group welfare } \\
\text { - State seen as vehicle for emancipation, } \\
\text { amalgamation of spheres of government to } \\
\text { concentrate power } \\
\text { - Goals of democracy are: } \\
\text { 1. Create a material outcomes-based } \\
\text { society } \\
\text { 2. Transform society to ensure welfare of } \\
\text { specific group(s) } \\
\text { 3. Create institutions to correct past } \\
\text { wrongs and further group needs }\end{array}$ \\
\hline Rule of law & $\begin{array}{l}\text { - Individual of utmost importance } \\
\text { - Negative liberty } \\
\text { - Formal equality } \\
\text { - Goal of rule of law is to create and maintain a } \\
\text { rule-based society } \\
\text { - Emphasis on future - focus on creating society } \\
\text { for future with little importance placed in } \\
\text { historical context } \\
\text { - Allows for multiple conceptions of the good, } \\
\text { moral pluralism }\end{array}$ & $\begin{array}{l}\text { - Community of utmost importance } \\
\text { - Positive liberty } \\
\text { - Substantive equality } \\
\text { - Goal of rule of law is to confer power, } \\
\text { wealth and preference onto specific group } \\
\text { - Emphasis on past - focus on rectifying } \\
\text { injustices of the past and the importance of } \\
\text { historical context } \\
\text { - Subscribes to specific conception of the } \\
\text { good, the 'public good' }\end{array}$ \\
\hline
\end{tabular}




\section{What should the rule of law mean in South Africa?}

Even though the conceptual framework presented above is verified on both empirical grounds and within other studies that rely on similar conceptual distinction, it still does not address the problem of what the rule of law in post-apartheid South Africa 'ought' to mean. The problem is neatly captured by Dazenhaus (2007:739) who warns that "...a commitment to the substantive conception of the rule of law cannot settle contention about the rule of law, since the content of that commitment remains controversial". The danger of a conception of the rule of law that relies too heavily on the social rule of law that is too closely entwined with notions of social justice is that it can "...become a hapless victim to the fierce moral and ideological conflicts of our time" (Mathews, 1986: 13).

There are aspects of both the liberal and social rule of law that need to be retained and discarded. The liberal rule of law's focus on individual freedom and autonomy needs to be strengthened in the South African context. Importantly though, this can and should not be done to the detriment of the most vulnerable groups of society. The state must ensure the continued expansion and delivery of basic services such as health care, education and housing to the millions of South Africans who did not enjoy access to such services under the apartheid regime. However, all minority groups in South Africa need to be ensured that their rights are not infringed upon in the name of the 'public good' or in the guise of 'building democracy'. Individual freedom and autonomy must be respected and the state must allow for moral pluralism. Moral pluralism is a central tenant of modern liberal democracy and must be respected in order to facilitate the consolidation of democracy.

Crucial to any conception of the rule of law is the notion of compliance to the law by all, from the president to the pauper. Within the South African context, the role and powers of the public protector need to be clearly defined and adhered to in all cases. The independence of the courts remains paramount in order to ensure democratic stability. Courts are the custodians of constitutional regimes. Thankfully the sanctity of the courts continues to remain a sacrosanct within the South African democracy.

In line with the independence of the courts, is the composition of the judiciary. Currently, the Judicial Service Commission (JSC) is responsible for making recommendations on appointments to the President, who selects judges from those proposed by the JSC. The composition of the JSC is however highly politicized with the majority of the body being of political nature, and more specifically ANC representatives. This ensures that the ruling party has an undue level of influence 
in the selection of judges and the composition of the judiciary. The JSC must retain space in its ranks for more legal representatives, and particularly for women from the legal fraternity as well as groups representing minority interests.

Finally, all South Africans need to have an open and frank discussion about our history. Those who subscribe to the liberal rule of law cannot continue to ignore past injustices that manifest as contemporary inequalities. The unrest on university campuses across South Africa in late 2015 is a symptom of the frustration felt by millions of young South Africans. However, those who subscribe to the social rule of law also need to be honest about the role of history, and importantly be honest about our recent history - namely the 20 years of democracy. Can those who claim that apartheid is responsible for all the injustices in society, honestly say that the ANC led government has done everything in their power to educate, care for, uplift and provide freedom for millions of disadvantaged South Africans? Public protests in the guise of "service delivery protests" would provide sufficient evidence that this may not be the case. The same can be said for chronic corruption and abuse of state power for personal gain. Are the people being put first in democratic South Afirca?

\section{Conclusion}

This chapter presented a typology for the classification of the rule of law that is grounded in a typology of democracy co-developed by Professor du Toit. It is my hope that the distinction between social and liberal rule of law can be employed as an analytical construct by other authors interested in the complexities of democracy and the rule of law in South Africa. The work by Professor du Toit on the meaning, nature and future prospects of the post-apartheid South Africa has left a footprint in the landscape of Political Science in South Africa. The conceptual typology presented here was influenced and guided by his knowledge and insight into the field Political Science in South Africa and other transitional regimes.

I cannot hope to pay adequate tribute to the contributions made to the field of Political Science by Professor du Toit other than re-stating that his work on conceptions of democracy was one of the earliest attempts to make sense of what democracy means in South Africa. I can only add, in my personal capacity, that Professor du Toit has shaped and influenced me as a scholar and academic in a manner that will forever influence how I think about political and social problems. The lessons of academic and analytic rigour imparted onto me are invaluable and I hope that my future work can live up to the standard he has set. 


\section{Bibliography}

Bratton, M. and Chang, E. C. C. 2006. State Building and Democratization in SubSaharan Africa: Forwards, Backwards, or Together? Comparative Political Studies, 39(9): 1059-1083. https://doi.org/10.1177/0010414005280853

Bratton, M. and Mattes, R. 2001. Support for Democracy: Intrinsic or Instrumental. British Journal of Political Science, 31: 447-474. https://doi.org/10.1017/S0007123401000175

Carothers, T. 1998. The Rule of Law Revival. Foreign Affairs, 77(2): 95-106. https://doi.org/10.2307/20048791

Carter, D. 2011. Sources of State legitimacy in Contemporary South Africa: A Theory of Political Goods. Afrobarometer, Working Paper no. 134. [Online]. Available: http:// www.afrobarometer.org/publications/working-papers/184-wp-134 [26 May,2013].

Craig, P. 1997. Formal and Substantive Conceptions of the Rule of Law: An Analytical Framework. Public Law. 1997:467-487.

Diamond, L. J. and Morlino, L. 2004. The Quality of Democracy. Journal of Democracy, 15(4): 20-31. https://doi.org/10.1353/jod.2004.0060

Du Toit, P. 2006. "The Rule of Law, Public Opinion and the Politics of Land Restitution in South Africa." Paper presented at conference on Land, Memory, Reconstruction and Justice: Perspectives on Land Restitution in South Africa. Houw Hoek.

Du Toit, P. and Kotzé, H. 2011. Liberal Democracy and Peace in South Africa.: The Pursuit of Freedom as Dignity. Great Britain: Palgrave Macmillan. https://doi.org/10.1057/9780230116320

Dyzenhaus, D. 2007. The Pasts and Future of Rule of Law in South Africa. South African Law Journal, 124(4): 734-761.

Elkins, Z., Ginsberg, T., and Melton, J. 2009. The Endurance of National Constitutions, Cambridge: Cambridge University Press. https://doi.org/10.1017/CBO9780511817595

Esquith, S. L. 1999. Towards a Democratic Rule of Law: East and West. Political Theory, 27(3): 334-356. https://doi.org/10.1177/0090591799027003002

Gagiano, J. and du Toit, P. 1996. Consolidating Democracy in South Africa: The Role of the Civil Society. In: H. Kotze, (ed). Consolidating Democracy: What Role for Civil Society? Stellenbosch: Centre for International and Comparative Politics.

Gibson, J. L. 2009a. Land Redistribution/Restitution in South Africa: A Model of Multiple Values, as the Past Meets the Present. British Journal of Political Science, 40(1): 135-169. https://doi.org/10.1017/S0007123409990378

Gibson, J. L. 2009b. The Evolving Legitimacy of the South African Constitutional Court. In: Du Bois, F. and Du Bois-Pedain, A. (eds.) Justice and Reconciliation in PostApartheid South Africa. New York: Cambridge University Press. https://doi.org/10.1017/CBO9780511575419.010

Gibson, J. L. and Gouws, A. 1997. Support for the Rule of Law in the Emerging South African Democracy. International Social Science Journal, 49(52): 173-191. https://doi.org/10.1111/j.1468-2451.1997.tb00015.x

Hudson, P. 2000. Liberalism, Democracy and Transformation in South Africa. Politikon, 27(1): 93-102. https://doi.org/10.1080/02589340050004118 
Johnson, K. 2003. Liberal or Liberation Framework? The Contradictions of ANC Rule in South Africa. Journal of Contemporary African Studies, 21(2): 321-340. https://doi.org/10.1080/02589000305442

Hayek, F. 1944. The Road to Serfdom. London: Routledge.

Linz, J. J. and Stephan, A. 1996. Towards Consolidated Democracies. Journal of Democracy, 7(2): 14-33. https://doi.org/10.1353/jod.1996.0031

Mathews, A.S. 1986. Freedom, State Security and the Rule of Law: Dilemmas of the Apartheid Society. Cape Town: Juta \& Co, Ltd.

Pretorius, L. 2006. Government by or Over the People? The African National Congress's Conception of Democracy. Social Identities, 12(6): 745-769. https://doi.org/10.1080/13504630601030933

Stacey, R. 2003.'We the people': The Relationship Between the South African Constitution and the ANC's Transformation Policies. Politkon, 30(2): 133-148. https://doi.org/10.1080/0258934032000147264

Swart, C. 2010. Public Opinion on Land Reform in South Africa. MA. Stellenbosch University, Stellenbosch.

Swart, C. 2013. Contending interpretations of the rule of law in South Africa. PhD. Stellenbosch University, Stellenbosch.

Tamanaha, B. Z. 2004. On the Rule of Law: History, Politics, Theory. Cambridge, United Kingdom: Cambridge University Press. https://doi.org/10.1017/CBO9780511812378

Zakaria, F. 1997. The Rise of Illiberal Democracy. Foreign Affairs, 76(22): 23-43. https://doi.org/10.2307/20048274

Zuern, E. 2009. Democratization as Liberation: Competing African Perspectives on Democracy. Democratization, 16(3): 585-603. https://doi.org/10.1080/13510340902884770 


\section{PERCEPTIONS OF EVIL AND THE EROSION OF SOCIAL CAPITAL IN SOUTH AFRICA}

Cindy STEENEKAMP AND REINET LOUBSER

\section{Introduction}

There are a plethora of empirical studies that highlight the importance of social capital to a wide range of socio-economic phenomena. Social capital is important for the efficient functioning of modern economies and stable liberal democracy. It also provides a base for co-operation across sector and power differences as well as being an important product of such co-operation (Brown and Ashman, 1996; Fukuyama, 2001). Social capital is also charged with a range of potential beneficial effects including: facilitation of higher levels of, and growth in, gross domestic product; facilitation of more efficient functioning of labour markets; lower levels of crime; and improvements in the effectiveness of institutions of government (Aldridge et al, 2002; Halpern, 2001; Kawachi et al, 1999; Putnam, 1993). Social capital is an important variable in educational attainment (Aldridge et al, 2002; Israel et al, 2001), public health and wellbeing (Steenekamp, 2011: 48-50), and community governance. The practical implications of social capital are thus broad and profound and inherently beneficial for those individuals and communities that possess it. It is hardly surprising then, that forging a unified society with strong social ties across communities - social cohesion - has been a significant developmental goal in democratic South Africa.

While the generation of social capital can be seen to support social norms, such as trust and tolerance, as well as co-operation between groups and communities and generally pro-social values and behaviour, the belief in evil and evil forces have a direct adverse effect on interpersonal relations and co-operation (Gersham, 2016: 183). The belief in evil, magic and witchcraft is a cultural phenomenon that features in the daily lives of many South Africans. Sensationalist stories of evil, witchcraft, demons and the like frequently appear in South Africa's tabloid newspapers like the Daily Sun. The belief in witchcraft and the fear and practice thereof plays a significant 
role in various instances of violence, including witch killings, muthi murders ${ }^{1}$ and the use of magic for protection by criminals and protesters such as the striking miners at Marikana in 2012 (Labuschagne, 2004:195; van der Vlies, 2013:511). There are also numerous examples in South Africa of allegedly bewitched school pupils blaming poor academic performance and illness on witchcraft and university students reporting their fear of being harmed through sorcery by jealous relatives, friends and neighbours (Leistner, 2014:10).

The existence of such contradictory value systems - prosocial versus antisocial norms and behaviour - are highly problematic in deeply divided and developmental societies, such as South Africa. While the dimensions of social capital and the values that underpin them advance liberal democratic values, the belief in evil and evil forces serve to undermine them. This chapter utilises data from the last two waves of the World Values Survey (WVS) in order to investigate the extent to which perceptions of evil erode social capital in South Africa, if at all.

\section{The concept of social capital}

Central to social capital theory is that social networks have value and that social contacts affect the productivity of individuals and groups (Putnam, 2000:18-19). More specifically, Putnam (2000:19) defines social capital as the "connections among individuals - social networks and the norms of reciprocity and trustworthiness that arise from them". The definition of social capital is a compound of two different terms: "social" indicates that it has something to do with relationships amongst individuals and "capital" that it constitutes some kind of asset for the people who possess it.

Societies work best where citizens trust their fellow citizens, work co-operatively with them for common goals, and thus share a civic culture (Rotberg, 1999:339). A civic community is marked, in Putnam's words (1993:170), "by an active, publicspirited citizenry, by egalitarian political relations, [and] by a social fabric of trust and cooperation". Vibrant networks and norms of civic engagement are essential for such a community. In societies where distrust is prevalent and horizontal ties of mutual involvement are replaced by hierarchical politics, social capital is absent, and little civic engagement exists (Rotberg, 1999:339). Indeed, the dilemmas of collective

1 Traditional health practitioners and alleged witches make use of muthi (Zulu for medicine) to help their clients. Muthi can be made from animal, plant or even human material. When it is made from human body parts, it has usually been obtained by attacking live victims. When such attacks lead to the deaths of the victims, it is known as "muthi murder" (Labuschagne, 2004: 192-193). 
action at almost any level can best be solved through networks of reciprocal trust, a key component of social capital and an essential ingredient of democracy (Putnam, 1993:172). For political stability and government effectiveness, Putnam (1993:183) argues that "social capital may be even more important than physical or human capital."

The accumulation of reciprocal trust, as demonstrated by a variety and combination of voluntary efforts for the creation of common goods, helps to build social capital and contributes to effective government (Putnam, 1993:172). Societies with high levels of social capital function with greater, rather than lesser, participation of citizens and as such, social capital contributes to the making of civil society. In other words, a civic culture exists because citizens have accumulated large amounts of social capital. Although political culture is the term that describes how a society and a collection of leaders and citizens choose, and has long chosen, to approach national political decisions, high levels of social capital contribute to the creation of a political culture that is open, pluralistic, deliberative, tolerant, and democratic (Putnam, 1993:33-38). These are some of the propositions advanced to explain why countries or regions within countries display high levels of civic engagement and democratic performance over years and decades, and why other countries and regions do not. Conversely, these propositions imply that without healthy levels of volunteerism, civic engagement, reciprocal trust, and citizen involvement in politics, civil society will not flourish, nor will plural democracy (Rotberg, 2000:340).

Even if there are variations in the content and components of social capital, most will agree that the concept basically refers to social connections that facilitate coordination and co-operation amongst people. So what is social capital composed of? Most forms can be seen to have three basic dimensions: social trust, social tolerance and social networks.

Social trust is the most frequent dimension in different approaches to social capital. Broadly understood, trust is about the expectations of the behaviour of others. Earle and Cvetkovich (1995:38) suggest that trust represents "a simplifying strategy that enables individuals to adapt to complex social environments, and thereby benefit from increased opportunities". Whilst Newton (2004:17) posits that trust is the "belief that others will not deliberately or knowingly do us harm, if they can avoid it, and will look after our interests, if this is possible". For Putnam (1993: 168), trust is the most important dimension of social capital, the one that facilitates citizens' cooperation. He also draws a distinction between generalised and the particularised trust. Particularised trust stems from our personal relationships with certain people 
i.e. "trust embedded in personal relations that are strong, frequent, and nested in wider networks is sometimes called thick trust" (Putnam, 2000:136). Opposite of this would be trusting the members of our own community whom we do not know, which Putnam (2000:136) calls generalised or thin or social trust, is an integral part of social capital as it enables us to extend the scope of trust beyond the circle of people we know personally.

Tolerance can be defined as "putting up with something that one does not like" (Vogt, 1997:1). Tolerance thus involves "support for the rights and liberties of others; others of whom one dislikes, disapproves of, disagrees with, finds threatening, or toward whom one has some other negative attitude" (Vogt, 1997:xxiv). In addition, tolerance can also vary according to the object of tolerance. Vogt (1997:17-20) identifies three overlapping but distinct categories of tolerance defined by its objects: political, social and moral. Political tolerance refers to tolerance of "acts in the public sphere", such as giving a speech, demonstrating, distributing leaflets etc, as is fundamental because it is important for winning and maintaining tolerance of other kinds. Moral tolerance refers to the tolerance of "acts in the private sphere". Most typically, and controversially, in recent decades this has concerned sexual conduct, such as "living in sin", pornography, homosexuality and abortion. Social tolerance, on the other hand, is tolerance of "people's state of being". That is, of characteristics people have at birth, such as skin colour, or as the result of early socialisation, such as language. For the purposes of this chapter, tolerance is defined by moral and social objects; i.e. all of those acts which take place in the private sphere and those concerned with an individual's state of being.

Voluntary associations are defined as "organisations that have a high degree of autonomy and whose members are relatively free to join or leave the organisation" (Fennema, 2004:431). Putnam (2000:65-78) argues that participation in voluntary associations generates social capital by supporting norms of reciprocity and civic engagement, building social trust, and providing networks of social relations that can be mobilized for civic action. Wang and Grady (2008) posit that there are four types of social networks: bridging social networks, informal social networks, civic engagement, and organised group activism. Social networks generally include bonding and bridging networks (Putnam, 2000). The former refers to networks among homogenous groups of people, while the latter refers to networks among heterogeneous groups. Bridging social networks represent the extent and diversity of social relations in which people engage. Individuals who have friends from different social backgrounds are expected to be more open and respectful of others. The 
second type, informal social networks, refers to interactions among family, friends, and others. These types of interaction foster a sense of reciprocity and caring among people, which are deemed to be virtues that lead to philanthropy (Martin 1994). The third type, civic engagement, refers to formal group involvement. Through group involvement, individuals build a sense of connection with another or categorising another as a member of one's own group (Jackson et al, 1995:74). The final type, organised group activism, refers to the extent of civic participation. Being a member of an organisation is different from actually attending local community events, club meetings, and public meetings. If being a member shows the breadth of an individual's social network, actual participation in organized group activities indicates the depth of the network.

\section{The concept of evil}

In the secular imagination the word "evil," when it is used at all, describes a particularly bad or exceptionally wrongful act. It refers to an act that is worse, more unreasonable or more prohibited than regular wrongdoing. The act is not necessarily perpetrated on a large scale, but is borne out of a lack of mercy and conscience (or the deliberate silencing of the conscience) (Garrard, 1998:44-60). Indeed, psychologist Simon Baron-Cohen (2011) argues that a lack of empathy due to restricted brain functioning lies at the root of some people's extremely inconsiderate and harmful behaviour.

Regardless of the science behind excessive wrongdoing, most secular societies - including most established liberal democracies - view wrongdoers as simply misguided or ignorant rather than inherently malicious or sinful (Glenna, 2002:207). People are believed to be fundamentally good and their harmful acts are seen as mistakes which can be corrected through education. Criminals are therefore rehabilitated rather than punished. The secular conception of evil is devoid of the supernatural, the religious and the spiritual. In fact, the latter is often seen as superstition. Although this view of evil - a person lacking in empathy or conscience

- can still be disturbing, it nevertheless identifies the root of evil as human and therefore in our power to correct (Loubser, 2015:41).

Unlike most established liberal democracies, South Africa remains a very religious country.

The secular conception of evil is therefore of limited value in a multicultural country which - despite its predominant Protestant Christianity - is in practice home to diverse religious and spiritual beliefs and practices. Thus in addition to the secular 
notion, two further conceptions of evil can be identified: the traditional Christian conceptualisation and the traditional African one (Loubser, 2015:31-41).

In Christianity, as in the other Abrahamic faiths, the world is traditionally viewed as a battlefield between good and evil, personified by two spiritual beings: God and the Devil. God is considered omnipresent and omnipotent and his prescriptions are to be adhered to. Satan, on the other hand, is God's malevolent challenger who attempts to undermine him by tempting his followers away from his prescriptions. Evil - in whatever form it manifests - is the result of the machinations of Satan and his followers (du Toit and Kotzé, 2011:60-63).

In addition to the over 11.1 million South Africans who worship at mainline Protestant churches, more than 14.5 million attend the African Independent Churches (AICs) - Christian Churches that also preserve traditional African customs (Rule, 2007:419421). Like other parts of the developing world, South Africa has also experienced a growth in Pentecostal and Charismatic sects (South African Institute of Race Relations [SAIRR], 2012: 81-83; 2014: 68).

The Pentecostal churches have over 6.8 million members and are characterised by the belief that God intervenes directly in human affairs and provides direct spiritual guidance to help people in their spiritual warfare against evil forces (Rule, 2007: 419421; Jenkins, 2002: 63). Evil can take the form of outright and obvious cruelty, but it can also manifest in small, subtle ways. Thus everything from a murder to mundane bureaucratic corruption and failed government policy can be perceived as the work of the devil, which must be confronted with the help of divine intervention (Loubser, 2015: 34).

A similar, literal conception of evil also exists in traditional African spiritual beliefs. The African spiritual world traditionally consists of benevolent and malevolent actors, both human and spiritual (Ashforth, 2010: 100). The power of the spirit world is harnessed by those who can communicate with them and used for either good or ill. Similar to Pentecostal belief, humans and spirits who are evil can perpetrate any kind of harm, be it poverty and disease, seemingly random car accidents or an individual's decision to commit suicide (Niehaus, 2012:36-37).

In traditional African belief, good fortune (or luck) is a finite resource of which everyone receives an equal share. A person who appears to be exceptionally successful is thus often suspected of foul play as one can only be so fortunate if one has somehow appropriated more than one's fair share of luck (Labuschagne, 2004: 193). A very successful person must have used supernatural means to steal from 
the good fortune of others, thus harming innocent people and upsetting the natural order. Someone who feels themselves to be on the receiving end of undue ill fortune, may therefore suspect deliberate evil rather than random suffering. The end result is a general fear of those who are thought capable of harnessing spiritual means to cause suffering (commonly referred to as witches) as well as the fear of becoming too successful, thus provoking jealousy, suspicion and allegations of witchcraft (Leistner, 2014:5-18).

When the natural order of life has been upset, it is necessary to engage with the spirit world. It is believed possible to manage one's relations with spiritual entities correctly and successfully. All that is needed is a powerful traditional healer ${ }^{2}$ or sangoma to help one battle the evil forces causing illness or misfortune. The sangoma communicates with the ancestors to find the source of one's troubles. The source of the evil is often identified as a person: a witch and his/her clients. When the evildoer(s) has been identified, violence sometimes follows (Loubser, 2015:36-38).

Traditional African beliefs and some Christian beliefs - particularly those endorsed by Pentecostalism - and even Western science are quite compatible in the South African context. Whereas science might explain how something happens, people often turn to religion to explain how and why it happens (Ashforth, 2005a:216). To find answers, South Africans can turn to a traditional healer (or several) or a number of religious leaders who claim to be communicating with God. Since there is no consensus from the various religious and spiritual authorities discussed above on what to do in the face of spiritual challenges, South Africans often avail themselves of a number of options. Indeed, it is quite common for fearful people to turn to several traditional healers (trying to find the most powerful one) as well as religious leaders (Loubser, 2015:41).

\section{Data set}

The focus of this chapter is on the measurement of the various dimensions of social capital and the perceptions of evil which (could) erode the formation of those dimensions in South Africa. One of the most successful and economical methods of tapping individual attitudes is by means of secondary data analysis, based on survey research.

2 South Africa has an estimated 350000 traditional healers (Ashforth, 2005b:8), consulted by up to $85 \%$ of (black) African households (Cohan, 2011:828). 
The descriptive analysis relies on data from the last two waves of the WVS conducted in South Africa in 2006 and 2013. The WVS provides a valuable tool with which to analyse the values, beliefs and motivations of ordinary citizens at the mass level over time. The increasingly prominent worldwide values research convincingly shows that changing value patterns have a strong impact on political, economic and social developments within a country.

The WVS is conducted by means of face-to-face interviews in the language of preference of respondents. Probability samples are drawn, with all adult citizens having an equal chance of being selected. The samples are also stratified into homogenous sub-groups defined by various demographic attributes. Since the samples are weighted to the full population and within a statistical margin of error of less than two per cent at the 95 percent confidence level, they are representative of the adult population of South Africa.

\section{Empirical analysis}

Despite socio-economic improvements since democratisation, South Africa still experiences very high levels of poverty, unemployment and income inequality that disproportionately affect South Africans by race (Lipton, 2014: 12). The demand to provide housing for the poor has grown much faster than supply, while the provision of basic services such as water, electricity, sanitation services and access to high quality education also remains highly skewed (Burger et al, 2015: 38). South Africans' frustration with poverty and inequality is evident in the country's increasingly frequent and violent social protest action. The protests are largely related to service delivery and labour rights, although many also include xenophobic violence (SAIRR, 2014:728). South Africa also has an excessively high crime rate. Not only is inequality linked to crime, but crime is linked to low productivity as well as high levels of stress, illness, fear and distrust in unequal and divided societies (SAIRR, 2014:707; Hamilton, 2011:359).

It is clear that South Africa lacks the benefits of equitable economic development and cultural unity. South Africans do not share the same resources, access to opportunities and social concerns. South Africans' diverging interests and concerns do not necessarily endanger its democracy, but it may impede the growth of liberal values as groups feel frustrated at their exclusion from social, political and economic resources. The same values are nevertheless needed as a vital source of stability and cohesion. Parallel to these values conducive for social cohesion is the belief of South 
Africans in the concept of evil forces, the power these forces have to do harm and the role that such beliefs may play in outbreaks of public violence.

The empirical analysis thus tracks the various dimensions of social capital in South Africa in order to determine the extent to which communities share common values that extend beyond their close ties; values that are essential for social cohesion and co-operation, especially in deeply divided societies. The analysis also tracks perceptions of evil and evil forces, which have the potential to disrupt and erode levels of social capital within South Africa.

\section{Dimensions of social capital}

Social trust is the belief that people are generally trustworthy and that most people share the same basic norms and values as one self. The values that form the basis of social trust, however, are not universal, but rather can vary among cultures, between contexts, and across time. Uslaner (2000, 2001, 2002) suggests that individual trust is shaped through processes of socialisation and learning. Since generalised trust, in the socialisation perspective, is shaped through interaction processes with one's social context, the expectation is that social context will be crucial for the possibility of social change. If "most people" in a social context are trustworthy then most interactions with them will result in positive outcomes.

In order to gauge levels of social trust in South Africa, respondents of the last two waves of the WVS were asked the following question: "Generally speaking, would you say that most people can be trusted or that you need to be careful in dealing with people?" Responses were recoded into the following categories: no trust, low trust, moderate trust, and high trust. The levels of social trust in South Africa in 2006 and 2013 are tabulated below (see Table 1).

TABLE 1 Levels of social trust in South Africa, 2006 and 2013 (percentages)

\begin{tabular}{lcc}
\hline Indicator of social trust & $\mathbf{2 0 0 6}$ & $\mathbf{2 0 1 3}$ \\
\hline No trust & 29.0 & 10.4 \\
Low trust & 42.8 & 48.5 \\
Moderate trust & 23.9 & 30.2 \\
High trust & 4.3 & 10.9
\end{tabular}

Overall, levels of social trust in South Africa are low. In both surveys, the majority of respondents indicated that they have no or low trust. A total of $71.8 \%$ of South Africans had little trust in others in 2006 , including $29.0 \%$ who indicated that they have no trust at all. Although the percentage of respondents that have moderate 
to high trust increased from 28.3 to 41.1 between 2006 and 2013, 58.9\% of South Africans indicated that they have little or no social trust. Despite the overwhelmingly low levels of social trust in South Africa, it is important to note that the number of respondents with no social trust at all decreased from almost three in ten South Africans to one in ten South Africans between the two surveys.

The second dimension of social capital - social tolerance - is related to perceptions of threat. High among the imperatives and values of democratic societies, especially ones as socially and culturally diverse as South Africa, is social tolerance for people and groups that are perceived as different. Complete social tolerance would entail "full recognition and acceptance of the identity and uniqueness of differences that are seen as not reducible to invisibility by their bearers" (Persell et al, 2001:208). In societies where such acceptance is absent, a lesser level of tolerance would include the willingness to grant equal political and legal rights to someone seen as different as well as an unwillingness to express intolerant attitudes openly (Persell et al, 2001:208).

In order to measure levels of social tolerance in South Africa, a composite variable was created by adding the tolerance of six groups of people together, including: drug addicts, heavy drinkers, people of a different race, people who have HIV/aids, immigrants and foreign workers, and homosexuals. The new variable indicates the level of tolerance as follows: no tolerance, low tolerance, moderate tolerance, and high tolerance. Table 2 provides an overview of the levels of social tolerance in South Africa in 2006 and 2013.

TABLE 2 Levels of social tolerance in South Africa, 2006 and 2013 (percentages)

\begin{tabular}{lcc}
\hline Indicator of social tolerance & $\mathbf{2 0 0 6}$ & $\mathbf{2 0 1 3}$ \\
\hline No tolerance & 0.2 & 3.1 \\
Low tolerance & 14.2 & 22.1 \\
Moderate tolerance & 69.8 & 53.2 \\
High tolerance & 15.8 & 21.6
\end{tabular}

From the data above, we can conclude that, unlike social trust, levels of social tolerance in South Africa are high. In both surveys, the vast majority of South Africans reported moderate to high levels of social tolerance, despite a decline from $85.6 \%$ in 2006 to $74.8 \%$ in 2013 . There are, however, also some interesting and contradictory findings relating to social tolerance. For example, the percentage of respondents with no or low tolerance increased from 14.4 to 25.2 in 2013, while the percentage of respondents with high tolerance also increased (by $5.8 \%$ ) during the same period. 
The majority of South Africans are moderately tolerant; however, this category of respondents decreased by $16.6 \%$ between 2006 and 2013.

The third dimension of social capital is that of social networks. Voluntary associations or social networks create civic community in that they create among their members' networks of horizontal and vertical relations. Active members of a social network form a 'distance-two' network if each pair of members $X$ and $Y$ know each other personally or have at least one acquaintance in common (Fennema, 2004:433). Thus, the quality of civil society depends not only on the number of active members and the level of membership, but also on the number of associations. Numerous and overlapping voluntary organisations also create cross-cutting ties that serve to bind society together by its own internal divisions and produce pluralist competition between different interests (Foley and Edwards, 1996).

As with social tolerance, a composite variable summed the membership of nine voluntary associations together, including: church or religious organisation, sport or recreational organisation, art, music or educational organisation, labour union, political party, environmental organisation, professional association, humanitarian or charitable organisation, and "other" organisation. The new variable indicates the number of social networks to which respondents are active members. The level of social network activity in South Africa in 2006 and 2013 is presented in Table 3 below.

TABLE 3 Level of social network activity in South Africa, 2006 and 2013 (percentages)

\begin{tabular}{lcc}
\hline Indicator of social network activity & $\mathbf{2 0 0 6}$ & $\mathbf{2 0 1 3}$ \\
\hline No activity (belong to no social networks) & 10.9 & 34.4 \\
Low activity (belong to 1-2 social networks) & 55.5 & 49.1 \\
Moderate activity (belong to 3-4 social networks) & 15.4 & 10.9 \\
High activity (belong to 5 or more social networks) & 18.3 & 5.6
\end{tabular}

Overall, social network activity is on the decline in South Africa. Approximately half of South Africans (55.5\% in 2006 and $49.1 \%$ in 2013) are active members in at least 1-2 social networks. It is highly likely that the bulk of activity in this category would be related to church or other religious organisations and sport or recreational clubs (such as gyms). High and moderate activity in social networks declined by $12.7 \%$ and $4.5 \%$ respectively, while South Africans are three times less likely to actively belong to any social networks (34.4\%) in 2013 than they were in 2006 (10.9\%). 


\section{Perceptions of evil}

While social capital has been likened to the "glue" that holds society together, perceptions of evil are thought to erode the social fabric of society. Evil as a belief is conceptualised in two ways: the belief in a literal evil is defined as the belief in real (if unseen), malignant spiritual forces that can cause real and direct harm in the lives of individuals, while secular evil is conceptualised as an entirely non-spiritual phenomenon characterised by wrongdoing on the part of flawed human beings (Loubser, 2015:57).

In order to measure perceptions towards evil (the independent variable), respondents were asked to indicate the extent to which they strongly agree, agree, disagree, strongly disagree or neither agree nor disagree with three questions: evil is everywhere; evil can take possession of some people; and the community must get rid of people possessed by evil even if it means that they have to be killed. A composite variable was created by adding the three measures together. The new variable indicates the extent to which South Africans have no, low/weak, moderate or high/strong beliefs in evil (see Table 4).

TABLE 4 Attitudes towards evil in South Africa, 2006 and 2013 (percentages)

\begin{tabular}{lcc}
\hline Indictor of attitudes towards evil & $\mathbf{2 0 0 6}$ & $\mathbf{2 0 1 3}$ \\
\hline No belief in evil & 0.4 & 0.7 \\
Low/weak belief in evil & 4.1 & 3.9 \\
Moderate belief in evil & 48.9 & 32.7 \\
High/strong belief in evil & 46.6 & 62.7
\end{tabular}

From the data above, it is evident that perceptions of evil are salient in South Africa. Almost all (95.5\% and 95.4\%) respondents indicated that they hold moderate or strong beliefs in evil in 2006 and 2013 respectively. Moreover, these beliefs appear to be strengthening over time as strong belief increased from $46.6 \%$ to $62.7 \%$ between the periods under investigation; marking a 16.1\% increase. Less than $5 \%$ of respondents in both waves do not believe in evil or have a weak belief in evil forces.

\section{Do perceptions of evil erode social capital in South Africa?}

An assessment of the levels or stocks of social capital in South Africa present some interesting and mixed results. Perhaps the most positive finding is that levels of social trust have increased, albeit from a very low level in 2006. Despite this positive movement, the majority of South Africans hold little or no trust in others in both periods under investigation. Levels of social tolerance and social network activity, 
on the other hand, are both on the decline. It is true that levels of social tolerance are particularly high in South Africa, with three quarters indicating that they have moderate to high levels of tolerance of outsiders - cultural, lifestyle and permissive. However, continued decline in tolerance could pose a threat to social cohesion and result in increased conflict between these different groups of South Africans. Similarly, more than a third of South Africans do not participate in any type of social network, compared to only $10.9 \%$ in 2006 . This decline is significant because the face-toface interaction that takes places in formally organised voluntary organisations and social networks is vital for generating democratic norms among citizens as they teach citizens the civic virtues of reciprocity, trust, compromise, and moderation (Newton, 1997). Overall, it appears that good stocks of social capital in South Africa are under threat.

At the same time, perceptions of or belief in evil are strong and increasing amongst South Africans. From our data, it is evident that belief in evil and evil forces is a cultural phenomenon that is a salient feature in the lives of many South Africans, the vast majority of whom also identify as being religious and attending church frequently (du Toit and Kotze, 2011:133-138; Loubser, 2015:85-86). This creates an imbalance in the underlying values structure of society between the positive role of social capital in facilitating and supporting co-operation and prosocial behaviour on the one hand and antisocial norms, attitudes and behaviour associated with belief in evil on the other.

Further statistical analysis - Pearson's $r$ - was conducted in order to determine the degree of linear dependence between the various dimensions of social capital and perceptions/beliefs in evil. The analysis from the 2013 data confirmed that there is indeed a negative correlation between social capital and perceptions of evil. More specifically, the analysis shows that the stronger the perceptions of evil, the lower the levels of social trust, social tolerance and social network activity in South Africa. Although the correlations are fairly weak, they are all statistically significant at the .05 level.

\section{Discussion}

According to secularisation theorists, religious or spiritual values (such as beliefs in evil) are bound to be more important in insecure societies. Where the state is generally powerful enough to protect people from harm and secure their wellbeing, there is little need to turn to religion for psychological assurance or explanations for life's troubles. However, in those societies where people experience high levels of 
existential insecurity, spiritual comfort is needed to relieve stress and help people cope with the challenges of daily life (Norris and Inglehart, 2004:13-19).

In South Africa, several causes of insecurity can be identified, namely poverty, inequality and crime. These problems adversely affect social capital. They also stimulate a need for spiritual comfort which may result in either positive social capital (community or church projects) or negative outcomes (scapegoating or vigilantism).

Despite socio-economic improvements since the end of apartheid, South Africa continues to struggle with endemic poverty and inequality. The Gini coefficient remains high at levels of between 0.65 and 0.69 (Statistics South Africa, 2014) and indeed, income inequality has increased among and within race groups (Du Toit and Kotzé, 2011:77-79). Although access to services has been extended, unemployment, poverty and high inflation leave millions unable to pay for these necessities (Bond and Mottiar, 2013:284-285).

Crime and violence pose yet a further threat to South Africans' physical security. It also undermines the social capital needed to address other socio-economic ills. South Africa - widely reputed as one of the most dangerous countries in the world - currently experiences approximately 49 murders and 48 attempted murders per day, amounting to 33 murders and 32 attempted murders per 100000 people (South African Police Service, 2015). This figure is more than five times higher than the global average (6.2 murders per 100000 people) (Newham et al., 2015). South Africa also has one of the highest rates of violence against women and children in the world, including rape and domestic abuse (Snodgrass and Bodisch, 2015:68).

Although crime does not always affect all South Africans equally, the fear of crime leaves no one untouched. A climate of fear leads to a change in behaviour - for example, limiting social activities or freedom of movement and fortifying homes - as people attempt to ensure their own safety. This serves to normalise crime and fear and can have a negative effect on social relations and social cohesion (Loubser, 2015: 106-109). Moreover, in countries or regions where, for whatever reason, citizens volunteer less and less, help each other less and less, and disengage from civic life more and more, plural democracy will suffer (Rotberg, 2000:340). Under these circumstances, a political culture that is plurally democratic will lose some of its key attributes of participation and cohesion.

A climate of extreme violence is also likely to stimulate the belief that some people are "evil" and that extreme measures are needed to remove them from society. 
South Africans' continued support for capital punishment may be one example of the negative impact of crime and fear of crime (Loubser, 2015:82-83).

In sum, South Africa remains deeply racialised, in cultural and social terms, as well as deeply unequal, in terms of the distribution of income and opportunities. As common in many deeply divided societies, South Africa is characterised by polarised and separated communities, which are both socially insulated and spatially isolated. This reality has adversely impacted the levels and growth of good stocks of social capital in South Africa, while also being conducive for the rise of beliefs in evil and evil forces.

\section{Bibliography}

Aldridge, S., Halpern, D. and Fitzpatrick, S. 2002. Social Capital: A Discussion Paper. London, England: Performance and Innovation Unit.

Ashforth, A. 2010. Human security and spiritual insecurity: Why the fear of evil forces needs to be taken seriously. Georgetown Journal of International Affairs. 11(1):99-106.

Ashforth, A. 2005a. Muthi, medicine and witchcraft? The implications of aids for the post-apartheid state. African Studies. 61(1): 121-143. https://doi.org/10.1080/00020180220140109

Ashforth, A. 2005b. Witchcraft, Violence, and Democracy in South Africa. Chicago: The University of Chicago Press.

Baron-Cohen, S. 2011. The Science of Evil: On Empathy and the Origins of Cruelty. New York: Basic Books.

Bond, P. and Mottiar, S. 2013. Movements, protests and a massacre in South Africa. Journal of Contemporary African Studies. 31(2). 283-302. https://doi.org/10.1080/02 589001.2013.789727

Brown, D.L. and Ashman, D. 1996. Participation, social capital, and intersectoral problem solving: African and Asian cases. World Development. 24: 1467-1479. https://doi.org/10.1016/0305-750X(96)00053-8

Burger, R., Steenekamp, C.L., van der Berg, S. and Zoch, A. 2015. The emergent middle class in contemporary South Africa: Examining and comparing rival approaches. Development Southern Africa. 32(1): 25-40. https://doi.org/10.1080/037683 5X.2014.975336

Cohan, J.A. 2011. The problem of witchcraft violence in Africa. Suffolk University Law Review. 44(4): 803-872.

Du Toit, P. and Kotzé, H. 2011. Liberal Democracy and Peace in South Africa: The Pursuit of Freedom as Dignity. New York: Palgrave MacMillan. https://doi.org/10.1057/9780230116320

Earle, T.C. and Cvetkovich, G.T. 1995. Social Trust: Toward a Cosmopolitan Society. Westport, CT: Praeger.

Fennema, M. 2004. The concept and measurement of ethnic community. Journal of Ethnic and Migration Studies, 30(3): 429-447. https://doi.org/10.1080/1369183041 0001682025 
Fukuyama, F. 2001. Social capital, civil society and development. Third World Quarterly. 22(1): 7-20. https://doi.org/10.1080/713701144

Garrard, E. 1998. The nature of evil. Philosophical Explorations: An International Journal for the Philosophy of Mind and Action. 1(1): 43-60. https://doi.org/10.1080/10001998018538689

Gershman, B. 2016. Witchcraft beliefs and the erosion of social capital: Evidence from sub-Saharan Africa and beyond. Journal of Development Economics. 120: 182-208. https://doi.org/10.1016/j.jdeveco.2015.11.005

Glenna, L. 2002. Operationalizing evil: Christian realism, liberal economics, and industrial agriculture. Agriculture and Human Values. 19(3): 205-216. https://doi.org/10.1023/A:1019985003236

Halpern, D.S. 2001. Moral values, social trust and inequality: can values explain crime? British Journal of Criminology. 41(2): 236-251. https://doi.org/10.1093/bjc/41.2.236

Hamilton, L. 2011. Collective unfreedom in South Africa. Contemporary Politics. 17(4): 355-372. https://doi.org/10.1080/13569775.2011.619756

Israel, G., Beaulieu, L. and Hartless, G. 2001. The influence of family and community social capital on educational achievement. Rural Sociology. 66: 43-68. https://doi.org/10.1111/j.1549-0831.2001.tb00054.x

Jackson, E., Bachmeier, M., Wood, J.R. and Craft, C. 1995. Volunteering and charitable giving: do religious associational ties promote helping behaviour? Nonprofit and Voluntary Sector Quarterly. 24(1): 59-78. ttps://doi.org/10.1177/089976409502400108

Jenkens, P. 2002. The Next Christendom: The Coming of Global Christianity. Oxford: Oxford University Press. https://doi.org/10.1093/0195146166.001.0001

Kawachi, I., Kennedy, B.P. and Glass, R. 1999. Social capital and self-rated help: a contextual analysis. American Journal of Public Health. 89(8): 1187-1193. https://doi.org/10.2105/AJPH.89.8.1187

Labuschagne, G. 2004. Features and investigative implications of muti murder in South Africa. Journal of Investigative Psychology and Offender Profiling. 1(3): 191-206. https://doi.org/10.1002/jip.15

Leistner, E. 2014. Witchcraft and African development. African Security Review. 1-25. https://doi.org/10.1080/10246029.2013.875048

Lipton, M. 2014. Is South Africa's constitutional democracy being consolidated or eroded? South African Journal of International Affairs. 21(1): 1-26. https://doi.org/10.1080/10220461.2014.890342

Loubser, R. 2015. Evil and Violence: Illiberal Beliefs in South Africa's Liberal Democracy. MA Dissertation at the University of Stellenbosch.

Martin, M.W. 1994. Virtuous Giving: Philanthropy, Voluntary Service and Caring. Bloomington: Indiana University Press.

Newham, G., Lancaster, L., Burger, J. and Gould, C. 2015. Factsheet: South Africa's 2014/15 Murder and Robbery Crime Statistics. Africa Check. https://africacheck. org/factsheets/factsheet-south-africas-201415-murder-and-robbery-crimestatistics/ (25 August 2016).

Newton, K. 2004. Social trust: individual and cross-national approaches. Portuguese Journal of Social Science, 3(1): 15-35. https://doi.org/10.1386/pjss.3.1.15/0 
Niehaus, I. 2012. From witch-hunts to thief-hunts: On the temporality of evil in the South African low-veld. African Historical Review. 44(1): 29-52. https://doi.org/10.10 80/17532523.2012.714159

Norris, P. and Inglehart, R. 2004. Sacred and Secular: Religion and Politics Worldwide. Cambridge: Cambridge University Press. https://doi.org/10.1017/ CBO9780511791017

Persell, C.H., Green, A. and Gurevich, L. 2001. Civil society economic distress and social tolerance. Sociological Form, 16(2): 203-230. https://doi.org/10.1023/A:1011048600902

Putnam, R.D. 1993a. Making Democracy Work: civic Traditions in Modern Italy. Princeton, NJ: Princeton University Press.

Putnam, R.D. 1993b. The prosperous community: Social capital and public life. The American Prospect, 4(13): 11-18.

Putnam, R.D. 2000. Bowling Alone: The Collapse and Revival of American Community. New York: Simon and Schuster. https://doi.org/10.1145/358916.361990

Rotberg, R. 1999. Social capital and political culture in Africa, America, Australia, and Europe. Journal of Interdisciplinary History, 29: 339-359. https://doi.org/10.1162/002219598551733

Rotberg, R.I. 2000. Patterns of Social Capital: Stability and Change in Historical Perspective. Cambridge: Cambridge University Press. https://doi.org/10.1017/ CBO9780511572777

Rule, S. 2007. Religiosity and quality of life in South Africa. Social Indicators Research. 81(2): 417-434. https://doi.org/10.1007/s11205-006-9005-2

Snodgrass, L. and Bodisch, A. 2015. Why are we such a violent nation? The legacy of humiliation in South Africa. Africa Insight. 45(3). 63-75.

South African Institute of Race Relations. 2012. South Africa Survey 2012. Johannesburg: South Africa.

South African Institute of Race Relations. 2014. South Africa Survey 2014. Johannesburg: SAIRR.

South African Police Service. 2015. Crime situation in South Africa. http://www.saps. gov.za/resource_centre/publications/statistics/crimestats/2015/crime_stats.php (25 August 2016).

Statistics South Africa, 2014. Poverty trends in South Africa. Press Statement. 3 April. http://www.statssa.gov.za/?p=2591 (25 August 2016).

Steenekamp, C.L. 2011. Bridging the Divide: The Development, Dimensions and Determinants of Social Capital in Post-Apartheid South Africa. PhD Dissertation at the University of Stellenbosch.

Uslaner, E.M. 2000. Producing and consuming trust. Political Science Quarterly. 115(4): 569-590. https://doi.org/10.2307/2657610

Uslaner, E.M. 2001. Volunteering and social capital: How trust and religion shape civic participation in the United States. In Dekker, P. and Uslaner, E.M. (eds.) Social Capital and Participation in Everyday Life. London: Routledge. https://doi.org/10.4324/9780203451571_chapter_8

Uslaner. E.M. 2002. The Moral Foundations of Trust. Cambridge: Cambridge University Press. https://doi.org/10.1017/CBO9780511614934 
Van der Vlies, A. 2013. The people, the multitude and the costs of privacy in South Africa's postcolony. Cultural Studies. 27(3): 496-518. https://doi.org/10.1080/0950 2386.2013.769155

Vogt, W. 1997. Tolerance and Education. Learning to Live with Diversity and Difference. Thousand Oaks, CA: SAGE.

Wang, L. and Graddy, E. 2008. Social capital, volunteering, and charitable giving. Voluntas, 19(1): 23-42. https://doi.org/10.1007/s11266-008-9055-y 


\title{
SOUTH AFRICA'S HIV AND AIDS RESPONSE: TWO SCENARIOS TOWARDS 2019
}

\author{
PIETER FOURIE AND CHARL SWART
}

\begin{abstract}
In May 2016 the South African Minister of Health announced a major policy shift in the country's response to the AIDS epidemic: from September all people who are HIVpositive will receive anti-retroviral treatment, regardless of their CD4 count. This shift to a universal test-and-treat strategy will have far-reaching consequences for the country's health system. Universal test-and-treatment assumes the availability of adequate financial, human, and management resources in the health system. By employing future scenarios methodology, this chapter states and problematises a spectrum of elite opinion about South Africa's current and future response to the epidemic. We identify critical decision points which need to be considered by policy makers to ensure the success of the national response. We apply an inductive scenario methodology to generate scenarios regarding the short-term future of South Africa's response to the epidemic. Policy demands, tensions and outcomes will be determined by how effectively the country responds to the particular challenges of human resources management, financing, and general health systems strengthening. Policy makers need to take particular cognisance of the inequities within South African society in general, and of the capacity deficits in the health system in particular.
\end{abstract}

\section{Background}

On 10 May 2016 the South African Minister of Health, Dr Aaron Motsoaledi, announced that

In September this year, we will remove CD4 count as an eligibility criterion for ARV treatment; [i]t means we shall move to test and treat in line with the new guidelines released by the World Health Organisation (WHO) in December last year. [.... This] will cost us an additional R1 billion in this year's budget... (Motsoaledi, 2016).

Such a radical policy shift could have far-reaching implications for the national health system, considering that the country has the largest AIDS epidemic in the world, with 6.4 million people who are HIV-positive in a population of just more than 50 million (Whiteside and Strauss, 2014). The shift towards adopting a universal test and treat 
(UTT) regime is based on a WHO recommendation that earlier treatment initiation reduces HIV incidence (WHO, 2015). The South African policy shift is premised on the assumption that the national health system can (1) afford and (2) effectively deliver treatment to nearly seven million (and counting) HIV-positive South Africans. The purpose of this debate piece is to problematise this assumption: is such a biomedical response sustainable in a middle-income country with the largest AIDS epidemic in the world?

What makes this shift to UTT remarkable, further complicating the challenge to the health system, is the idiosyncratic South African policy response to HIV and AIDS. The apartheid and Mandela governments largely ignored the growing epidemic, whilst the government of Thabo Mbeki (1999-2008) denied either the existence of HIV or its link to AIDS, refusing to make available at public health facilities the anti-retroviral drugs (ARVs) that could save the lives of millions. A study at Harvard University (Chigwedere et al, 2008) stated that Mbeki's foot-dragging to provide ARVs to South Africans living with the virus in the years between 2000 and 2005 cost more than 330,000 lives, with 35,000 babies born HIV-positive because of delays in the provision of these drugs to pregnant women. Max Essex, a virologist who has led Harvard's AIDS research programme since the early days of the global pandemic, called South Africa's response to AIDS under Thabo Mbeki 'a case of bad, or even evil, public health' (Dugger, 2008).

The country has move beyond those dark days and now has the largest AIDS treatment programme in the world. Of the 6.4 million HIV-positive South Africans, 2.2 million now receive $A R V s$ at public health facilities, and 200,000 receive $A R V$ s through their private health insurance (Du Toit et al, 2015; Interview 6). As a result, South Africans now live longer and healthier lives: life expectancy in 2003, the year prior to ARV roll-out in the public sector, was estimated at 49.2; by 2011, life expectancy had risen to 60.5 years (Bor, Newell and Bärnighausen, 2013). The South African HIV epidemic began later than the HIV epidemics in most other African countries, but it rapidly grew to be the largest HIV epidemic in the world.

The Thembisa model estimates that HIV incidence rates in adults (ages 15-49) peaked at 2.3\% per annum in 1998 and has been slowly declining since then, reaching $1.5 \%$ by the start of 2012 (Johnson, 2014). These declines in incidence have been largely attributable to increases in condom use over time, particularly following the large HIV communication programmes initiated in the late 1990s and early 2000s (Johnson et al, 2012). However, in recent years there has been limited growth in condom use; some evidence even suggests that condom use may have declined 
(Shisana et al, 2014). Although HIV incidence in South Africa is projected to continue to decline in future, these future declines are likely to be driven mainly by increases in uptake of antiretroviral treatment (ART) rather than behaviour change.

Annual numbers of AIDS deaths in South Africa peaked at over 300,000 in 2005, but since that time there has been a dramatic decline in levels of AIDS mortality, largely due to the success of the ART programme in the public sector (Johnson, 2014). It is expected that levels of AIDS mortality will continue to decline in future, as ART initiation criteria change to recommend earlier ART initiation, and as fewer individuals remain untreated in the advanced stages of HIV disease. Although there is concern that rising levels of drug resistance may compromise the ART programme, detailed mathematical modelling suggests that levels of mortality in ART patients are likely to continue to decline even in the absence of specific interventions to limit drug resistance.

But how sustainable is the good news? Are we alert to the pitfalls that could undermine the way forward? Have we identified and are we prepared for the tensions, difficult decisions and mutually exclusive choices that the country will have to face? For instance, the New York Times on 25 August 2014 noted that South Africa would stop receiving American funding towards its ARV programme in 2017, stating that 'the South African government must find hundreds of millions of dollars, even as its national caseload grows rapidly' (McNeil, 2014). How will the already fragile health system cope with the additional demands of UTT?

\section{Methodology}

In order to answer these questions, we employed a future scenarios methodology. The assumption underpinning the methodology of future scenarios is that key elements or determinants of the future are present in the current reality, and that there is a scientific method - a methodology - that can access and expose them (Van der Heijden, 1996). These drivers of the future can then be extrapolated upon and, applying both qualitative and quantitative methods, it then becomes possible to talk intelligently about what may happen in a more informed manner. Scenarios are about exposing and comparing different sets of assumptions about the present, which are then extrapolated into the future (Van der Heijden et al, 2002). In this way scenario methodology is as much about the here and now as they are about any future; in fact, scenarios are simply a way to use the future as a vantage point from which to view the present. 
The different storylines or scenario narratives are best read as a single set. The mistake is often made to isolate one scenario and to note how 'good' or 'bad' its findings are. However, the real value lies in comparing the insights and lessons of different scenario storylines with one another. It is important to remember that scenarios are about what may happen in the future, rather than what one wants to happen in the future (Wack, 1985a and 1985b). A scenario set should contain coherent, credible and challenging story elements that are neither simply derivative and predictable nor so radical that they alienate the reader. Such a scenario set can then assist decision makers in reviewing the appropriateness of their own assumptions, in highlighting hidden mental maps, and in drafting future policies.

The scenarios reported here were derived from an inductive methodology. The scenario set results from the inference of an overall structure to begin with - prior to this, the authors had done some research and key informant interviews to come up with a pair of key variables that may influence the future. We interviewed 15 top opinion makers, government officials and medical experts who work at the forefront of the South African AIDS response. All of the interviews were conducted between December 2013 and April 2014, and in order to enable reflections that are free of institutional and other constraints, we have anonymized these key respondents' answers. Our interview schedule was informed by variations on the 'seven questions' often used in scenario planning (De Geus, 1985; Van der Heijden, 1996; Schwartz, 1996; Ringland, 2002; Chermack, 2011), to enable reflection on the status quo, but with a view to the future governance of the South African epidemic.

The reflections of the current and future realities of AIDS in South Africa that emerged from the interviews can be clustered into three broad themes: AIDS science, AIDS management, and the social determinants of AIDS. The interviews demonstrate that since 2008 the policy response to the epidemic has been thoroughly biomedicalised. Despite improvements in anti-retroviral drug rollout and life expectancy at the aggregate national level, considerable challenges and uncertainties in the response remain. These include a dangerously weak national health system, which may buckle under the strain of demands of an ever- and rapidly expanding ARV programme. The key decision point for the future governance of AIDS in South Africa will be the rising demand for an effective response on the one hand, and the reality of the uncertain and unequal availability of human, infrastructural and financial resources on the other.

These variables are then plotted on $2 \times 2$ axes and different scenarios are extrapolated from the resultant matrix. Quantitative data is then fitted into the framework. The key 
strength of future scenarios is that they reveal to us what may happen, rather than what we want the future to be; they help us to move beyond our own mental maps, to think the unthinkable, and to plan accordingly. We developed these findings by employing the above-mentioned inductive future scenario methodology to generate story spaces and make explicit the policy implications of what may happen in the near future, rather than normative aspirations about which future may be desirable. This exercise provides us with insights regarding the complexities of policy choices that need to be considered in order to ensure an effective response to the AIDS epidemic in South Africa.

Our analysis proceeds as follows: first, we discuss the elite interviews, identifying the key themes to emerge; then, we confirm the research problem, time horizon, and key driving forces, along with the socio-political context of the scenarios. We then sketch the scenario story spaces, and conclude with reflections on possible policy implications.

\section{Findings}

\section{Interview findings}

The interview responses can be clustered into three themes: the science of AIDS, the management of AIDS, and the social determinants of AIDS.

The interviews reflect remarkable consensus on the reality and challenges posed by AIDS in South Africa - virologically, epidemiologically and politically. There are few marked differences of opinion regarding the 'science' of AIDS, and the concomitant clinical and government interventions required to combat it. We were struck by the broad and unquestioned embrace of a biomedical perspective on the epidemic. This is a major departure from the Mbeki era: during that time a narrative about poverty and the social determinants of health dominated policy considerations related to the epidemic. However, in our recent interviews even when respondents chose to mention or focus on behavioural and social factors regarding the epidemic, they still placed far greater emphasis on biomedical responses rather than on the need for behaviour change.

Respondents emphasize four specific medical interventions as primary responses to the epidemic: ART, the prevention of mother-to-child transmission (PMTCT), medical male circumcision (MMC), and male condoms. There is wide agreement that ART is the greatest success story in South Africa's recent response to AIDS. Mother-to- 
child transmission of the virus has dropped dramatically across the country as ARVs became available at public antenatal health facilities (Grimwood et al, 2012).

Although ART scale-up is universally embraced, more than six million South Africans are HIV-positive, and there is some concern that the sustaining and expanding the ARV programme will pose significant challenges to the health system of South Africa, both in terms of capacity and affordability. Despite such challenges, respondents agree that the test-and-treat strategy has been successful. However, one respondent warned that 'people who think treatment is the be-all-and-end-all of the problem [...] are in for a bad shock one day' (Interview 14). The principle of treatment-asprevention is not supported across the board, with some respondents cautioning that what seems like an ARV-driven drop in incidence (the year-on-year increase in new infections) may rather be attributable to a naturally occurring epidemiological cycle (Interview 6).

Other issues that complicate ART as a success story include concerns about ARV drug resistance, viral mutation, treatment adherence, retention in care, and general virological monitoring and knowledge. Much is made of the changing demographics of the South African epidemic, specifically in light of the increase in aggregate longevity (Bor et al, 2013). Respondents are concerned that, as greater numbers of HIV-positive people remain alive due to the success of ART, an ageing HIV-positive cohort represents a significant clinical unknown, and may also demand resources that will not readily be available in future. This issue is further complicated by considerations regarding non-communicable diseases and other co-morbidities such as tuberculosis (TB), at scale and over time.

The other medical interventions are explicitly gendered. Many respondents mentioned the importance of $M M C$ as a fairly recent programmatic intervention. However, there is not consensus about the wisdom of giving MMC such prominence as an effective tool for reducing the risk of HIV transmission, especially in the absence of concerted behaviour-change information campaigns. The concern is raised that $\mathrm{MMC}$ is presented as a preventive measure that lowers the risk of viral transmission significantly for the circumcized male, but leaves their sexual partners unprotected: '[p]eople have this idea that if you are circumcized you are okay; women think that if a man is circumcized, she is okay. [...] And this is really, really bad' (Interview 9). Such muted enthusiasm is also reflected in perspectives on (male) condoms: although there is agreement amongst respondents about the efficacy of condoms, there is some concern regarding the somewhat unknown trajectory of condom use amongst South Africans (Interview 7). 
In addition to these medical interventions, respondents expressed concern about our ability to correctly measure, interpret and address incidence. These concerns are expressed as variations of disagreement amongst respondents, who differed on the causal relationship between lower AIDS mortality and higher HIV prevalence levels on the one hand, and incidence levels on the other. There was also a lack of consensus about the inferred direct causal link between ARV rollout and declining incidence levels. Such variations of opinion about basic epidemiological datagathering reflects an unease regarding the availability and validity of data generally, and incidence data specifically. Although measuring models are viewed to be improving, with more nuanced and mathematically sophisticated models being developed, respondents emphasize the continued need for population-specific data, meaningfully disaggregated. For instance, some of the respondents noted the need for population studies amongst sentinel cohorts (e.g. gay men in Cape Town, young women in KwaZulu-Natal province, and the rural poor in the Eastern Cape province) to gain a more accurate and meaningful understanding of variations in incidence.

Some of the respondents suggested that the development and wide use of a single patient identifier would be a helpful statistical and information-gathering tool to address such concerns about data. That said, these respondents acknowledged that the South African health system may not be ready for the implementation of a single patient identifier, as it would require many resources (human, financial and infrastructural) to implement and sustain its use across the country. When pushed to suggest a wish list of further measures to combat AIDS, respondents express the hope that AIDS cure-science could one day produce a miracle, such as an effective antibody. However, respondents believe that developments towards a vaccine or a vaginal microbicide may be a more realistic aspiration in the more immediate future. That said, two medical innovations were mentioned that may become gamechangers in the next three to five years: (1) a microchip to monitor a patient's viral load, suggesting automatically updated treatment regimens, and (2) a long-acting ARV injectable administered four times a year, which would enable simpler treatment protocols, which in turn could ensure greater treatment adherence.

In terms of AIDS management, respondents overwhelmingly agree that the postMbeki minister of health, $\operatorname{Dr}$ Aaron Motsoaledi's arrival in South Africa's national health governance was a positive game-changing development. To illustrate the respondents' sentiment towards the minister, the only 'negative' comment about his personality, management style, and abilities is that his very energy, competence and innovation may make him such a standout in the government of president Jacob 
Zuma that his appointment may become unsustainable. Supporting this sense of optimism about the minister, one respondent notes that the Motsoaledi's political and managerial agenda is so ambitious that the minister may be side-tracked by wanting to do too much, too soon. In the main, however, the overall sense is positive, namely that South Africa has a national minister of health who is the opposite of his predecessors in the Mbeki administrations: we have a minister who is serious about addressing not only HIV, but who wants to transform the country's entire health system.

Such complimentary reflections are not, however, applicable to the South African health system more generally. One respondent noted that 'the more we can protect people from the health care system the better' (Interview 6). Respondents are scathing in their criticism of the lack of coordination within the national department of health, and between different levels of government, across various institutions with direct import in AIDS governance, including the South African National AIDS Council (SANAC) and its coordination with non-government organizations (NGOs) and the larger health community. The South African health system is seen as dysfunctional, specifically at the provincial level. Although there is variability amongst the provincial departments of health, respondents are deeply concerned about poor management skills and a lack of concerted management across national, provincial, district and local spheres of public health facilities, including hospitals and clinics.

Respondents decry the absence of medical professionals (particularly medical doctors) at top management levels. There is a sense that management expertise is lacking, in particular in hospitals and clinics, and that managers with medical backgrounds have a more appropriate skill set than other 'professional managers'. Other respondents are satisfied with non-medical managers, provided that they are competent, adequately trained, and receive ongoing skills development. One respondent noted that 'management is not rocket science, management is reasonably straight forward, and this country has enough resources to provide good services' (Interview 3).

In the South African context the disjuncture between rural and urban health care facilities is of particular concern. In health system terms the challenge is to adapt the appropriate delivery mechanism(s) for all health and related services, including equitable access to health personnel, the delivery of medical consumables, diagnostics and outpatient care. The role of mobile voluntary counselling and testing clinics, home-based care facilities and the National Health Laboratory Services is emphasized, and respondents recommend that the public and private sectors 
cooperate more closely to improve health outcomes. Interestingly, the private sector is only mentioned in the context of public-private partnerships, and then almost incidentally, as part of discussions about the development of a National Health Insurance (NHI) system.

Respondents express significant scepticism about the $\mathrm{NHI}$, and emphasize the lack of specificity of what the scheme would essentially seek to achieve: 'I think the fuzzy political leadership around the NHI is a big negative' (Interview 6). There seems to be a general sense that the $\mathrm{NHI}$ will fail to get started, that it will bankrupt the country, and fail to deliver anything meaningful. Respondents are overwhelmingly in favour of profound reform of the national health system, but the $\mathrm{NHI}$ is not seen as any kind of panacea. One positive development in terms of AIDS management in general, however, is the move away from GPs as the primary point of care for AIDS patients; nurses are becoming the primary point of care. At the same time there is recognition that nurses already bear a heavy burden of care in the health system in general, and this has been compounded by AIDS. Respondents note that communityfocused interventions are a way to alleviate pressures on health care workers, and recommend further innovation in bottom-up rather than top-down care initiatives.

Central to all reflections regarding the national health system is the reality of increasing demands in the management of the rapidly expanding national ARV programme: 'we are going to need to put about six million people on treatment. There is no way South Africa can put six million people on treatment in the current strategy [....] it would completely collapse the health care system' (Interview 14). The concomitant burden on the health system is difficult to overstate, and the respondents highlight the following as particular challenges: drug stock-outs, supply chain management, challenges around dispensing, logistics, and the management of tender processes and drug pricing mechanisms. As mentioned earlier, many of the respondents suggest the introduction of a single patient identifier as one significant way to ease this burden.

The issue of funding is closely linked to concerns about the NHI as well as South Africa's health system restructuring and the proposed expansion of the ARV programme. Several respondents mention the end of President's Emergency Plan for AIDS Relief (PEPFAR) funding in 2017 as a predictable development that will require serious fiscal planning. Although the national treasury is seen as a centre of excellence within government, the consequences of the departure of PEPFAR money will be significant. South Africa funds 80 percent of its national AIDS response (including ARV rollout), but in the absence of PEPFAR the national department of 
health and the treasury will need to think innovatively about plugging the funding deficit. Compounding such pressures is the lethargic growth outlook for the South African economy, and the implications that this could have for the total national health budget.

The third theme around which interview responses converged was the social determinants of AIDS. In July 2013, during a plenary session of the $2^{\text {nd }}$ International Conference for the Social Sciences and Humanities in HIV in Paris, a high-ranking UNAIDS official stated that 'interventions or programmes to prevent AIDS and which focus on behaviour change are dead'. The shift away from behaviour change-led interventions towards a mostly biomedical intervention model has prevailed since 2008, and this new norm is echoed amongst all those interviewed for this project. A small minority of the respondents mentioned the continuing need for behaviour change programmes for preventing HIV transmission - particularly as part of an emphasis on societal values and nuclear families - but the vast majority of those interviewed do not at all mention behaviour change as a major factor in the current South African AIDS epidemic. When asked about this, one respondent suggests that South Africans might be in denial about the AIDS denialism of the Mbeki era (a so-called 'second generation of AIDS denialism') (Interview 1), as a way of moving beyond the infighting and dysfunction of a decade ago. This sense of historical revisionism regarding Mbeki's tenure, specifically his treatment of HIV, is something other commentators have also mentioned (Steinberg, 2014).

Despite the scepticism and silence regarding behaviour change as a viable option for mitigating the epidemic, respondents were invited to comment on the social determinants of AIDS. They acknowledge a general lack of meaningful social messaging regarding the epidemic. However, issues around gender are acknowledged as a key driver of AIDS. A cocktail of socio-cultural behaviour is seen as fanning incidence: early sexual debut, intergenerational sex (young women with older men), alcohol abuse, and, most importantly, gender-based violence. Black men and black young women and girls are mentioned as the main vulnerable populations in the epidemic. (Interestingly, in the interviews men who have sex with men and intravenous drug users are not generally included as vulnerable populations).

In turn, factors that may influence individual vulnerability include low income (poverty), low levels of education, general levels of material inequality, and ruralurban differences (as well as regular movement between rural areas and urban centres). None of the respondents specifically mentioned poor nutrition, general unemployment, or cultural values as key determinants of AIDS. Having said that, 
ageing cohorts of HIV-positive people and higher numbers of people with noncommunicable diseases are viewed as significant new 'consumers' of health services.

\section{The scenarios}

The aim of the scenarios is to expose the policy implications associated with two interrelated questions:

Is a biomedical response (specifically UTT) sustainable in a middle-income country with the largest AIDS epidemic in the world? How will the twin demands of an effective response and the availability of resources be accommodated in South Africa's AIDS governance towards 2019?

It is evident that the scenarios cover a short period of time, namely the years 2016 to 2019. The end year (2019) was selected as it refers to the end of the current government administration and electoral cycle. As is the case with any scenario study, there are elements in the near future that one can predict with great certainty. These certainties result from the current reality and contribute towards determining the policy- and decision-making frameworks or 'branching points' which may differentiate one scenario from another.

For example, political certainties in South Africa include the provincial elections of 2016, the African National Congress' national conference to be held in December 2017, and the national elections of 2019. We also know that South Africa will lose significant PEPFAR support for funding its fiscal HIV response in 2017; this will create a considerable deficit in South Africa's HIV budget. In addition, GDP growth will remain weak for the entire scenario period, but at the same time government is committed to expanding South Africa's ARV rollout programme, which is already the largest in the world.

There are also elements of the AIDS epidemic that we can predict with a high degree of certainty. As AIDS mortality is declining more rapidly than HIV incidence, the annual numbers of new infections still exceeds the annual numbers of AIDS deaths. This implies that the total number of HIV infections in South Africa is still increasing, and will probably continue to increase for the next few years. However, the age distribution of the HIV-positive population is changing substantially, with fewer HIV-positive youth but rapidly-increasing numbers of HIV-positive adults at older ages. Some analysts (Hontelez et al, 2012) project that the number of HIV-positive South Africans aged 15-49 will decline slightly over the 2011-2025 period, while the number aged 50 and older will increase by $57 \%$. This ageing HIV-positive cohort 
will, in turn, be characterised by comorbidities such as non-communicable diseases and TB. Lastly, new medical technologies such as quarterly-administered injectable ARVs and more sophisticated virological monitoring techniques may come online within the next five years; these innovations could be game-changers in the daily management of AIDS.

In addition to these certainties there are key driving forces, which include actors, institutions and narrative elements that will be critical in any scenario of AIDS governance in South Africa over the next four years. These driving forces can be clustered into five issue areas:

1. Elements regarding treatment, including adherence, universal testand-treatment, treatment-as-prevention, biomedical responses.

2. The health system, including delivery mechanisms, health facilities, supply chain management, the proposed National Health Insurance scheme, urban-rural differences.

3. Social determinants, including poverty, alcohol abuse, unemployment, gender, education.

4. Behavioural elements, including culture, gender-based violence, condom use, sexual behaviour.

5. Significant actors, including the Treasury, the minister of health, the health ministry, different tiers of government, medical health personnel, civil society, the private sector, vulnerable populations

\section{The scenario dynamics}

Figure 1 provides a summary of the scenario story spaces:

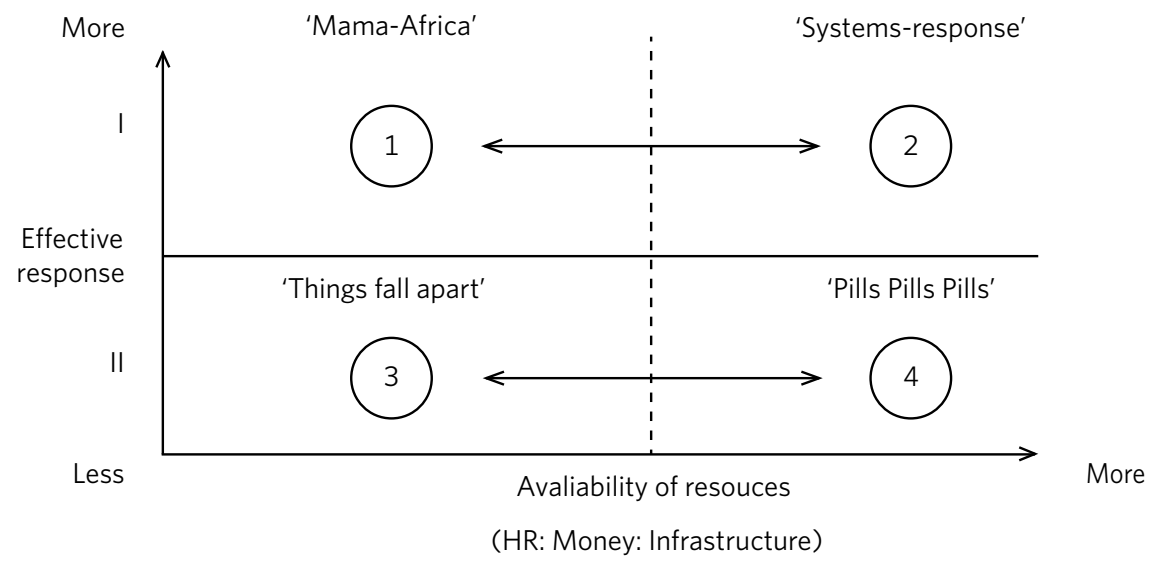

FIGURE 1 Story spaces 
This figure captures the particular challenge within the South African health system, and refers to tensions between, firstly, an effective AIDS response plotted against, secondly, the (non-)availability of resources (i.e. financial, human, infrastructural inequalities and inequities). This key tension reflects the two major themes that emerge from the scenario exercise: AIDS Science and AIDS Governance.

\section{Story space I}

In this future the response to AIDS is relatively effective. However, this effectiveness is differentiated by the availability of resources. In story space 1 (top-left, called 'Mama Africa') this describes a mostly rural reality, whereas story space 2 (topright, called 'Systems response') describes a mostly urban setting. Spaces I.1 and I.2 should be viewed as a continuum, rather than as strictly separate realities. The improvements in these story spaces start in the next five years, with the benefits accruing in years to come.

In 'Mama Africa' (I.1), poor, mostly rural South Africans are able to cope despite the relative lack of financial, infrastructural and human resources. People are financially dependent on social grants, and rely on social and community networks. Over the next four years, women continue to carry the greatest burden of care. However, partnering with church and community-based organisations they are able to catalyze a more effective, bottom-up response. Community-based ARV programmes are a central feature at the frontline of the epidemic, enabling a sustainable ARV supply accompanied by life skills training. Having to make do with fewer resources, government and elements of the private sector target specific micro-financing schemes and initiatives to facilitate this response. This future does not, however, see any significant change in either gender roles, or any improvement of the rural health system. Alcohol abuse and diseases of poverty remain scourges to be managed daily. In 'Systems response' (I.2), a more effective response is driven by an improved health system enabled by the greater availability of human and financial resources, as well as infrastructural development. Despite economic lethargy, government and the private sector prioritise fundamentals of the health system, building public and private health facilities, and focusing on improving management skills and the training of health workers. Working together, the public and private sectors work with civil society to establish a sustainable financing mechanism for health. This scenario reflects solid progress towards the establishment of a health system that is able to absorb the challenges of HIV in a general health systems response. The improved management of the health system is a key feature of this story, with much improved 
coordination and integration across tiers of government, specifically in the health sector. Provincial healthcare receives special attention at all levels, and is populated with competent managers.

\section{Story space II}

In this future the response to AIDS is relatively ineffective. However, this ineffectiveness is differentiated by the availability of resources. In story space 3 (bottom-left, called 'Things fall apart') this describes a mostly rural reality, whereas story space 4 (bottom-right, called 'Pills Pills Pills') describes a mostly urban setting. Spaces II.3 and II.4 should be viewed as a continuum, rather than as strictly separate realities.

In 'Things fall apart' (II.3) the economic slowdown and the lack of any meaningful progress towards the establishment of a health systems financing mechanism over the next four years has a crippling effect on health budgets. In terms of subsistence, unemployment increases, with an even greater burden of care on women. Government fails to plan adequately for the end of PEPFAR funding in 2017; this exacerbates the already acrimonious relationship between government and business. Instead of investing in health systems interventions, government prioritises social grants, ignoring warnings that the social grants scheme would no longer be able to accommodate more grant recipients. Health system improvement is viewed as an unaffordable luxury, and so the health system gradually erodes. Over the next four years, more of South Africa comes to approximate the current health crises in the rural Eastern Cape province and the Free State province. Health workers flock to urban centres, or follow the demand curve overseas. Service delivery protests becomes the norm, are ignored by an increasingly defensive government, with populist pressures mounting from the ideological left, especially in the run-up to the 2019 elections. The existing gap between the health-haves and have-nots is increased, and the country's aggregate health indicators reflect a reversal of progress made in the years following Thabo Mbeki's departure.

'Pills Pills Pills' (II.4) is a scenario that closely resembles the current reality, in particular the biomedicalisation of the epidemic, the focus on the scale-up of the ARV programme and treatment-as-prevention. Concurrently, in this story scant attention is paid to any effort at behavioural change to combat HIV. There is a drive to place as many HIV-positive people as possible on ARVs, with a rapid uptake of ART from the current level of 2.2 million HIV-positive people to all HIV-positive individuals. In the first half of the story, such rapid uptake is absorbed by the health system. However, this is not sustainable, and a critical point is reached when the health system is no 
longer able to cope with the uptake of millions of additional patients. The system buckles, stock-outs occur, and this aggregate burden over time incrementally renders the public health system ineffective. In this scenario the investment in medicalisation and $A R V$ provision outpaces the ability of health systems managers and infrastructure to accommodate the demand.

\section{Conclusions}

There are four primary insights that emerge from the scenario set:

1. No conversation or strategy about AIDS in South Africa is meaningful unless it places the consideration and governance of the health system at its very core.

2. AIDS workers should not be seduced into a specious notion of impact effectiveness as a result of the impressive gains made possible by biomedicalisation during the last decade. Although the demands and pressures of the epidemic are significant and decisive action is required, policy-makers need to remain aware of the fact that an appropriate response to AIDS is a long-term process.

3. The rural-urban divide in responses to AIDS is significant, both in terms of the burden(s) of care and in terms of policy, systems and investment realities. This differential bespeaks the entrenchment of a more profound health apartheid.

4. Gender disparities remain at the core of this epidemic. Biomedical responses to AIDS in South Africa have had many good consequences, but unless systemic issues related to culture, sex and gender are addressed, women will continue to bear the brunt.

In sum, these four insights point to an important reality that will inform all decision and policy making regarding the future of AIDS governance in South Africa: an appropriate response to AIDS in this country demands fundamental national introspection regarding and a long-term vision to address systemic inequalities. AIDS in South Africa exposes a long list of national and societal inequalities and inequities: gender, material, demographic, racial, geographical, technological, sociocultural, economic, governmental, managerial and health systemic.

The main policy implication of these insights is that the current policy response to AIDS, namely an embrace of biomedicalisation (focusing on the scale-up of ART without paying sufficient attention to the social determinants of health as well as to 
health systems strengthening) is insufficient and unsustainable. In the first half of the scenario period - up to 2017 - the current response can remain effective, but the combination of stressors introduced after that period (economic stasis, less donor support, political uncertainty) can collapse the already weak health system. As the biomedical response has not had a sufficient impact on HIV incidence in South Africa, behaviour change messaging and AIDS education should be reprioritised. An appropriate response to AIDS in South Africa does not imply a zero-sum policy strategy between biomedical interventions and socio-behaviour change.

Taking the scenarios spaces as a whole, both an effective and an ineffective response to the epidemic in South Africa are intimately related to the governance of the health system. In the case of ineffective responses, the neglect of health systems strengthening lies at the root of the failure to respond effectively to the epidemic. Conversely, responses to AIDS in South Africa can only be effective if adequate investments are made in the health system. The epidemic requires significant and sustained investment in human resources broadly, health managerial skills specifically, infrastructural development (public health facilities in particular), and in information systems.

For the national minister of health, this implies a diversification of attention away from the ostensible vertical 'success story' of AIDS in South Africa after 2008, towards greater clarity regarding what the $\mathrm{NHI}$ actually means, as well as urgently strengthening the health system. This would include greater coordination across government departments and tiers; particular attention should be paid to poorperforming provincial departments of health. SANAC is well-placed to facilitate much needed coordination across various actors and sectors, but is over-bureaucratised and lacks the agency to make such a role meaningful. Meaningful coordination would eliminate duplication and waste, and streamline the response to the epidemic.

The private sector in particular needs to contribute to an effective response to the epidemic. Government and business need to cultivate constructive engagement on AIDS specifically and health more broadly, in order to alleviate the pressure on the public health system. Considering that the private health sector accounts for over $50 \%$ of all health expenditure in South Africa (WHO, n.d.), they are a key actor in finding innovative and sustainable financing mechanisms for restructuring the health system.

Finally, the scenarios emphasise the importance of rural/provincial health systems in particular. An integrated response to the epidemic demands the improved 
management of provincial public health in general, with adequate and appropriate attention to female and rural end-users of health services. A bottom-up response in rural settings implies greater consultation with poor women in particular. Specifically, this may include innovation around micro-financing schemes for poor women in rural areas.

AIDS is a long-wave event that exposes many of the fault lines in our society. If we fail to place the reduction of inequality and inequity at the centre of our response to HIV and AIDS, we shall simply and tragically neglect the most important lesson of this epidemic.

\section{Acknowledgements}

The authors wish to thank Leigh Johnson (Centre for Infectious Disease Epidemiology and Research, University of Cape Town) and Marisa Casale (Health Economics and HIV and AIDS Research Division, Durban) for their constructive inputs in this study. We are also grateful to Stefano Prato and the Society for International Development for granting us permission to republish parts of earlier versions of this study that had appeared in the journal Development. All errors remain our own.

\section{References}

Bor, J., Herbst, A. J., Newell, M-L., Bäringhausen, T. 2013. 'Increase in adult life expectancy in rural South Africa: valuing the scale-up of HIV treatment', Science, 339(6122): 961-65. https://doi.org/10.1126/science.1230413

Chermack, T. 2011. Scenario Planning in Organizations: How to create, use and assess scenarios, San Francisco: Berrett-Koehler Publishers.

Chigwedere, P., Seage, G., Gruskin, S., Lee, T-H., and Essex, M. 2008. 'Estimating the lost benefits of antiretroviral drug use in South Africa', J Acquir Immune Defic Syndr 49(4): 410-15. https://doi.org/10.1097/QAI.0b013e31818a6cd5

De Geus, A. 1988. 'Planning as Learning', Harvard Business Review, March-April: 70-74.

Dugger, C. 2008. 'Study cites toll of AIDS policy in South Africa', The New York Times, 25 November.

Du Toit, E., van Schalkwyk, C., Dunbar, R., Jennings, K., Yang, B., Coetzee, D., Beyers, N. 2014. 'Missed Opportunities for Retention in Pre-ART care in Cape Town, South Africa', PloS One 9(5): e96867. https://doi.org/10.1371/journal.pone.0096867

Fourie, P. and Swart, C. 2014. 'South Africa's Future AIDS Governance: A focused elite survey', Development, 56(4): 511-17. https://doi.org/10.1057/dev.2014.59

Grimwood, A., Fatti, G., Mothibi, E., Eley, B., Jackson, D. 2012. 'Progress of preventing mother-to-child transmission of HIV at primary healthcare fascilities and district hospitals in three South African provinces', South African Medical Journal 102(2): 8183. https://doi.org/10.7196/SAMJ.5294 
Hontelez, J. A., de Vlas, S. J., Baltussen, R. et al. 2012. 'The impact of antiretroviral treatment on the age composition of the HIV epidemic in sub-Saharan Africa'. AIDS, 26 (Suppl 1), S19-30. https://doi.org/10.1097/qad.0b013e3283558526

Johnson, L. 2014. THEMBISA version 1.0: A model for evaluating the impact of HIV/AIDS in South Africa. Centre for Infectious Disease Epidemiology and Research, University of Cape Town. Available: http://www.publichealth.uct.ac.za/publication-reports-0.

Johnson, L. F., Hallett, T. B., Rehle, T. M. and Dorrington, R. E. 2012. 'The effect of changes in condom usage and antiretroviral treatment coverage on HIV incidence in South Africa: a model-based analysis'. Journal of the Royal Society Interface, 9: 154454. https://doi.org/10.1098/rsif.2011.0826

Kahn, T. 2014. 'SA to treat HIV patients earlier, says Motsoaledi', Business Day, http:// www.bdlive.co.za/national/health/2014/07/23/sa-to-treat-hiv-patients-earliersays-motsoaledi (accessed 27 August).

McNeil, D. G. Jr 2014. 'AIDS progress in South Africa is in peril', New York Times, 25 August, www.nytimes.com/2014/08/26/health/aids-south-africa-success-pepfar. html?smid=tw-nytimesscience\&_r=0 (accessed 26 August).

Motsoaledi, A. 2016. Minister's speech: Health Department Budget Vote 2016/17. National Assembly, Republic of South Africa. 10 May 2016. http://www.gov.za/ speeches/debate-health-budget-vote-national-assembly-10-may-2016-dr-aaronmotsoaledi-minister-health\%20 (accessed 23 May).

Phillips, A., Cambiano, V., Miners, A. et al. 2014. 'Effectiveness and cost-effectiveness of potential responses to future high levels of transmitted HIV drug resistance in antiretroviral drug-naïve populations beginning treatment: modelling study and economic analysis'. Lancet HIV, 1, e85-93. https://doi.org/10.1016/S23523018(14)70021-9

Ringland, G. 2002. Scenarios in Public Policy. Chichester: John Wiley \& Sons, Ltd.

Schwartz, P. 1996. The Art of the Long View: Planning for the future in an uncertain world, New York: Currency Doubleday.

Shisana, O., Rehle, T., Simbayi, L. C. et al. 2014. South African National HIV Prevalence, Incidence, and Behaviour Survey, 2012. Human Sciences Research Council. Available: http://www.hsrc.ac.za/en/research-outputs/view/6871.

Steinberg, J. 2014. 'SA wants to forget about Mbeki and HIV/AIDS', Business Day, http:// www.bdlive.co.za/opinion/columnists/2014/05/30/sa-wants-to-forget-aboutmbeki-and-hivaids (accessed 27 August 2014).

Swart C. and Fourie P. 2015. 'South Africa's AIDS governance: two scenarios towards 2019'. Development 57(3/4): 618-24.

Van der Heijden, K. 1996. Scenarios: The art of strategic conversation, Chichester: John Wiley \& Sons, Ltd.

Van der Heijden, K. et al. 2002. The Sixth Sense: Accelerating organizational learning with scenarios. Chichester, John Wiley \& Sons, Ltd.

Wack, P. (1985a) 'Scenarios: Shooting the rapids'. Harvard Business Review, NovemberDecember: 139-50.

Wack, P. (1985b) 'Scenarios: Uncharted waters ahead'. Harvard Business Review, September-October: 73-89. 
Whiteside, A., Strauss, M. 2014. 'The end of AIDS: Possibility or pipe dream? A tale of transition'. African Journal of AIDS research, 13(2): 101-108. https://doi.org/10.2989/ 16085906.2014.927780

World Health Organization (WHO). 2015. Accelerate expansion of antiretroviral therapy to all people living with HIV. Geneva: WHO. http://www.who.int/mediacentre/news/ statements/2015/antiretroviral-therapy-hiv/en/. (Accessed 23 May 2016).

World Health Organization Global Health Expenditure Database, n.d., http://apps.who. int/nha/database/ViewData/Indicators/en, (Accessed 7 November 2014). 


\title{
STELLENBOSCH UNIVERSITY'S 'BORN-FREES': RESPONSIBLY ENGAGED
}

\author{
NICOLA DE JAGER AND UBANESIA ADAMS-JACK ${ }^{1}$
}

\section{Introduction}

The second quarter of 2015 saw the advancing of student protests across the campuses of South Africa's universities. The impetus was the ever-increasing student fees, ${ }^{2}$ making higher education a costly burden. Stellenbosch University (SU) was no exception to these student protests, which became embodied in the \#FeesMustFall movement. The upward spiralling of student fees was largely due to government subsidies to universities declining in real terms in relation to student numbers, which have grown considerably. Student numbers, under government pressure, have increased from approximately 500000 in 1994 to over 1 million in 2014, without the subsidies to support such growth (Bozzoli, 2014). See figure 1 for SU's increasing student enrolments between 1910 and 2014. South Africa's government expenditure on Higher Education is comparatively low, accounting for $12 \%$ of expenditure on education, whereas for the rest of Africa it is $20 \%$ and the rest of the world is $19.8 \%$ (Bozzoli, 2014). Between 2000 and 2013 government's contribution to university budgets declined from $49 \%$ to $40 \%$, subsequently student fees increased from $24 \%$ to $33 \%$ (Rudin, 2015). This meant student fee contributions more than doubled from a total of R7.8-billion to R17.83-billion (Rudin, 2015). Of interest, where the norm was for government subsidies to contribute towards $40 \%$ of the universities' budgets, for SU only $24 \%$ of its income was from government (Stellenbosch University, 2016). Even so, SU's students fees for 2015 were not amongst the highest; for 2015 fees for a Bachelor of Arts at the University of Cape Town ranged between R43500-R59000, compared to SU's R32534 ('Top SA Universities', 2015).

1 This chapter has been written to honour Prof. Pierre du Toit. Pierre, your contribution has not just been in the measurable academic-outputs, but in the immeasurable inputs you have made in the lives of your students and colleagues. Thank you for your example of excellence and integrity, your mentorship and your friendship.

2 Although there is a genuine grievance in terms of high fees, there is growing concern that this grievance is being mobilised for political ends. In his open letter the Rector of WITS University, Professor Adam Habib recognised that there is a 'political project of some actors to delegitimise institutional structures and replace them with revolutionary alternatives'. See: https://www.wits. ac.za/media/wits-university/news-and-events/documents/An\%20open\%20letter\%20to\%20 colleagues\%20critical\%20of\%20campus\%20safety\%20and\%20security\%20arrangements.pdf. 


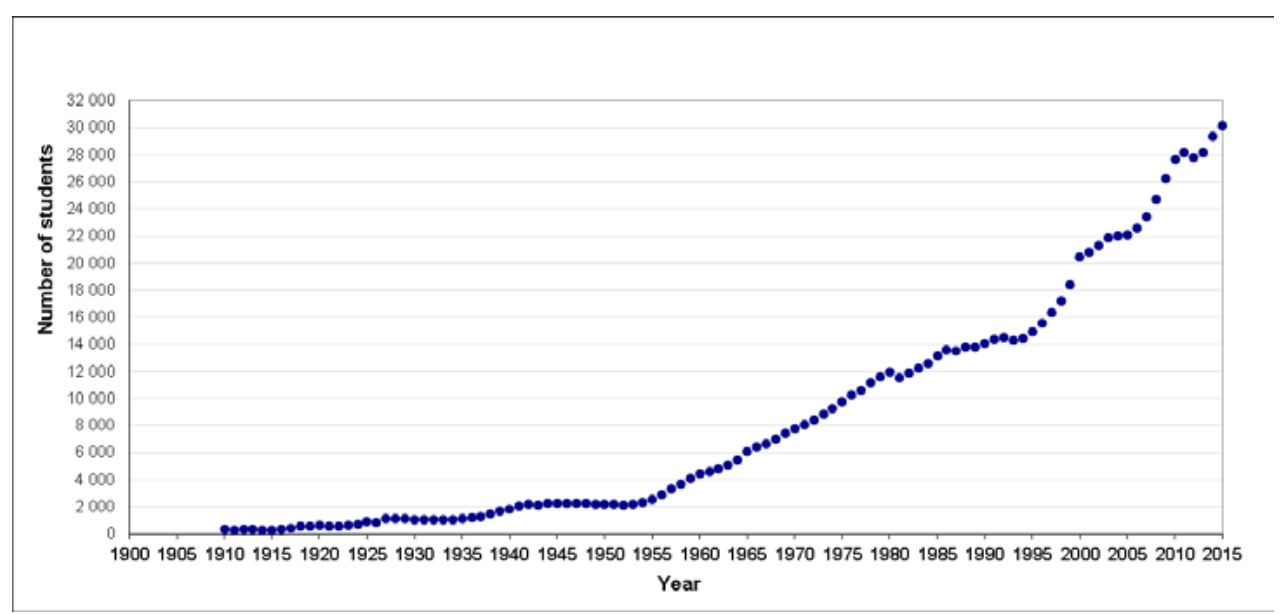

FIGURE 1 Number of Stellenbosch University students for the years 1910 to 2015

Source: Data adapted from Stellenbosch University's Statistical Profile, see: http://www.sun.ac.za/english/Pages/statistical_profile.aspx

Notes: The SU student number for 1981 is estimated.

The nature of the protests on the campus of Stellenbosch tended to differ to that of many of the other universities. Besides the illegal occupation of administrative buildings, some incidences of property being damaged and a few occurrences of intimidation, the Stellenbosch protests were largely characterised by being peaceful. In anecdotal conversations with Stellenbosch students and conversations overheard during the protests, protestors from other campuses accused the SU students of being too 'bourgeois'. We were interested to find out if this meant SU's 'born-frees' were politically apathetic.

In light of the developments on the SU campus we were particularly interested in how SU's 'born-frees' (those born during South Africa's democratic dispensation) perceived political engagement in a democratic dispensation and how they engaged in the political realm. The survey revealed that SU's student cohort, far from being politically apathetic: understand their role of being citizens in a democracy; largely base their vote on the performance of a political party; and are willing to engage in protests but not of a violent nature.

\section{Methodology}

Surveys provide windows into the minds of the respondents, hence our intention with this survey was to gain a better understanding of the political culture and behaviour of SU's born-frees as they form part of the emerging future decision-makers and 
aspiring middle class of South Africa. The SU survey forms part of a broader nationwide project, The Political Attitudes of South Africa's first Democratic Generation: A Survey of the first democratic generation's University Students, spearheaded by Prof. Joleen Steyn Kotze from Nelson Mandela Metropolitan University (NMMU). This is an important project as those participating in the surveys represent the first generation of post-apartheid voters, the so-called 'born-free' generation. The project thus seeks to generate data on electoral trends, political behaviour and political attitudes of a generation that has grown up exclusively within the democratic dispensation (since 1994). Noting that only $12.1 \%$ of the South African population holds a tertiary qualification (StatsSA, 2012), the project is primarily concerned with the evolving political culture of the educated as an elite group. It is expected that this group will form a core cohort of future leaders and influencers in South Africa, hence the importance of understanding them better.

The SU survey was conducted in the first quarter of 2015, with the participants broadly reflective of the university's demographic profile. The sample of students was selected to be representative (in terms of gender and race) of the university's undergraduate student body across all academic disciplines, though our key sampling criterion were age and nationality, namely South African 'born frees'. ${ }^{3}$ Over-sampling was utilized to attain as representative a sample as possible. Students from nine of the ten faculties, ${ }^{4}$ namely AgriSciences, Arts \& Social Sciences, Economic and Management Sciences, Education, Engineering, Law, Medicine, and Health Sciences, Science and Theology participated. The survey largely comprised a battery of closed questions, but there were also open-ended questions to enable the students to expand on their answers.

\section{Understanding political participation and political culture in a democratic setting}

Democracy in its most basic understanding is premised on citizens playing an active role in governing their communal affairs. A core value of a liberal democracy is freedom (du Toit and Kotzé 2011:1), in particular the freedom to participate in the democratic process. Dalton (2000:927) explains the connection between democracy and political participation when he notes that 'democracy expects an active citizenry because it is through discussion, popular interest and involvement in politics that societal goals should be defined and carried out'. Furthermore, he points out that if the public are not

3 Sample size was 310 students of an undergraduate population of 18138 using 2014 figures.

4 Military Science was not included because its students were from an older age group. 
involved in a democracy then the democracy 'lacks both its legitimacy and its guiding force' (Dalton, 2000:927). It therefore remains important to ascertain whether the citizenry in a democracy are interested in participation and their attitudes toward political participation. Almond and Verba (1965) studied the cultural attributes of a successful democracy in their seminal cross-national study, the "Five Nation Study". Their findings were reported in their book, Civic Culture, where they challenged the rational-activist model, which held that a successful democracy needed a wellinformed citizenry that took an active interest and role in public affairs. The logic held that this active citizenry would hold governing elites in check. Instead, Almond and Verba found that the majority of the citizenry in successful democracies were neither politically active nor well informed. They rather put forward the civic culture model, arguing for balance in having both an active and an inactive citizenry, thus allowing government the discretion needed to govern, whilst also being held to account. Mayer, Burnett and Ogden (1996:76) refer to this necessary tension in a democratic government as that between the 'imperatives of ...responsiveness... on the one hand and stability on the other'. Similarly, Hague and Harrop (2004:90) explain Almond and Verba's civic culture as a blending of subject, parochial and participant cultures ${ }^{5}$ to create a balance between 'popular control and effective governance: [allowing for] citizen influence while retaining flexibility for the governing elite'. Furthermore, the freedom to participate in a democracy is not unrestrained, and we argue that political participation in a democratic setting requires responsible freedom. The form of the political participation, either conventional or unconventional, is illustrative of whether that freedom is being used responsibly or not.

Political participation can take various forms. Scholars have used various categorisations to make sense of the variety of ways in which political participation occurs. Sabucedo and Arce (1991:94) note that the common classification category is to distinguish between conventional and unconventional political participation. They note that alternative distinctions such as legal and illegal and institutional and noninstitutional methods of political participation have also been used. Verba and Nie (1972 in Janowski and Strate, 1995: 90) refer to conventional political participation as comprising 'campaigning, voting, communal action, and personalised contacting'. According to Sabucedo and Arce (1991:94) scholars such as Kaase et al. (1979)

5 People with a subject political culture see themselves not as participants but as subjects of the government and thus largely remain passive. Those with a parochial political culture are either remotely or completely unaware of the existence of a central government. In a participant political culture citizens believe that they can contribute to the political system and that they are affected by it. They thus tend to be more active in politics. 
view 'legal demonstrations, boycotts, illegal strikes damage to property and personal violence' as non-conventional methods of political participation. When Kotzé (2001: 137) unpacks South Africans' attitudes to protest using the World Values Surveys, he too refers to 'protest and direct action' as 'unconventional' forms of political participation.

The specific categorisation of forms of political participation as either conventional or unconventional requires critical reflection for two reasons. The first reason is the source of these categorisations. Sabucedo and Arce (1991:94) argue that the nature of the categorisations stem from the status quo and anything other than the status quo or traditional activities, were viewed in a negative way. The second reason why this categorisation must be critically considered is because the distinction between conventional and unconventional political participation may differ by context. For example what constitutes conventional and unconventional in the South African democratic context does not necessarily align with the aforementioned categorisations. If we take the effect of the struggle for freedom into consideration then protest as a form of political participation in the South African political culture has become normalised. This observation raises a question regarding whether any normalised mode of political participation within a particular context should be considered conventional. Even so, a concern with this approach relates to the regime context. The struggle for freedom was under apartheid, an authoritarian regime, where conventional participation, in particular voting, was inaccessible to the majority of South Africans. On the other hand, the post-1994 dispensation is a democratic regime, which recognises and protects the rights of all citizens to participate in the conventional methods of participation. Kotzé's (2001:151) observations support the notion that protest should be considered a conventional form of political participation for a sizeable proportion of South Africans when he notes that 'the persistently higher level of protest among black South Africans indicates that the political exclusion of this group over decades did in fact establish a culture of protest unmatched among other groups' in South Africa. He further asserts that protests seem to be more part of the black South African's political culture than other groupings (Kotzé, 2001: 151). If one takes into account South Africa's racial demography, then black South Africans comprise the overwhelming majority of the population, then protest could be considered a 'conventional' political activity in the South African context.

There is other evidence that notions around what constitutes conventional and unconventional political participation in a democracy need reformulation. Sabucedo and Arce (1991:94) refer to research done on the 1970s and early 1980s which 
they say implied that there are 'people who try to use more direct methods of influencing political life, without losing their interest in, as well as their ability to practice, traditional modes of political participation.' They therefore noted that social scientists need to 'recognize these new forms of action' in relation to the concept of political participation and that there is a need 'to create new and distinct categories in order to provide a greater understanding of these emerging phenomena.' Dalton (2000) also provides such evidence in his review of the scholarship on political participation when he indicates that the literature suggests that citizens in older and newer democracies are looking for other ways to engage politically beyond merely voting. Dalton (2000: 929) notes that citizens are engaging more in direct action and these methods of participation are employed to gain more influence. What his observations suggest is that some people's political participation has become more strategic. What Dalton is highlighting is that it would seem that people want more value from their political participation. If this is indeed the case, then we have to examine how we classify modes of participation and we have to consider whether some of the activities previously classified as unconventional forms of political participation have actually become normalised modes of political participation in various contexts.

The question about how we interpret the normalised political participation practices is very relevant in the South African context. Apart from protest as a tool of political participation during apartheid, protest is also a chosen method of political participation in post-apartheid South Africa. This is not to the exclusion of voting. However, de Jager (2015: 161) notes that a key trend in political participation has been a declining voter turn-out, where 'South Africa's biggest voting block is those who do not vote'; in the 2014 national elections more ( $41 \%$ of the voting age population) did not vote than those that voted for the ruling party (36\% of the voting age population voted for the African National Congress). In other words $41 \%$ of those eligible to vote (voting age population) decided to rather opt out of the formal electoral system. Concomitant with the decline in voter participation has been an increase in so-called 'non-conventional' forms of political participation. These methods of participation, often referred to as service delivery protests, have increased significantly, especially between the period 2009 and 2014. However, Municipal IQ's Municipal Hotspots Monitor shows that since $2004,70 \%$ of these protests have been violent and destructive in nature.

In light of the question about how different modes of political participation are categorised, the South African political context offers an input that focuses on the 
relabelling of protest as part of what would constitute conventional political activity. The word conventional signifies that this practice is considered unproblematic and is deemed broadly acceptable within a democratic setting. The right to peacefully assemble and demonstrate is endorsed in section 17 of the Bill of Rights, which states: 'Everyone has the right, peacefully and unarmed, to assemble, to demonstrate, to picket and to present petitions' (Constitution of the Republic of South Africa, 1996). In light of this constitutional provision, even if violence is popularised it remains an unconventional form of political protest, incompatible with democratic political participation. Violence is recognised as the anti-thesis of democratic behaviour (du Toit and Kotzé, 2011:4). Instead, within a liberal democracy virtues of 'forbearance, compromise, accommodation, and fair-mindedness' emanating from the recognition of the 'essential equality of humans' (du Toit and Kotzé, 2011:16) should guide political behaviour. Violence also contravenes Almond and Verba's aforementioned democratic political culture as required for a successful democracy. Violent protest tilts the needed balance in a democracy between participation and stability, rendering government and institutions unstable.

We, therefore argue, for the use of law (in South Africa's case the 1996 Constitution) as the basis of reassessing the categorisation of conventional versus unconventional participation. In other words the dividing line is between legal and illegal participation, where peaceful protests are legal and therefore conventional, and the use of violence is illegal and thus remains unconventional.

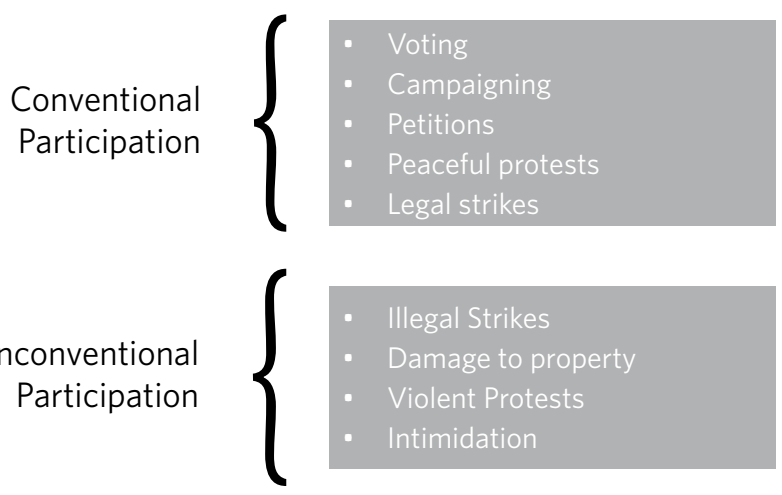

Figure 2 Re-Categorising Political Participation

We now explore the responses of SU born-frees to questions about their intended and actual political participation as well as their attitudes towards conventional and unconventional forms of participation by examining the responses to questions about support for different types of protests (peaceful and violent protest). 


\section{An empirical overview of the political participation of SU's born-frees}

Using the SU born-frees survey we sought to understand how SU's students viewed political participation in a democracy, in particular, voting. Moving from this, we sought to understand which political party these students either voted for or would vote for, and on what basis they determined their support. Finally we sought to understand how they viewed protest, both peaceful and violent, as forms of political participation.

SU's born-frees support the tools of democracy and they are interested in politics

For a democracy to survive, people need to believe in it and participate in its processes. To determine the SU born-frees' political attitudes towards voting as a democratic process, the survey presented the following statements- 'my vote makes a difference'; 'it is the duty of all citizens to vote'; 'voting can be a valuable exercise as we elect politicians we can trust and have the best interest of the citizenry at heart'to which the students could respond strongly agree, agree, neither/nor, disagree or strongly disagree.

TABLE 1 Stellenbosch University's born-frees' views of voting, 2015

\begin{tabular}{lc}
\hline & $\begin{array}{c}\text { Agreed with } \\
\text { statement }\end{array}$ \\
\hline My vote makes a difference & $74 \%$ \\
It is the duty of all citizens to vote & $84 \%$ \\
Voting can be a valuable exercise as we elect politicians we can & $62 \%$ \\
trust and have the best interest of the citizenry at heart &
\end{tabular}

Our survey findings indicate that SU born-frees believe in participating in political activities such as voting and they are generally quite positive toward voting. Voting is an important element of democracy because it allows people to choose who they want to govern them. The survey indicates that a majority of the students recognise the value of elections as a means to recruit people to govern on their behalf. We found that most SU born-frees believe that voting is something that citizens should do. More than $80 \%$ agreed with the statement that it is the duty of all citizens to vote. Over $70 \%$ agreed that voting makes a difference, and $62 \%$ agreed that voting can be a valuable exercise. If we were to use their commitment to voting and their positive orientation toward political participation as signs of a commitment to democracy then the SU 'born frees' show a strong sense of being responsible democratic citizens. 


\section{SU's born-frees vote on the basis of performance}

South Africa's elections since 1994 have been described as a "racial census", where race has been a principle predictor of voting behaviour. Of interest to us was whether race was a key determinant of political party support for SU's students or not. To answer this we determined to know which political party (asking the respondents to pretend that they were all eligible to vote) they voted for in the 2014 national elections. Then to properly understand the basis of this support we used crosstabulations to analyse the responses, on the basis of race, to the statement of 'race plays a role in my voting preference'. To further understand their preference for a political party, open-ended questions were included, asking them to specify why they preferred the party they selected.

TABLE 2 SU's born-frees political party support, 2014 national elections

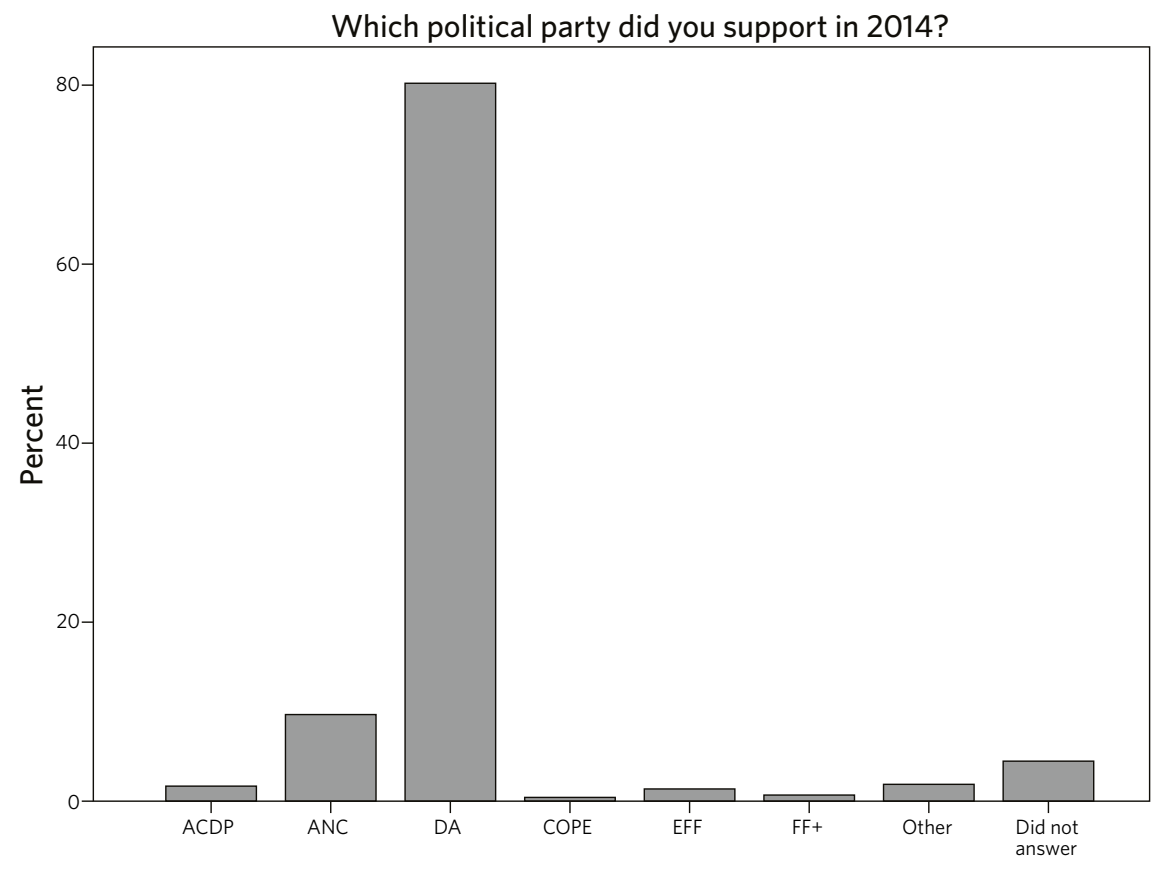

Table 2 shows an overwhelming support ( $80 \%$ ) for the Democratic Alliance, with the ANC receiving $9.7 \%$ of the support, followed by the African Christian Democratic Party (ACDP) with $1.6 \%$ and the Economic Freedom Fighters with $1.3 \%$. 
TABLE 3 Race as a basis for voting preference

\begin{tabular}{lc}
\hline & $\begin{array}{c}\text { 'Race plays a role in my voting preference' } \\
\text { Disagreed with statement }\end{array}$ \\
\hline Black & $47 \%$ \\
Coloured & $60 \%$ \\
White & $62 \%$ \\
All & $59 \%$
\end{tabular}

In response to the statement 'Race plays a role in my voting preference' 59\% of the respondents either disagreed or strongly disagreed with the statement. When accounting for race, $47 \%$ of the black respondents, $60 \%$ of the coloured respondents and $62 \%$ of the white respondents disagreed with the statement. SU's born-frees thus appear to be breaking away from this pattern of race-based voting. Instead, they are considering how a political party performed when they vote. More than $80 \%$ of SU's born-frees indicated they did or would vote for the DA, citing past performance as the key reason for this. Examples of their statements from the open-ended question include: "Proven track record of service delivery, as shown by the running of the Western Cape"; "The DA seems more capable to bring order and makes wiser choices"; "The DA runs the Western Cape and statistically the Western Cape is the best run province" and "The DA makes a significant difference in my local community and therefore can do the same nationally". Taking the responses to the open-ended question for only those that answered that they had voted for the DA, a word cloud was derived from the frequency of word usage in the text where higher frequencies displays larger block. It provides an interesting visual illustration of the key reasons for supporting the DA.

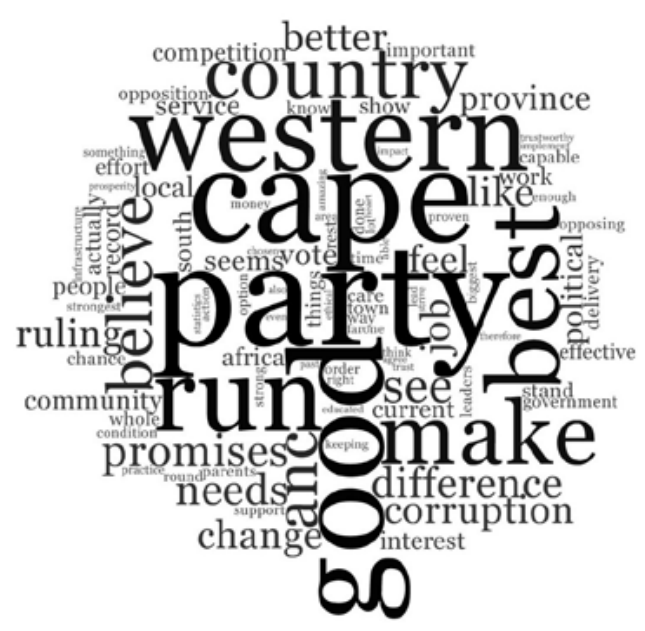

FIGURE 3 Reasons given for preference for the DA 


\section{SU born-frees support peaceful protest action, but not violent protest action}

Following from our theoretical discussions concerning the categorisation of political participation in terms of conventional and unconventional participation, we sought to understand how SU's born-frees perceived political participation in terms of protest, and then in terms of violent versus peaceful protest.

TABLE 4 SU's born-frees' support of mass action

\begin{tabular}{lcc}
\hline & Agree & Disagree \\
\hline $\begin{array}{l}\text { Non-violent mass action is an acceptable way for } \\
\text { people to express their views in a democracy }\end{array}$ & $73 \%$ & $12 \%$ \\
$\begin{array}{l}\text { Violent mass action is an acceptable way for people } \\
\text { to express their views in a democracy }\end{array}$ & $5 \%$ & $89 \%$
\end{tabular}

$73 \%$ of the respondents agreed with the statement that 'non-violent mass action is an acceptable way for people to express their views in a democracy', with $12 \%$ disagreeing and the rest remaining neutral. On the other hand, only $5 \%$ of the respondents agreed that violent mass action is acceptable with an overwhelming majority ( $89 \%$ ) disagreeing with violent mass action and remainder were neutral. Thus the SU born-frees, consider non-violent protest as an acceptable and thus conventional form of political participation. The largely peaceful nature of the protests on SU's campus in 2015 is therefore unsurprising in light of $89 \%$ of the respondents being unsupportive of violent mass action.

\section{Conclusion}

The recent \#FeesMustFall campaign demonstrates that a sizeable proportion of South Africa's university students view protest as a legitimate means of political participation. The nature of the protests differed across university campuses. While Stellenbosch University protests were mainly peaceful, many campuses experienced violent protests. If one argues along the lines of Dalton's observation then we see here evidence of citizens who want to engage politically, but they want to engage in ways that bring about more influence. When these protests are compared in terms of impact it may be argued that the student protests had more influence than service delivery protests because there was a significant policy response from government. The South African president, with little broader consultation, responded within days and announced that there would be no fee increases in 2016 and the government undertook to help universities carry the cost of not increasing their fees. This 'victory' could potentially deepen the normalisation of peaceful protest as an accepted means 
of political participation amongst the more privileged in a society, meaning those who have access to higher education and who could be future leaders. But, the 'victory' was also won based on a campaign that included violent protests on many other campuses in South Africa. While SU students may continue to support and engage in peaceful protests, one has to be cognisant of the fact that government's swift response may also be interpreted as violent protests 'work'. It may therefore inculcate the value that violence is effective. The long-term implications of this unconventional and unconstitutional behaviour for the stability of South Africa's democracy should not be taken lightly.

Nevertheless, the encouraging message from the SU born-free survey remains, which is that these born-frees hold the kind of political attitudes to participation that support a democratic government system. As Stellenbosch University is but one of a number of higher education institutions in South Africa, it is essential to examine, through comparative research, whether similar or divergent attitudes persist elsewhere and what the findings suggest in terms of our future leaders' support for a democratic system.

\section{Reference list}

Almond, Gabriel and Verba, Sidney. 1965. The Civic Culture. Boston: Little Brown.

Constitution of the Republic of South Africa, Act 108 of 1996, 'Chapter Two: Bill of Rights'.

Bozzoli, Belinda. 2014. 'Behind the university funding crisis'. Politicsweb. http://www. politicsweb.co.za/news-and-analysis/behind-the-university-funding-crisis (accessed 3 December 2015).

Dalton, R.J. 2000. Citizen attitudes and political behaviour. Comparative Political Studies 33 (6/7): 912-940. https://doi.org/10.1177/001041400003300609

De Jager, Nicola. 2015. 'Elections, political parties and voting trends in South Africa's dominant party system'. South African Politics: An Introduction. Cape Town: Oxford University Press.

Du Toit, Pierre and Kotzé, Hennie. 2011. Liberal democracy and peace in South Africa: The pursuit of freedom as dignity. New York: Palgrave Macmillan. https://doi.org/10.1057/9780230116320

Hague, Rod and Harrop, Martin. 2004. Comparative Government and Politics: An introduction, $6^{\text {th }}$ edition. Hampshire and New York: Palgrave Macmillan.

Janowski, T. B. and Strate, J.M. 1995. Modes of participation over the adult life span. Political Behaviour 17(1): 89-106. https://doi.org/10.1007/BF01498785

Kotzé, H. J. 2001. Unconventional political participation and political confidence in South Africa: a longitudinal analysis using data from the world values study. Social Dynamics 27(2): 134-155. https://doi.org/10.1080/02533950108458716

Mattes, R. 2012. The 'Born Frees': the prospects for generational change in postapartheid South Africa. Australian Journal of Political Science 47(1): 133-153. https://doi.org/10.1080/10361146.2011.643166 
Mayer, Lawrence C., Burnett, John H. and Ogden, Suzanne. 1996. Comparative Politics: Nations and Theories in a Changing World, second edition. New Jersey: Prentice-Hall.

Municipal IQ. 2014. Municipal IQ condemns the use of excessive force in service delivery protests. http://www.municipaliq.co.za/index.php?site_page=press.php (accessed 2 December 2016).

Rudin, Jeff. 2015. No fees: Breathe fire into Ubuntu. Mail \& Guardian online. http://mg.co.za/article/2015-11-26-no-fees-breathe-fire-into-ubuntu (accessed 2 December 2015).

Sabucedo, J. M. and Arce, C. 1991. Types of political participation: a multidimensional analysis. European Journal of Political Research 20: 93-102. https://doi.org/10.1111/j.1475-6765.1991.tb00257.x

Statistics South Africa 2012. Census 2011: Census in brief. http://www.statssa.gov. za/census/census_2011/census_products/Census_2011_Census_in_brief.pdf (accessed 6 December 2016).

Stellenbosch University. 2016. Fact Sheet: Student fee increase for 2016. http://www.sun. ac.za/english/Documents/CommOct2015/FACT\%2OSHEET\%2OBUDGET\%20 2016.pdf (accessed 1 November 2016).

'Top SA Universities: How much they cost'. 2015. https://businesstech.co.za/news/ general/77079/top-sa-universities-how-much-they-cost/ (accessed 6 December 2016). 


\section{SOUTH AFRICAN STUDENT PROTESTS AS NEW IMAGINED COMMUNITIES IN THE DIGITAL AGE}

\section{BAREND LUTZ}

\section{Background and Introduction}

In 2014 Professor Pierre du Toit and I co-authored a book on digital media and democracy titled: Defining Democracy in a Digital Age: Political Support on Social Media. In addition to exploring the development of democracy and the impact of emerging technologies on this development, we constructed a methodology for measuring public expressions on political issues from social media platforms. In the book we focussed specifically on global public expressions on democracy from the popular social media platform Twitter. Without spoiling the findings of the book, or overextending the scope of this chapter, it will suffice to say that we found that a significant proportion of Twitter users were negative about the prospects of democracy. The book was an introductory study testing the methodology and the aim was to open up the field for future research in the measurement of public expressions on social media. We were particularly interested in the notion of social media conversations as a form of Habermasian public sphere (Habermas, 1989) where influential opinions and cohesive imagined communities are formed that can influence real world change. As part of the study, we proposed a number of avenues for future research to take to further this work. This chapter of this Festschrift honouring the achievements of Professor du Toit will examine a case study implementing multiple avenues for future research that was proposed in our book.

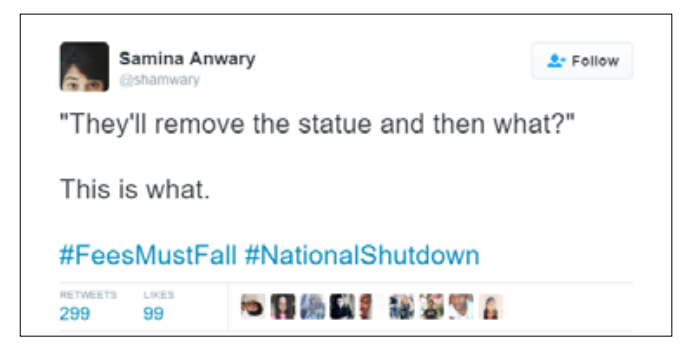

A popular Tweet from a Johannesburg-based woman that was shared on 22 October 2015, the day that the \#FeesMustFall protest was most active on Twitter, and the day that students marched to the ANC's Luthuli House in Johannesburg and the magistrate's court in Cape Town. The tweet also refers to the Rhodes Statue that was removed on 9 April following the related \#RhodesMustFall movement.

The tweet above hints at the theme of the case study that this chapter will focus on, namely the 2015 student movements that were the largest student protests seen 
in the country since the epoch-defining Soweto uprising in 1976. One of the key differences between the uprisings in 1976 and the ongoing student movement is the impact of digital media in not only the mobilisation of protests, but more importantly the formation of what can be called 'imagined communities'. These communities form 'societies' which are connected by social engagement, and share social capital that bond and bridge individuals into a cohesive grouping. In our book we propose that social media forms a critical communication network with a stable source of content, that is open to contextualisation, self-reflection and aggregation, and provides symbolic content visually to its consumers (Lutz \& du Toit, 2014).

The first section of this chapter will examine the avenues for future research proposed in Defining Democracy in a Digital Age: Political Support on Social Media. The following section will look briefly at the dynamics of modern democracies, the impact that social media have on these, and further expand on the ideas of the public sphere and imagined communities. The final section of this chapter is a case study on the \#FeesMustFall student movement that emerged in October 2015, but has ramifications that are continuing to impact the South African political sphere. This student movement will be examined from the perspective of an imagined community that has real-world impact, and some of the methods proposed for future research will be used in analysing the movement.

\section{Proposals for future research in Defining Democracy in a Digital Age: Political Support on Social Media}

Given that Defining Democracy in a Digital Age: Political Support on Social Media was an introductory study to develop and test the methodology of measuring public expressions on democracy from Twitter, it was impossible to look at all the potential uses of measuring public expressions from social media sites. In chapter 4 of the book we examined further potential analyses using variations of the study that might be of benefit to future studies.

Firstly, we stated that although the original study focused on the topic of democracy, it could be replicated with any topic of a researcher's choosing. If people discuss a topic on the Internet the same methodology should function. As such this chapter will look at student protests in South Africa rather than democracy. More specifically, the study will focus on one specific popular hashtag that is used by student protesters, namely \#FeesMustFall.

Secondly, one could use other online social media networks for this study, however as tweets are relatively freely available, and were the most popular tool for 
communication during the \#FeesMustFall movement, it was decided to remain with tweet data only.

Thirdly, the initial study looked only at the content of the tweets and examined the sentiment of this content. Tweets contain additional data such as information about the person tweeting - specifically location data. In this chapter location data will be used to identify only tweets from users in South Africa.

Fourthly, we proposed that there are a number of ways in which a future researcher can get more profound understanding of collected data. In this study word counts will be used to identify the most popular topics that co-occurred with the \#FeesMustFall tweets.

Next, more mature sentiment and natural language processing was used in analysing the data and determining sentiment scores. However, given that the hashtag that was followed is about protests - which by its nature should evoke negative sentiment

- it is debatable how useful the sentiment analysis section of this study will be.

Finally, a more granular analysis of tweets over time will be conducted in order to see how the \#FeesMustFall movement started, developed and evolved. This section will form the basis for exploring how this Twitter-based public sphere works and how an imagined community on a social network is formed and evolves.

\section{Democracy, Social Media, the Public Sphere and Imagined Communities}

In our book, Defining Democracy in a Digital Age: Political Support on Social Media (2014), Professor du Toit and myself looked at the evolving dynamics of modern democracies. Throughout history democracies have been continuously shaped by technological and institutional innovations, the values and beliefs found in the political culture of societies, and by the factor of size. The Age of Modernity which took off in Europe by the late fifteenth century, was said to have led this process with three technological innovations (all of which originated elsewhere): gunpowder, oceanic navigation and the printing press. The major institutional innovation that emerged from the Middle Ages was that of representative assemblies. Modern democracies benefited directly from one of these innovations - the technology of the printing press - invented in Europe in 1454 (and much earlier in China), which allowed ever larger populations of citizens to be drawn into political society. The political cultures that developed in the durable democracies of the twentieth century built on notions about, inter alia, the identity of the political society (shaped primarily by the ideology of nationalism); the institutional framework of the nation(al)-state; 
and the civic and political virtues captured in the evolving liberal-democratic human rights doctrines. Since the invention of the printing press technologies such as radio, television, the internet (all of which can impact societal development), have been advancing at a rapid rate.

In our book we focussed specifically on one such new technology - social media. We argue that the ever increasing group of social media platforms, such as Twitter, Facebook, WhatsApp, YouTube, Instagram, Sina Weibo, Renren, QZone, VKontakte and Odnoklassniki, can be seen as new types of Habermasian public spheres.

Although these opinion-rich sources come from an increasing variety of users and although this group of users do not (yet) represent the fullness of society, it can at least give one a glimpse of a specific influential sector of society. At present, this section of society consists largely of the young, and they are, arguably, one of the most influential sectors society with the potential to bring (or at least instigate and promote) revolutionary change to the larger population. It is precisely these 'netizens' who have been instrumental in recent large political upheavals, such as the so-called Arab Spring; the 2013-14 Ukrainian civil unrest; and the ongoing socio-economically driven political unrest in Chile, Argentina, Brazil, Venezuela, Thailand and many other countries across the globe.

In the next section the impact of this sector of society on the South African political spectrum will be explored. These social media netizens use Facebook, Twitter, blogs and the thousands of other digital channels available to them, to express their opinions on everything from the latest fashion trends, to foreign policy and expressions on democracy. Their thoughts, beliefs and expressions are publicly available, and free to be interpreted and analysed by researchers.

In our book, we focussed specifically on one of the most popular social network tools, the microblogging site, Twitter. We used the broad theoretical perspectives of the German sociologist and philosopher Jürgen Habermas, and treated expressions on Twitter as a form of discourse within a Habermasian public sphere. Scholars such as Habermas and Hannah Arendt (1963) have discussed the public sphere and how it is constantly changing. Habermas has looked specifically at the influence of the media on political opinion in the public sphere (Habermas, 1989).

\section{Public Sphere}

The public sphere refers to a place, be it physical or virtual, where citizens gather and exchange views on public affairs. These spheres are 'places' where citizens can 
meet and discuss, debate and deliberate on current affairs which eventually leads to the formation of public opinion (Castells, 2008). The contemporary view of the public sphere is mainly based on the works of Habermas (1989). He defines the public sphere as a "network for communicating information and points of view ... filtered and synthesised in such a way that they coalesce into bundles of topically specified public opinions" (Habermas, 1996). Such a public sphere will subsequently be illustrated with a South African case.

Throughout the development of democracy there have been many versions of public spheres promoting political accountability. Some examples are the agora of Greek City States, where citizens gathered and discussed public affairs. Another form would be the tribal gatherings and certain church congregations throughout history. In European monarchies the royal court was also a public sphere, but it was dominated by the monarchy. During the seventeenth and eighteenth centuries, salons (France), coffeehouses (England) and table societies (Germany) were public spheres that were limited to the aristocracy. As technology developed and mass newspapers became distributed, the discussions from these coffeehouses and salons became truly public (Habermas, 1996; CommGAP, 2012).

Today, with the rapid development of technology, there are those who argue that new forms of public spheres are developing with the help of information and communication technologies. This means people no longer have to physically gather somewhere to discuss public affairs.

Using the ideas from Habermas (1989), a number of scholars such as Papacharissi (2009) have examined social media sites and the Internet as new types of public spheres where public opinion is being generated and discussed. The creator of Twitter, Jack Dorsey, stated at the 2012 Digital Life Design Conference in Munich that Twitter is a public medium that hosts public conversation in a way simple enough for anyone to use (VentureBeat, 2012). If this statement is an accurate representation of Twitter, the discussions on Twitter might be comparable to a type of Habermasian public sphere and the opinions generated here can be of the utmost value in gauging public opinion. The expressions on democracy from this sphere could then be indicative of the legitimacy of democracy as a whole (Habermas, 1976; CommGAP, 2012).

Downey and Fenton (2003) have stated that public discussion on new media sites might lead to the creation of counter-public spheres, which could challenge the opinions of the current public sphere. This idea of counter-public spheres was developed by Habermas (1996) when he recognised that alternative public spheres 
might challenge the current dominant sphere. This might also be the case for Twitter, but we are of the opinion that expressions on Twitter would rather form part of the dominant public sphere. This, however, remains to be tested in future studies.

In her book, A Private Sphere: Democracy in a Digital Age, Papacharissi (2010) has argued that new technologies have, in fact, eroded the boundaries between the private and the public sphere. She believes that the public sphere is no longer the centre of democratic debate and that private citizens now broadcast gestures of a social, civic, political, cultural and economic nature from the mobile enclosures of the private sphere, to mass global audiences. She also believes that these spheres are not fully public as there is an unfair distribution of access to information, a lack of reciprocity in communication, and an overarching commercialisation that inhibits open discussion. Papacharissi, therefore, would rather explain expressions on new media as falling within the private sphere.

As yet, there is no definitive answer to whether Twitter can be seen as a Habermasian public sphere in which public opinion can be created. In our book we accepted that Twitter does indeed meet the criteria of a public sphere. The expressions measured in this study would, therefore, form part of the discussion that influences the formation of public opinion. The South African case study below will attempt to further this research by illustrating how influential Twitter is in opinion forming and in influencing political action in the country.

What we do point out already is that views expressed on Twitter do not necessarily "coalesce into bundles of topically specified public opinions" (Habermas, 1989) as required by Habermas' definition of the public sphere. For this process of coalescence to emerge, new methodologies of aggregation of data are needed. Such a process will be discussed in the case study below.

\section{Imagined Communities}

According to Lutz and du Toit (2014) within the public sphere, the process of shaping the social base of democracy can also be seen as the role of innovation in communications technology. An inclusive national identity can emerge in the civic culture of mature democracies through a process of both formal and informal political socialisation that proceeds from one generation to the next. Or, if context and circumstance requires the more speedy establishment of a cohesive citizenry, a deliberate use of symbols, symbolic events and leaders can be used to 'create' such a collective identity. For Benedict Anderson (2006), the social construction of such 
a community in the form of a nation is that of the establishment of an "imagined community".

In this view, the nation (or group) is imagined as an inherently sovereign and limited social entity. It is imagined in the sense that nations, even very small ones, consist of thousands of members - the vast majority of whom will never meet one another, but each one, in their mind's eye, is aware of the others and has a sense of him/ herself in sharing this particular identity. The nation is sovereign - is not being ruled by foreigners, nor is it limited with defined (albeit malleable) boundaries with other nations, similarly defined. It is, importantly, a community, understood as membership with "deep horizontal comradeship" (Anderson, 2006). As the printing press helped with the formation of these imagined communities, so today digital media, specifically social media, assists in this role.

This cohesive well-knit citizenry can now enter democratic politics through efficient institutions for demand generation. The key processes of presenting interests and preferences to policy makers are through that of interest articulation (mostly through organised interest groups) and interest aggregation (mostly political parties), who provide the institutional conveyor belt for taking citizens into electoral politics, and from there, into representative assemblies where public policy is made. Making decisions about public policy, inter alia, on the basis of demands made by citizens, is the first crucial step in achieving system capacity. Effectively implementation of such policy decisions, when all the while maintaining the constitutional rules that define the regime and its policy-making processes is the second crucial step; one that delivers legitimacy to the democratic process, which in turn, is expressed in further public support for the regime. According to Almond and Verba (1963), effective system capacity generated and maintained in this way, contributes to maintaining the belief at the very core of civic culture - namely, the myth of citizen competence by providing a partial empirical base for this belief.

A question that was examined in Defining Democracy in a Digital Age: Political Support on Social Media (Lutz \& du Toit, 2014) was:

"Can digital media, including the social media, contribute to creating new and durable imagined communities favourable to the reconstruction of the social base of democracies?"

In the next section an examination of an imagined community - bound by the artefacts of popular Twitter hashtags - participation in an online public sphere in South Africa will be examined in order to attempt to further answer this question. 


\section{Case Study: South Africa's 2015/16 Student Protests - the \#FeesMustFall Movement as an Imagined Community}

In April 2015 South Africa began celebrating the third decade of democracy, following the end of apartheid in 1994. According to an April 2015 article on the government's website: "South Africa has come a long way in addressing the economic, social and cultural challenges created under apartheid" (ZA Government, 2015). During the celebrations of Freedom Month much of the media in the country focussed on the so called "Born Frees" or "New Youth" - those born under the new post-1994 regime. However, even though the country might have come a long way since 1994 as the government suggests, a key theme that was emerging under the Born Frees was "continuing inequality and injustice, particularly economic" (Coleman, 2015). This case study will examine the radical student-led movements that emerged out of this sentiment in 2015. These movements challenge the status quo at universities in South Africa and express frustrations at the lack of a more diverse and representative educational system. Communications on Twitter will be examined and viewed as an imagined community participating in a form of public sphere with real-world impact.

\section{The Statue that Fell}

In addition to marking the third decade of democracy in the new South Africa, April 2015 was also the month that the University of Cape Town's (UCT) council voted to remove the statue of Cecil John Rhodes following a protest campaign.

Although the removal of the statue was one of the movement's goals, the \#RhodesMustFall movement began on 9 March 2015 and described itself as "a collective movement of students and staff members mobilising for direct action against the reality of institutional racism at UCT" (Rhodes Must Fall, 2016). Thus, the removal of the statute and Rhodes' place in history was but one of its main issues to be redressed (Kamanzi, 2015; Hlophe, 2015).

Whilst the removal of the Rhodes statue was an initial aim, the movement also protested against perceived white privilege on university campuses across the country, with historically-white universities bearing the brunt of the protests. The fall of the statue can be seen as a symbolic victory, an example of interest aggregation and binding artefact for the imagined community that was developing in the national consciousness, media and social media alike. The \#RhodesMustFall campaign attracted much national and international attention and could be seen as the catalyst 
for an ongoing allied student movements at other universities, both within South Africa and elsewhere in the world.

Between April and October 2015 there were multiple smaller, related student led movements across the country - such as the protests over language issues that started at Stellenbosch University in July 2015 and later also surfaced at the University of Pretoria. One social media artefact and driving force behind protesters at Stellenbosch University was a documentary shared on YouTube entitled Luister (Youtube, 2015). The documentary received thousands of views and told the stories the lives of students of colour who attend Stellenbosch University. In a series of interviews, students recount instances of racial prejudice that they continue to experience in the town of Stellenbosch and the challenges that they face due to the use of Afrikaans as a language of teaching at the university. However, it was not until October 2015 that the full force of this newly-developed imagined community would be seen in the form of the \#FeesMustFall protests.

In the next section the \#FeesMustFall movement will be examined as an imagined community that used Twitter ${ }^{1}$ as a public sphere and impacted real-world change. The movement gave rise to the largest student protests since 1976 (Masola, 2015). From tweets collected from Twitter, one can examine the development, impact and growth of this movement down to the second.

\section{This is What: Telling the Story of \#FeesMustFall with Tweets}

In addition to being one of the largest student protest movements that the country experienced, the \#FeesMustFall movement was also one of the largest social media events in the country (Pedroncelli, 2015). This researcher has compiled a collection of tweets published publically on Twitter between 10 October 2015 and 29 February 2016, from the hashtag \#FeesMustFall. The tweets are from users who are selfreported to be located in South Africa. ${ }^{2}$ The collection consist of 912,790 tweets from 98,354 unique Twitter accounts and includes all public Twitter mentions of the hashtag \#FeesMustFall for the collection period. From this collection one can follow

1 Other digital media sources, such as Facebook, were also pivotal in this movement and can be examined in future research.

2 It should be noted that the methodology of only using users who are self-reported to be located in South Africa could exclude certain influential South Africans, such as Trevor Noah, who is in the United States, however the goal here is to get a picture of events on the ground, as such the methodology should be sound. It would not be difficult to extend the search to all tweets, however this will include international media sources which might not be formative in this imagined community. The volume of tweets if all mentions of \#FeesMustFall would have been included is 1222910, therefore 310120 tweets were removed. 
events closely and examine how this imagined community developed and changed on Twitter.

\section{The Birth of a Hashtag}

Aside from the ongoing student unrest in the country, a catalyst for the \#FeesMustFall movement was the announcement in October 2015 by the University of Witwatersrand (Wits) management that student tuition fees will be increased by $10.5 \%$ in 2016 (Nkosi, 2015). From 8 October students from Wits used the hashtag \#WitsFeesMustFall when talking about the proposed fee increase. However on 13 October a new broader hashtag emerged as a call to action. At 13:46 on 13 October the Twitter account of Wits Student Representative Council (SRC) tweeted: "\#FEESMUSTFALL \#JOINTHEMOVEMENT \#OCT14" with a picture with more information, seen below. This was the first use of the hashtag \#FeesMustFall on Twitter.

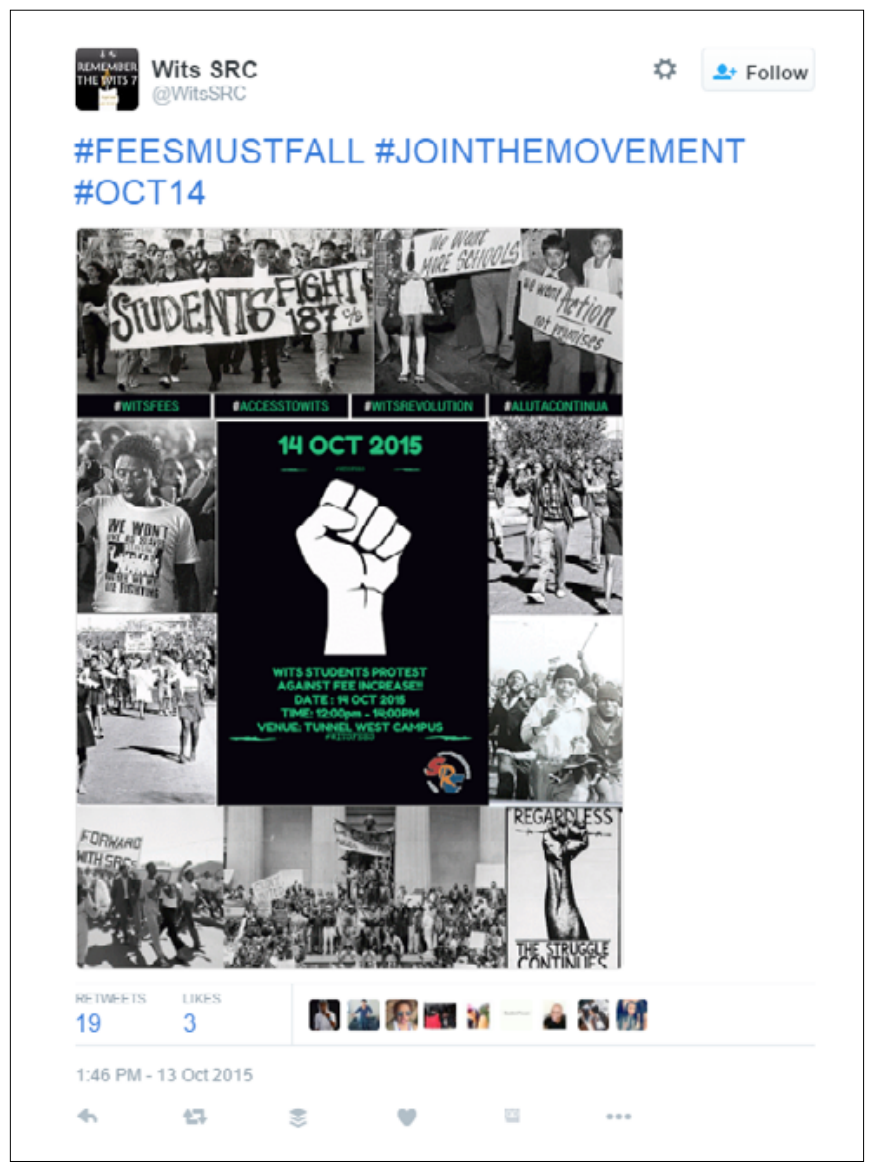


For this study this tweet can be seen as the first interaction in this emerging imagined community on the Twitter public sphere. It was the birth of a hashtag and a protest movement that started off as a simmer of discontent and soon became a veritable national movement (Allison, 2015).

Figure 1 below illustrates the first few days after the formation of the hashtag. Although it garnered some interactions, the use of the hashtag was still limited compared to what would happen in the days to follow.

\section{\#FeesMustFall: 12-18 October}

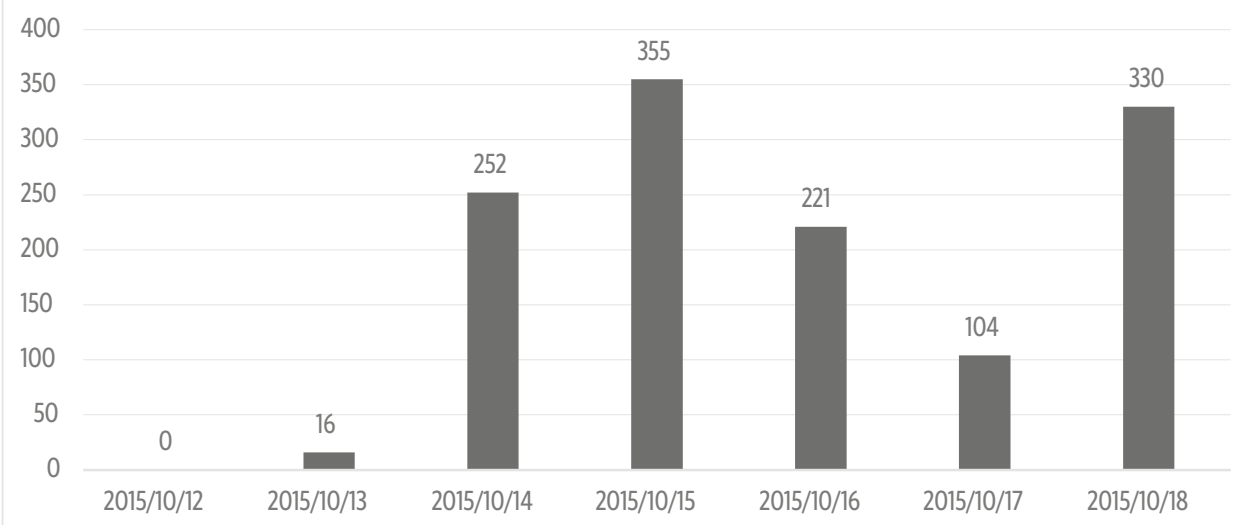

FiguRE 1 Tweet data for \#FeesMustFall between 12-18 October 2015.

One of the most significant tweets from this initial period was from the author Khaya Dlanga (tweet below) who stated on 15 October: "People who say that race has nothing to do with \#FeesMustFall haven't applied their minds to the history that haunts the present". This tweet can be seen as an initial indicator of the racial narrative that was forming in this imagined community. Another key theme from this period was that students from other universities in the country were also embracing the hashtag, with some of the most popular tweets mentioning the universities of Fort Hare, Stellenbosch and Cape Town. This illustrates how the hashtag was being aggregated more broadly into South African society. 


\section{The Hashtag Trends}

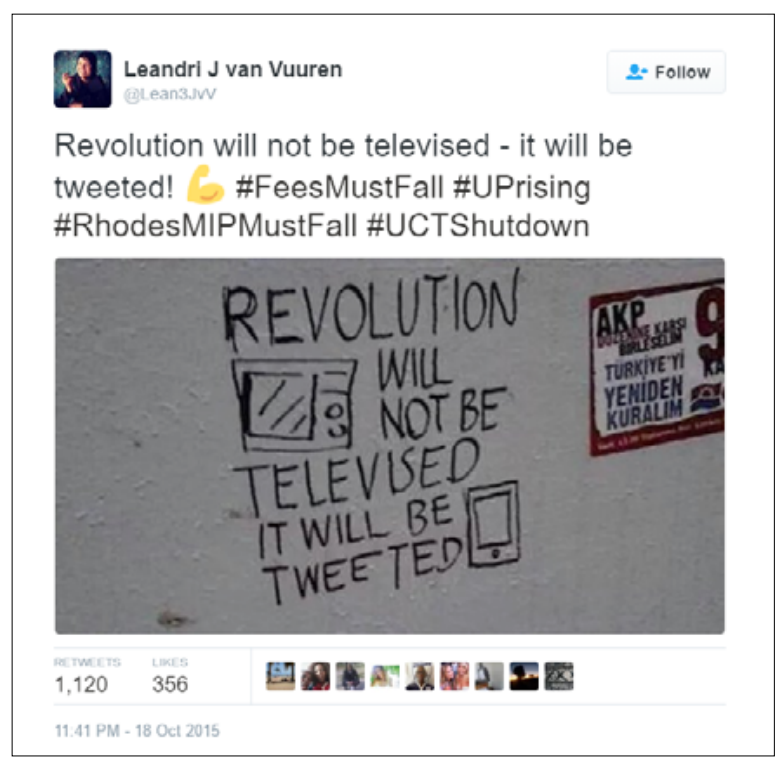

On Sunday 18 October 2015 the hashtag \#FeesMustFall stood on 330 mentions for the day. The tweet above, with a picture co-opted from the 2013 Gezi Park protests in Turkey, was shared late that Sunday evening and can be seen as foreshadowing for what was to come in the next week. On Monday 19 October the hashtag began to spread like wildfire and the imagined community was truly born. As seen in Figure 2 below, between Monday and Friday (19-23 October 2015) there were 754917 tweets mentioning \#FeesMustFall. On 19 October the protests had spread to UCT and Rhodes University in Grahamstown. In Cape Town road blocks at university entrances were set up by students. In Grahamstown students occupied university administration buildings and 25 were arrested (Van der Merwe, 2015). Other key hashtags on the day were \#UCTShutdown, which received 2698 tweets, \#witsfeeswillfall (1219 tweets) and \#RhodesMIPmustFall (1125 tweets). 


\section{\#FeesMustFall: 12-30 October}

300000

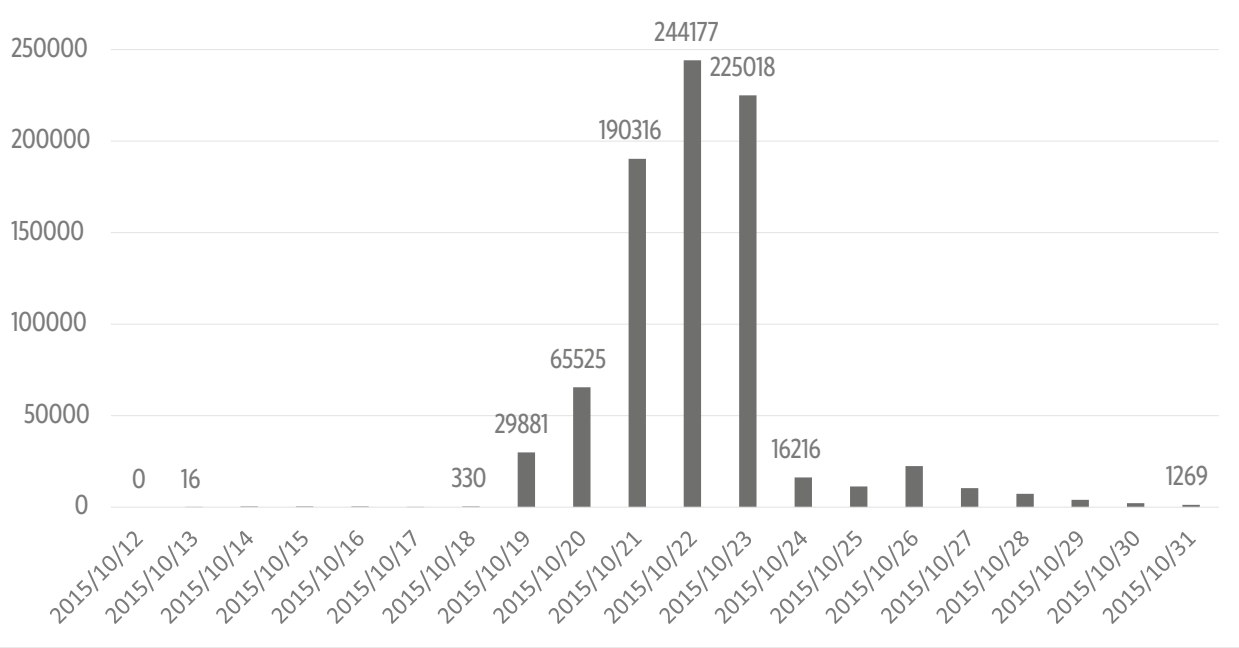

Figure 2 Tweet data for \#FeesMustFall between 10-31 October 2015.

On 20, 21 and 22 October 2015 related protests also occurred at Cape Peninsula University of Technology (CPUT), Fort Hare University, Stellenbosch University and Nelson Mandela Metropolitan University (NMMU). Other key hashtags on these days were \#NationalShutdown (12049 tweets), \#UWCShutdown (2192 tweets) and \#FeesMustFallForAll (1202 tweets). On 21 October an estimated 5000 students marched on the South African Parliament in Cape Town. The march coincided with the meeting of the national assembly where both President Jacob Zuma and Higher Education Minister, Blade Nzimande, were present.

This was the most popular tweet mentioning both \#FeesMustFall and the parliament protests.

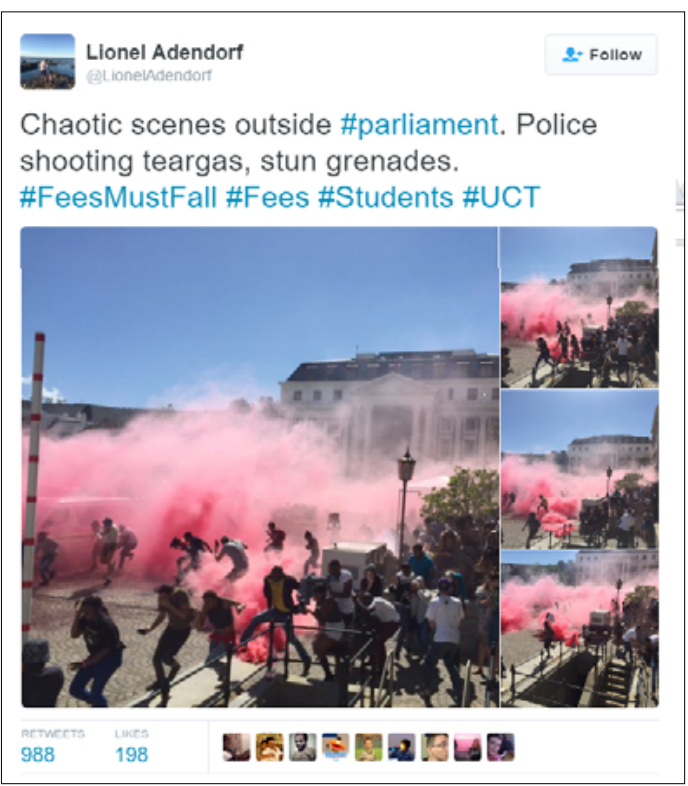


As mentioned previously, sentiment analysis was most useful in the book, Defining Democracy in a Digital Age. However, it is not as beneficial for understanding student protests that by their very nature elicit negative sentiment. Figure 3 below shows negative neutral and positive for tweets mentioning \#FeesMustFall between 19 and 23 October 2015. It is interesting to note that the day with the most tweets, 22 October, was not the day with the most negative sentiment - however, one would have to examine the data more closely to see why this is the case. This examination falls outside the scope of this study.

The following table represents the key words that were used between 19 and 23 October 2015. The word count can give one an indication of which topics were most important in those days. The key themes that emerge from this list are links to students, violence and police, and the government.

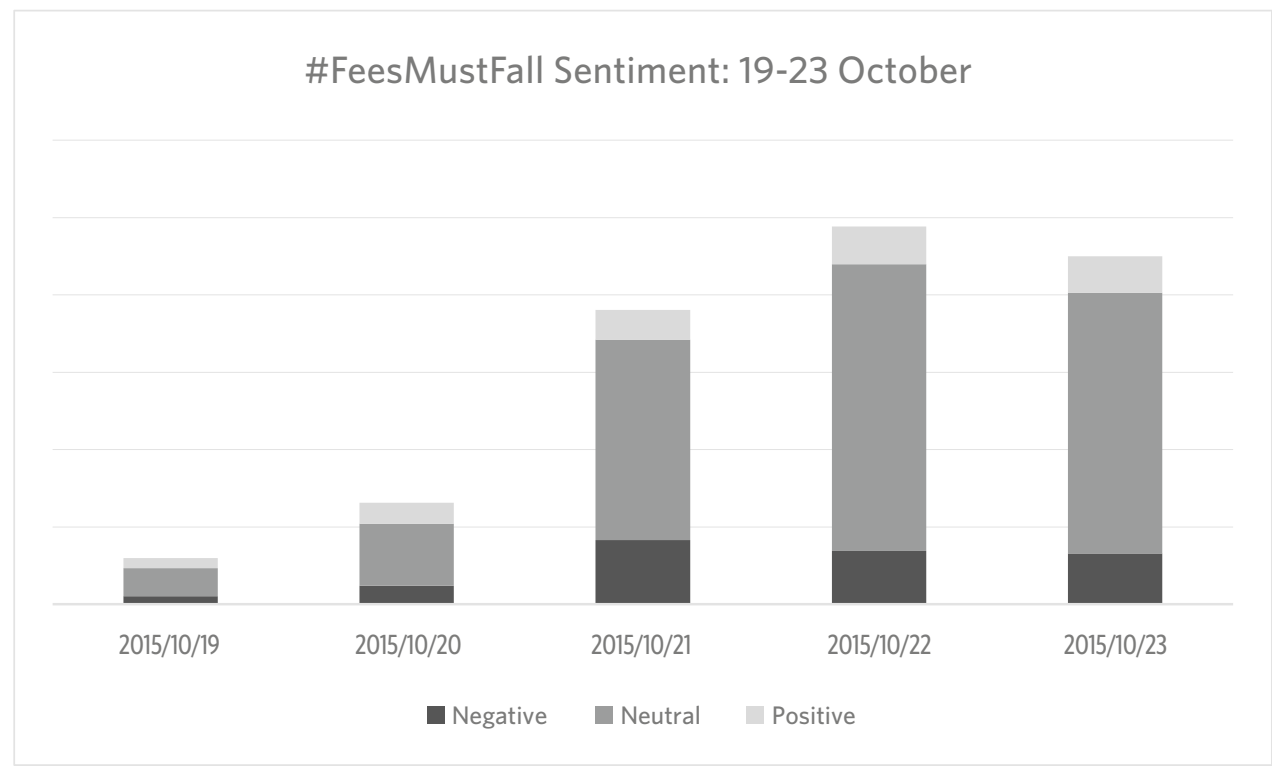

FIGURE 3 Sentiment data for \#FeesMustFall Tweets between 19-23 October 2015. 


\begin{tabular}{lll}
\hline \multicolumn{3}{l}{ Top Keywords in Tweets } \\
\hline 1 & students & 25060 \\
2 & zuma & 10902 \\
3 & \#unionbuilding & 9268 \\
4 & increase & 8717 \\
5 & fees & 6494 \\
6 & president & 5779 \\
7 & \#feeshavefallen & 5573 \\
8 & \#nationalshutdown & 5526 \\
9 & police & 5297 \\
10 & \#unionbuildings & 4785 \\
11 & anc & 4193 \\
12 & union & 4085 \\
13 & student & 4072 \\
14 & education & 3432 \\
15 & buildings & 3411 \\
16 & people & 3306 \\
17 & south & 3240 \\
18 & @enca & 3123 \\
19 & violence & 3121 \\
20 & @ewnreporter & 3091 \\
& &
\end{tabular}

\section{\#FeesHaveFallen}

Friday, 23 October 2015 was a pivotal day for the movement. That morning saw a 10000 strong crowd of students gathered at the Union Buildings in Pretoria calling on President Zuma to come out and answer to the crowd - which he eventually did not do, sparking more violence to erupt, as seen in the following tweet:

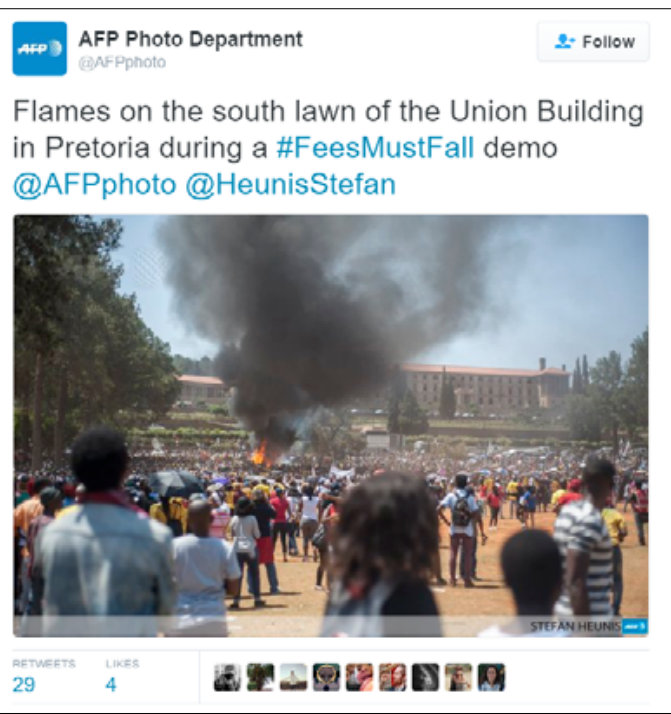


Although President Zuma did not address the crowd, he did announce via the media plans to scrap the proposed tuition fee hike (Allison, 2015). With the announcement the core demand of the movement was met, however this would not be the end of the student movement. This imagined community that consisted mostly of students continues to develop, as will be illustrated below.

\section{The Hashtag Loses Momentum as the Imagined Community Evolves}

In the first tweet in the introduction of this chapter, Samina Anwary hinted that the \#FeesMustFall movement developed out of the \#RhodesMustFall movement. In Figure 4 below one notes that the \#FeesMust-

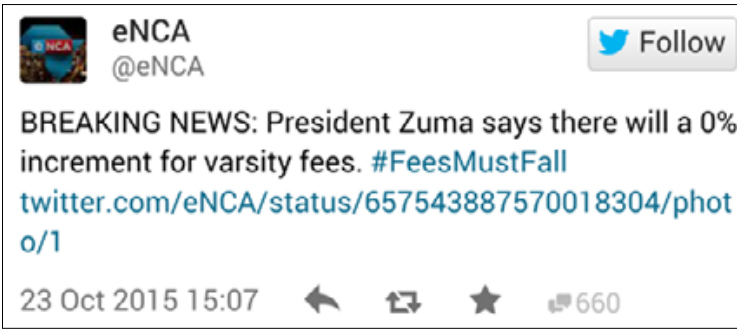
Fall movement lost most of its popularity following the October 2015 events. Although a small spike in mentions occurred in January 2016, the imagined community that congregated around this social artefact has now largely moved on. As with the \#RhodesMustFall protests, the underlying issues - such as inequality and injustice, racial tensions, language issues and various concerns with governance - remain. Although it falls outside of the scope of this study to examine the full development of the movement since October 2015, some of the key hashtags used in recent months have arguably evolved out of this imagined community. Some of these are: \#AfrikaansMustFall, \#ZumaMustFall, \#OutsourcingMustFall, \#Shackville, \#ZuptaMustFall and \#AskBlade.

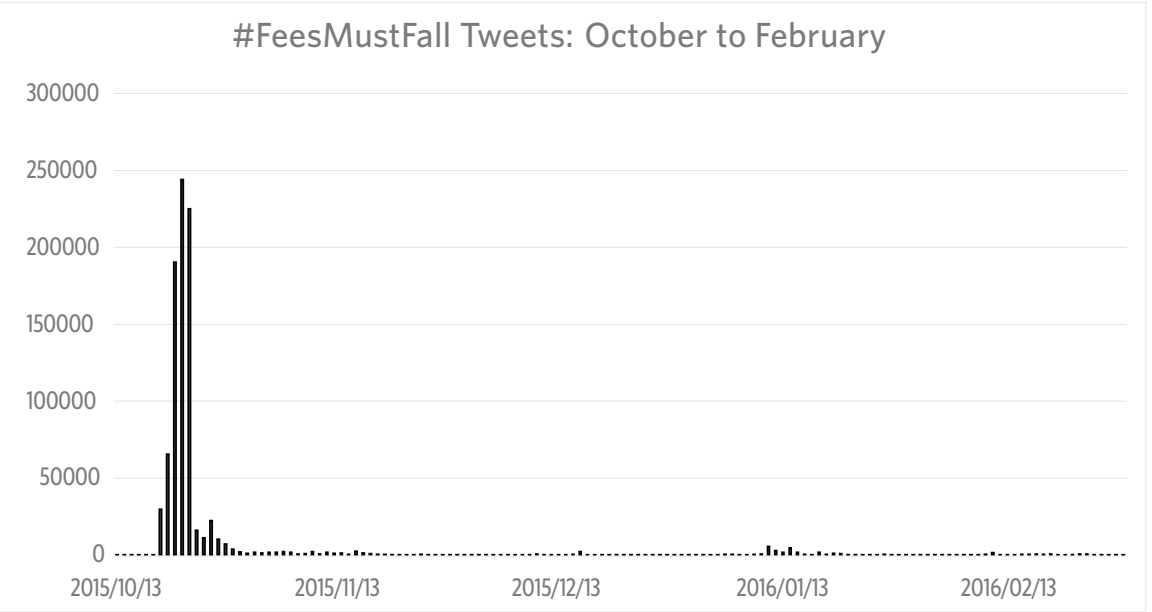

Figure 4 Tweet data for \#FeesMustFall between 13 October 2015 - 29 February 2016. 


\section{Conclusion}

The goal of this chapter was to expand on the study of public expressions using social media tools that were presented in the book Defining Democracy in a Digital Age: Political Support on Social Media. By focusing on a South African case study and implementing the avenues proposed for future research from the book is possible to see how public expressions on Twitter can generate somewhat cohesive social media communities.

The social media community formed around the \#FeesMustFall hashtag adhered to the core principles of an imagined community set out in Defining Democracy in a Digital Age: Political Support on Social Media (2014:99-100). The movement effectively used Twitter as a critical communication network and effected real-world change. It provided a stable source of content, inspiring the imaginations of individual group members as seen in the thousands of tweets. These tweets and the various hashtags used by the movement provided contextualisation to members as it illustrated realworld issues that inspire them. This form of contextualisation then lead to interest aggregation, as was seen with the key demand of the students, namely that fees must fall. The visual nature of Twitter and other social media platforms is also key in establishing an effective imagined community and forms symbolic representations of artefacts that can be shared by the community.

This chapter therefore argues that digital media, including social media, can contribute to creating new and durable imagined communities. Within the bigger political sphere these imagined communities could be favourable to the reconstruction of the social base of democracies, as was discussed in Defining Democracy in a Digital Age: Political Support on Social Media. What is indeed clear however, is that they can affect real world change.

\section{Bibliography}

Allison, S. 2015. South African Students Score Tuition Fee Protest Victory. The Guardian (online), 23 October. Available: http://www.theguardian.com/world/2015/oct/23/ south-african-students-protest-pretoria-tuition-fees-rise (accessed 5 May 2016).

Almond, G. and Verba, S. 1963. The Civic Culture. Political Attitudes and Democracy in Five Nations. New York: SAGE Publications.

Anderson, B. 2006. Imagined Communities. Reflections on the Origin and Spread of Nationalism. London: Verso.

Arendt, H. 1963. On Revolution. London: Macmillan.

Castells, M. 2008. The New Public Sphere: Global Civil Society, Communication Networks, and Global Governance. The Annals of the American Academy of Political and Social Science, 616: 78-94. 
Chadwick, A. and Howard, P. N. (eds.) 2009. Routledge Handbook of Internet Politics. Oxon: Routledge.

Coleman, N. 2015. South Africa needs serious interventions to fix extreme inequality. Daily Maverick (online). Available: http://www.dailymaverick.co.za/ opinionista/2015-10-06-south-africa-needs-serious-interventions-to-fix-extremeinequality/\#.VzsAov196Uk (accessed 20 February 2016).

CommGAP. 2012. "The Public Sphere. Communication for Governance and Accountability Program". The World Bank (online). Available: http://siteresources. worldbank.org/EXTGOVACC/Resources/PubSphereweb.pdf (accessed 20 August 2012).

Downey, J. and Fenton, N. 2003. New Media, Counter Publicity and the Public Sphere. New Media \& Society 5(2): 185-202.

Habermas, J. 1996. Between Facts and Norms. Cambridge: MIT Press.

Habermas, J. 1976. Legitimation Crisis. London: Heinemann.

Habermas, J. 1989. The Structural Transformation of the Public Sphere: An Inquiry into a Category of Bourgeois Society. Cambridge: Polity Press.

Hlophe, W. 2015. Hlophe: Rhodes Must Fall Everywhere. Yale Daily News (online). 1 April. Available: http://yaledailynews.com/blog/2015/04/01/rhodes-must-falleverywhere/ (accessed 5 May 2016).

Kamanzi, B. 2015. 'Rhodes Must Fall' - Decolonisation Symbolism - What is happening at UCT, South Africa? The Postcolonialist (online), 29 March. Available:

http://postcolonialist.com/civil-discourse/rhodes-must-fall-decolonisationsymbolism-happening-uct-south-africa/ (accessed 5 May 2016).

Lutz, B. and du Toit, P. 2014. Defining Democracy in a Digital Age: Political Support on Social Media. London: Palgrave Macmillan.

Masola, A. 2015. Dear Jacob Zuma, this time white people haven't made us angry. You have. The Guardian (online), 26 October. Available: http://www.theguardian. com/world/2015/oct/26/letter-jacob-zuma-feesmustfall-protests-south-africa (accessed 5 May 2016).

Nkosi, B. 2015. Wits Fees Protest Intensifies. Mail \& Guardian (online), 15 October. Available: http://www.mg/article/2015-10-15-wits-fees-protest-intensifies (accessed 5 May 2016).

Papacharissi, Z.A. 2010. A Private Sphere: Democracy in a Digital Age. Chicago: Polity.

Papacharissi, Z.A. 2009. The Virtual Sphere 2.0: The internet, the public sphere and beyond, in Chadwick, A. and Howard, P. N. (eds.) 2009. Routledge Handbook of Internet Politics. Oxon: Routledge.

Plato. The Republic.

Pedroncelli, P. 2015. 10 Popular South African Hashtags in 2015. AFK Insider (online), 22 December. Available: http://www.afkinsider.com/108524/10-south-africanhashtags-that-went-viral-in-2015/4/ (accessed 5 May 2016).

Rhodes Must Fall movement. 2016. Avaliable: http://rhodesmustfall.co.za/ (accessed 5 May 2016).

Van der Merwe, M. 2015. \#FeesMustFall Thursday: Promises vs. Petrol Bombs. Daily Maverick (online), 30 October. Available: http://www.dailymaverick.co.za/ article/2015-10-30-feesmustfall-thursday-promises-vs.-petrol-bombs/\#. VzWfyYR97IU (accessed 5 May 2016). 
VentureBeat. 2012. Jack Dorsey: Twitter seeing 3 to 5 percent engagement on Promoted Tweets and Trends. Venture Beat News (online), 22 January. Available: http://venturebeat.com/2012/01/22/jack-dorsey-promotedproducts/\#vGidlvFfak4DDYXQ.99 (accessed 30 January 2012).

YouTube. 2015. Luister. Available: https://www.youtube.com/watch?v=sF3rTBQTQk4 (accessed 5 May 2016).

ZA Government. 2015. Celebrating the Beginning of the Third Decade of our Freedom through Accelerating Radical Economic Transformation. Available: http://www.gov. za/freedom-month-2015 (accessed 5 April 2016). 


\section{POSTSCRIPT}

In 1985, as a second-year undergraduate student in Political Science, at the end of the class, two fellow students and I were asked to remain behind. The lecturer, Pierre du Toit, announced that "a select few" (uitverkorenes in Afrikaans) should remain behind to receive their essays from him in person. He then went on to speak to each one of us individually and told us why our essays were good and what we should do to develop and grow in the discipline. I was over the moon, because Pierre was the one lecturer who inspired me and whom I wanted to impress. On that day, I knew that I wanted and could become a scholar in Political Science; he inspired that confidence in me. It was the beginning of some 30 years of mentorship and collegiality, not just academically, but also personally. A period which, if we have to put an end to it, reached its fulfillment just the other day when Pierre presented me with a copy of his ninth book. Just like all the other books, it was on a topic of immediate concern and relevance, namely, the need to revisit and rethink the meaning of South Africa's Constitution in the midst of a time of crisis.

I think that the highest compliment I could bestow on Pierre is this: he not only inspired me to choose the career of a professional academic, but he was instrumental in how I developed and grew into that role, and also in how I view the pursuit of knowledge. In that sense, I firmly believe that a scientific study of politics, or in my own formulation, political economy, is not only possible but also essential. He also taught me that one should read widely, way beyond the confines of your own discipline. When visiting his office, I would scan his desk and note the titles and authors on a variety of topics. Not too long ago, as I embarked on a new research project, far removed from the study of political economy issues, Pierre pointed me in the right direction. He stressed, as he always did, that one should not overlook the giants in any field. For Pierre, quality always took precedence over quantity - this notwithstanding the fact that, during his career, he published steadily and productively. Quality remained the measure of excellence. It is because of this that a compliment coming from him, as on that day in his second-year undergraduate class, always continued to inspire and encourage.

Pierre is someone who chooses his words and reflects on them, before speaking. His classes, seminars and the many conversations we had were characterised by the 
dictum of using time wisely, not abusing it or artificially inflating it. I once asked him how many sources one should cite in a journal article. His reply was "as many as it takes to do the job." His advice was the same for my doctoral dissertation. I think he managed to instill in me a sense of being economical with words, although here, I must admit, he probably thinks that I am still a work in progress!

Over the years, he also gave me wise advice on a personal level that always stuck with me, or at the very least warranted reflection. During the years which were characterised by the states of emergency and intensification of the struggle in South Africa, I once had a vehement argument with my former father-in-law who was, at the time, an enlightened National Party supporter. I recounted the argument to Pierre and told him, with some intensity, exactly what I thought of my father-in-law. I used a word which does not need repeating here, but suffice to say that it was not complimentary. There was a pregnant pause, after which Pierre said that I should not talk about him in that manner, because he was family and that one, at any rate, always engaged with the argument and never attacked the person. I was brought up short, and rightly so. This fundamental rule in academic debate is one which resonates beyond academics and is a crucial value to uphold in our interpersonal relationships. We cannot live out our values in a compartmentalised, ad hoc manner. Pierre's professional life is also his personal life. The words integrity and consistency best describe the person whom I am privileged to know and from whom I learned so many things over the past three decades.

I share Pierre's love of the mountains, the peace they bring, the challenges they pose, and the self-reflection which results from being surrounded by their imposing presence when you enter alone. It is that discipline of the mind which is, perhaps, his lasting gift to me, his student and colleague.

ANTHONY LEYSENS Associate Professor Acting Dean: Faculty of Arts and Social Sciences, Stellenbosch University 